\title{
WestVirginiaUniversity
}

THE RESEARCH REPOSITORY @ WVU

Graduate Theses, Dissertations, and Problem Reports

2013

\section{Calibrating the LaModel Program for Shallow Cover Multiple- Seam Mines}

Morgan M. Sears

West Virginia University

Follow this and additional works at: https://researchrepository.wvu.edu/etd

\section{Recommended Citation}

Sears, Morgan M., "Calibrating the LaModel Program for Shallow Cover Multiple-Seam Mines" (2013). Graduate Theses, Dissertations, and Problem Reports. 676.

https://researchrepository.wvu.edu/etd/676

This Dissertation is protected by copyright and/or related rights. It has been brought to you by the The Research Repository @ WVU with permission from the rights-holder(s). You are free to use this Dissertation in any way that is permitted by the copyright and related rights legislation that applies to your use. For other uses you must obtain permission from the rights-holder(s) directly, unless additional rights are indicated by a Creative Commons license in the record and/ or on the work itself. This Dissertation has been accepted for inclusion in WVU Graduate Theses, Dissertations, and Problem Reports collection by an authorized administrator of The Research Repository @ WVU.

For more information, please contact researchrepository@mail.wvu.edu. 


\title{
Calibrating the LaModel Program for Shallow Cover Multiple-Seam Mines
}

\author{
Morgan M. Sears \\ Dissertation submitted \\ to the Benjamin M. Statler College of Engineering and Mineral Resources \\ at West Virginia University \\ in partial fulfillment of the requirements for the degree of \\ Doctor of Philosophy in \\ Mining Engineering
}

\author{
Keith Heasley, Ph.D., Chair \\ Christopher Bise, Ph.D. \\ Yi Luo, Ph.D. \\ Brijes Mishra, Ph.D. \\ Christopher Mark, Ph.D. \\ Department of Mining Engineering
}

Morgantown, West Virginia

2013

Keywords: LaModel, Pillar Design, Shallow Cover, Failure Database, Calibration 


\title{
ABSTRACT
}

\section{Calibrating the LaModel Program for Shallow Cover Multiple-Seam Mines}

\author{
Morgan M. Sears
}

Stable underground mine openings are fundamental to ensuring the safety of miners and providing a safe work environment. During the past decade, approximately $40 \%$ of underground mining fatalities were caused by roof falls, rib collapses, or bumps/bursts, $19 \%$ of which occurred during retreat mining (Pappas and Mark, 2012). In addition, approximately 600 miners are non-fatally injured (often severely) every year by rock falls in coal mines (Pappas and Mark, 2012).

To help with designing stable mine pillars in deep-cover situations, a new calibration method for deep-cover pillar retreat mining was developed and implemented into the LaModel 3.0 program a few years ago (Heasley et al., 2010). This calibrated method was demonstrated to have very good results with a limited database of 47 deep-cover case histories, where a stability factor (SF) of 1.40 or above showed a $90 \%$ chance of success. During the development of the deep-cover calibration method for LaModel 3.0, there was nothing fundamental in the derivation that limited the method to only deep-cover mines; however, the method has not been specifically validated for shallow-cover mines.

This research work seeks to extend calibration of the LaModel program to shallow-cover mines. To perform this expansion, 40 shallow cover case histories from 12 different mines were obtained. The difficulty in finding shallow-cover failure cases for single seam mines necessitated creating a database which also included multiple-seam interactions. In general, with shallow cover, most mines were very successful, unless some type of multiple-seam stress became involved.

An initial analysis of the data showed two distinct failure populations, one comprised of inadequately sized pillars for global stability (mostly massive collapses) and one where local entry stability (massive roof falls or floor heave) was compromised by pillar stresses, weak roof/floor and/or multiple seam stresses. This distinction in failure mode required analyzing the database in two steps. First, an adequate pillar safety factor for global design stability was determined based on the pillar failure subset of the data. Then, once global stability was confirmed, the entry stability was analyzed separately to quantify the significance of parameters such as depth, coal mine roof rating (CMRR), entry stresses, etc. to the local stability of the entry.

Statistical analysis of the pillar failure subset of the data indicated that a SF of 2.0 or above resulted in an approximate $90 \%$ chance of maintaining global stability. Then, for the entry stability subset of the data, it was found that the CMRR and the multiple seam stress were most significant in predicting success or failure. With the addition of these two parameters, entry stability was able to be predicted with an approximate $75 \%$ accuracy.

Incorporating a shallow-cover, calibration technique into the LaModel program further enhances the most widely used boundary-element model to help develop stable pillar design at all depths. With the addition of this shallow-cover analysis tool, engineers can now perform basic pillar design where challenging geometries, multiple-seam interactions, and adverse geologic conditions are all considered. 


\section{Dedication}

This dissertation and its accompanying research are dedicated to my father, the late Casey A.

Sears. Without his support, guidance, encouragement, and numerous years in the mining industry, I would not be where I am today. 


\section{Acknowledgements}

I would like to thank everyone who made this project possible. I would especially like to thank Dr. Keith Heasley, my advisor, whose hard work and guidance kept me on track through the countless hours involved in this project. In addition, I wish to acknowledge Dr. Christopher Bise, Dr. Yi Luo, and Dr. Brijes Mishra for being committee members as well as instructors and mentors during both my undergraduate and graduate studies.

I would also like to thank Dr. Christopher Mark for being a committee member and for his personal guidance in the area of Statistics, specifically the logistic regression portion of this research. In addition, the ground control groups at the NIOSH Pittsburgh Research Laboratory and Spokane Research Laboratory, who provided funding, guidance, and support, are appreciatively recognized.

Finally, I want to thank my family, for how many times they asked me "when I was going to graduate." Specifically, I wish to thank my wife Christy for her unconditional love and support through both the writing of this thesis and for carrying and recently delivering our first child. 


\section{Table of Contents}

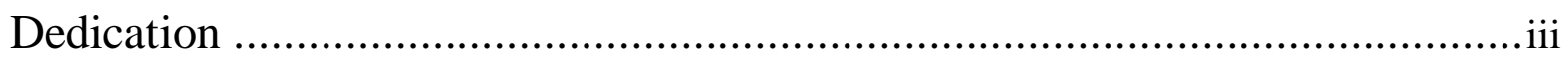

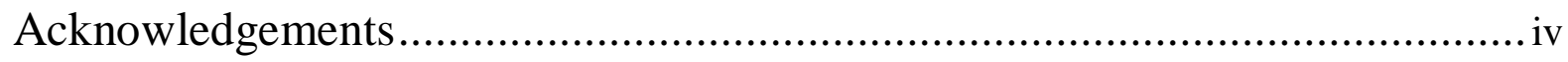

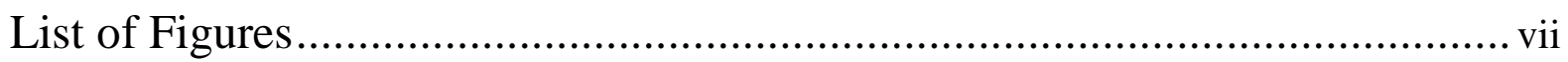

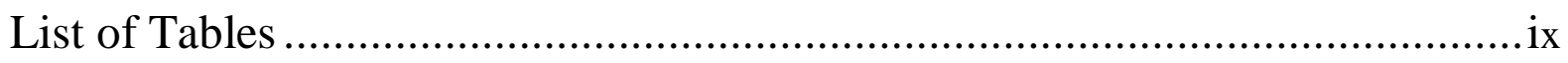

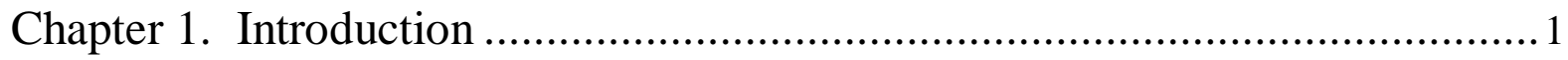

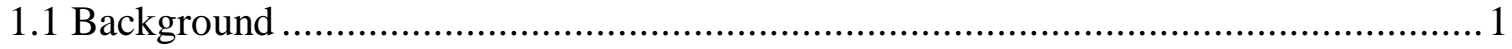

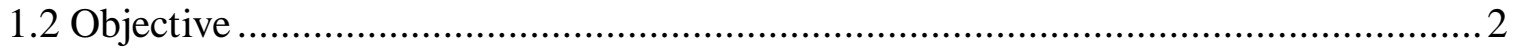

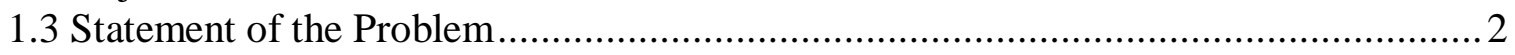

1.4 Scope of Work ............................................................................................... 3

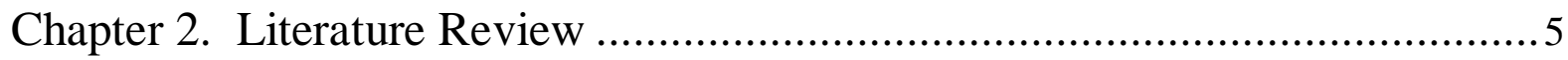

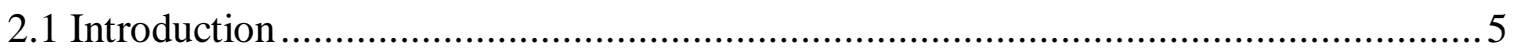

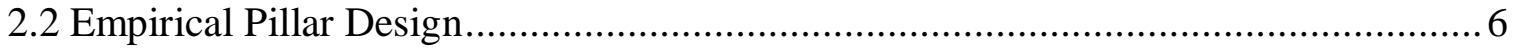

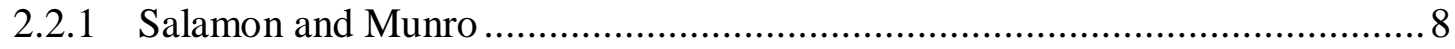

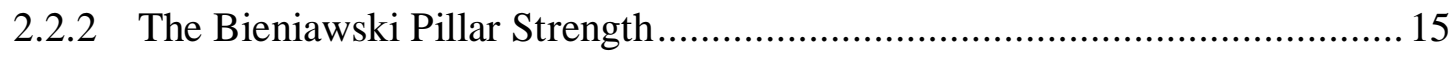

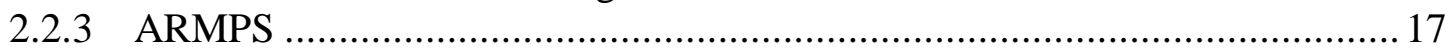

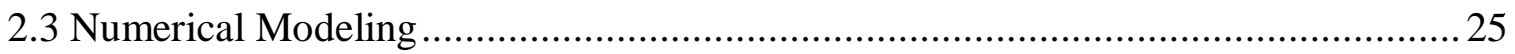

2.3.1 The LaModel Program ........................................................................ 26

2.4 Fusion of Empirical and Numerical Modeling....................................................... 31

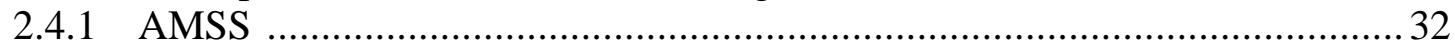

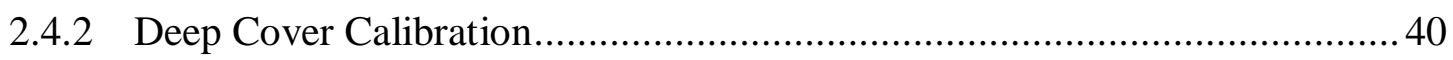

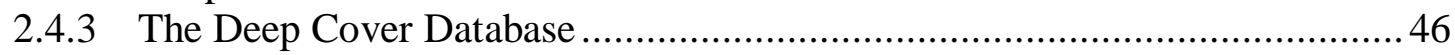

2.4.4 Analysis of the Deep Cover Database .............................................................4 47

Chapter 3. The Shallow Cover Database ....................................................... 52

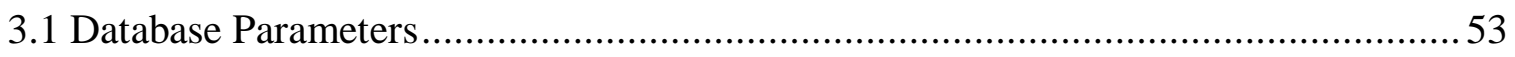

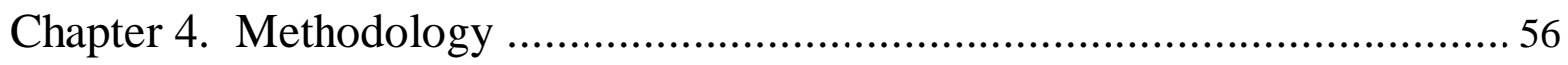

Chapter 5. Calibration and LaModel Analysis ............................................. 58

5.1 Relationship Between Rock Mass Stiffness and Stresses........................................58

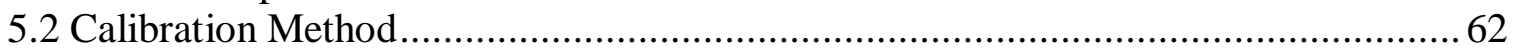

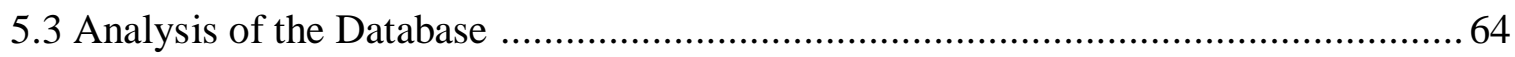

Chapter 6. Results of the Logistic Regression Analysis ............................... 66

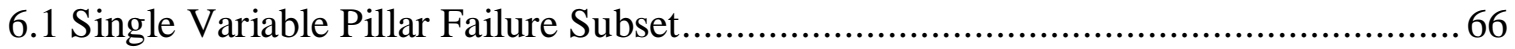

6.2 Multi Variable Pillar Failure Subset ...................................................................... 71 


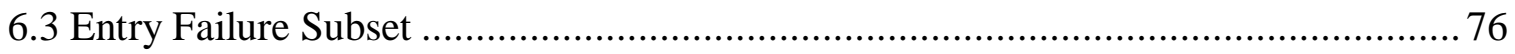

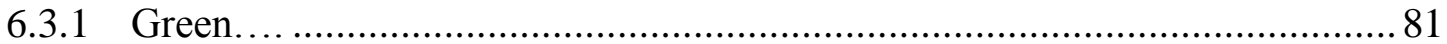

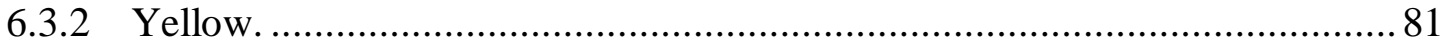

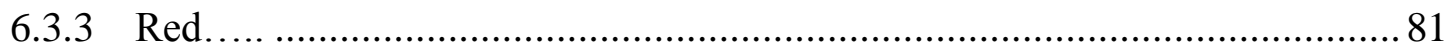

6.4 Combining the Shallow Cover and Deep Cover Databases..................................... 82

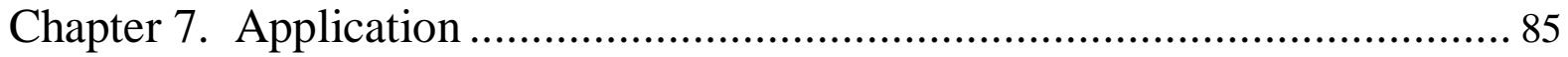

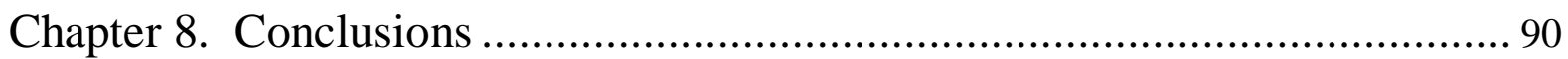

Chapter 9. Suggestions for Future Research................................................. 93

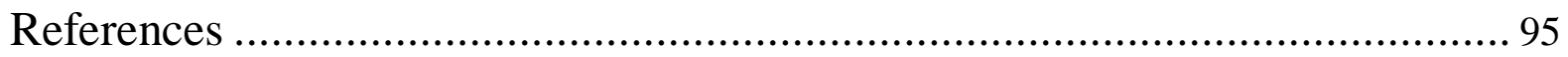

Appendix A. The Shallow Cover Database. .................................................100

Appendix B. Detailed Logistic Regression Analysis with R.........................102

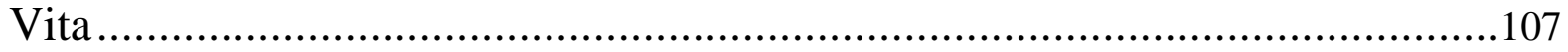

\section{List of Figures}


Figure 2.1: Examples of relative frequency, $f(S)$, distribution of critical safety factors (after Salamon and Munro, 1967).

Figure 2.2: Examples of cumulative frequency, $\mathrm{F}(\mathrm{S})$, distribution of critical safety factors (after Salamon and Munro, 1967)

Figure 2.3: Log-normal distribution in the logarithmic scale (after Salamon and Munro, 1967).

Figure 2.4: Distribution of the abutment stress (after Mark et al., 1995).....

Figure 2.5: Geometry of typical retreat mining panel showing the ARMPS input parameters (after Mark et al., 2011)

Figure 2.6: The initial loads applied to the AMZ (after Mark et al., 2011)..... 20

Figure 2.7: The "abutment angle" concept ued to extimate loads in ARMPS. (A) Supercritical panel. (B) Subcritical panel (after Mark et al., 2011)

Figure 2.8: The pressure arch in ARMPS. (A) The initial pressure arch. (B) The transfer of loads from (A) back to AMZ with undersized barrier (after Mark, et al., 2011).

Figure 2.9: ARMPS 2002 stability factors vs. depth for the deep cover database showing the standard design criteria (after Mark, 2010).

Figure 2.10: ARMPS 2010 stability factors vs. depth for the deep cover database showing the standard design criteria (after Mark, 2010) 25

Figure 2.11: The six material models used in LaModel (after Heasley et al., 2011) ............ 27

Figure 2.12: The laminated overburden (after Heasley, 1998) ........................................ 28

Figure 2.13: The lamination thickness wizard in LamPre 3.0 (after Heasley et al., 2010) .... 29

Figure 2.14: Seam elements with stiffness depicted as springs (after Heasley, 1998).......... 30

Figure 2.15: The gob wizard in LamPre 3.0 (after Heasley et al., 2010) ........................... 30

Figure 2.16: Receiver operating characteristic (ROC) curve for equation 2.17 (after Mark et al., 2007)

Figure 2.17: Plot of sensitivity and specificity versus cut-point (after Mark et al., 2007).... 38

Figure 2.18: Abutment stress as a function of distance for the laminated model and the empirical data (after Heasley et al., 2011)

Figure 2.19: ARMPS (2002) stability factors for the case histories (after Heasley et al., 2011).

Figure 2.20: LaModel stability factors for the idealized cases (after Heasley et al., 2011). 
Figure 2.21: LaModel stability factors for the detailed cases (after Heasley

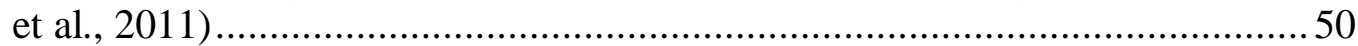

Figure 3.1: General location of case histories for the shallow cover database. .................52

Figure 5.1: Side abutment stress for the average case by calibration method...................59

Figure 5.2: Multiple seam stress on the underlying seam by calibration method............... 61

Figure 5.3: Depth versus LaModel stability factor............................................. 64

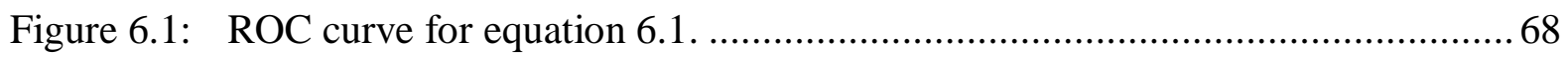

Figure 6.2: Plot of specificity and sensitivity vs cut-point for equation 1 showing the optimum cut point to be between 0.5 and 0.6 ...................................... 69

Figure 6.3: Design guidelines for $70 \%$ correct failure classification $(\mathrm{SF}=1.62)$ and

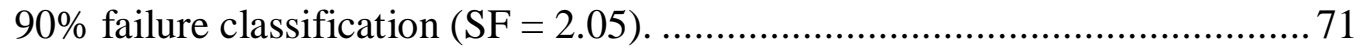

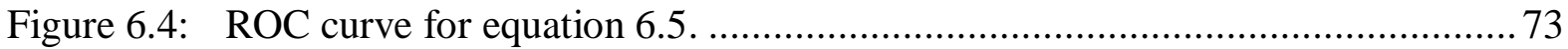

Figure 6.5: Plot of specificity and sensitivity vs cut-point for equation 6.5 showing

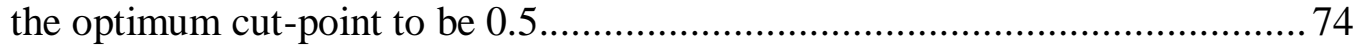

Figure 6.6: Design guidelines for $90 \%$ correct failure classification using

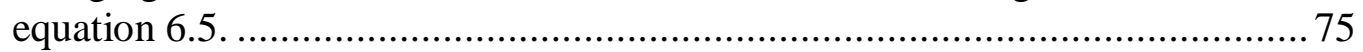

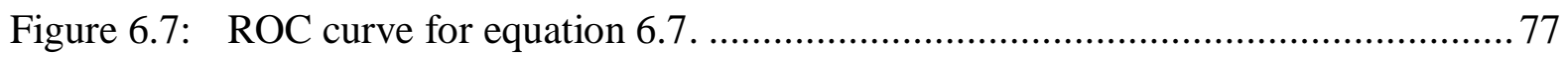

Figure 6.8: Plot of specificity and sensitivity vs cut-point for equation 6.7 showing the

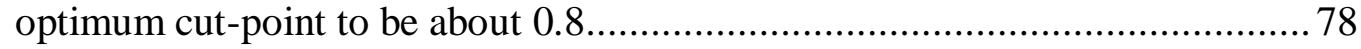

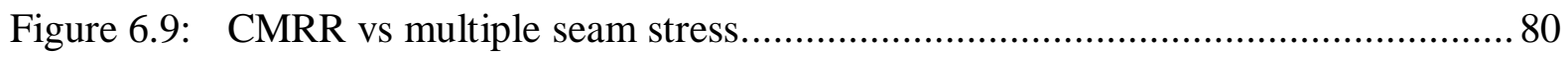

Figure 6.10: Design guidelines for approximately $90 \%$ correct failure classification. ..........83

Figure 7.1: Default Overburden/Rock Mass Parameters in the LaModel program .............85

Figure 7.2: Elastic-Plastic for COAL Material Wizard........................................... 86

Figure 7.3: Strain-Hardening for GOB Material Wizard ........................................... 87

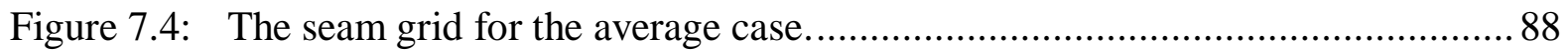

\section{List of Tables}


Table 3.1: Details of the shallow cover database ..................................................5 53

Table 5.1: Input parameters for the average case ............................................... 58

Table 5.2: LaModel input parameters for the three calibration techniques ......................59

Table 6.1: Logistic regression table for the single variable (SF) model ......................... 66

Table 6.2: $\quad$ Performance of the design equation against the database at a

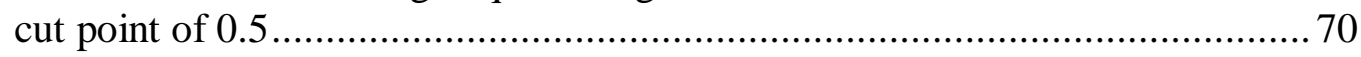

Table 6.3: Performance of the design equation against the database at a

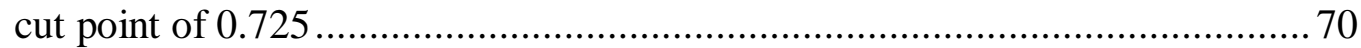

Table 6.4: Logistic regression table for the multi-variable ( $\mathrm{SF}$ and $\mathrm{H}$ ) model .................. 72

Table 6.5: Performance of the multi-variable model against the database at the

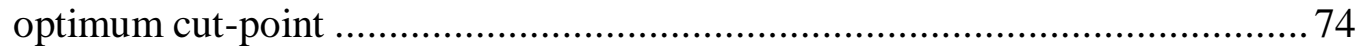

Table 6.6: Logistic regression table for the MSS model ......................................... 77

Table 6.7: Performance of the entry stability model against the database at the

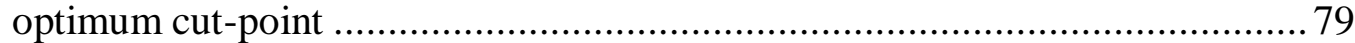

Table 6.8: Performance of the entry stability model against the database at a cut-point

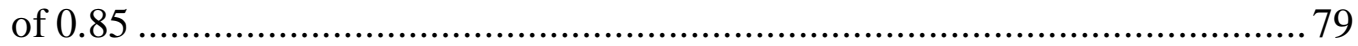

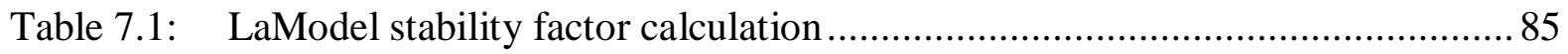

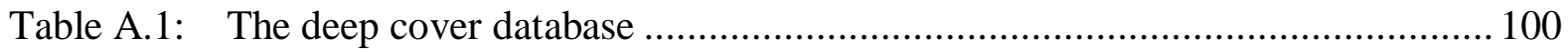




\section{Chapter 1}

\section{Introduction}

\subsection{Background}

The fatal coal bump accidents at the Crandall Canyon Mine in August 2007 (Gates et al., 2008) rapidly brought the insidious problem of coal bumps back into the public spotlight. This multiple bump event, over the course of several days, resulted in nine fatalities including three rescuers. Moreover, what the public did not necessarily see was the underlying problems with inadequate pillar design stemming from inaccurate calibration and mistakes using the LaModel program. During the past decade, approximately $40 \%$ of underground mining fatalities were caused by roof falls, rib collapses, or bumps/bursts, $19 \%$ of which occurred during retreat mining (Pappas and Mark, 2012). In addition, approximately 300 miners are non-fatally injured (often severely) by rock falls in coal mines annually for the past few years (Pappas, 2013). These statistics highlight the need for increasing the body of knowledge in the field of pillar design using all available methods: empirical, numerical, and/or analytical.

Research in the wake of the Crandall Canyon bump fatalities resulted in updating current design methods specifically for deep-cover retreat mining (Heasley et al., 2010 and Mark, 2010). In particular, the LaModel program (Heasley, 1998), a displacement discontinuity, boundary element model (BEM), was updated with a new deep-cover calibration method. The deep cover case histories were analyzed using LaModel with this new calibration method and then, similar to an empirical method, practical design guidelines were determined from statistical analysis (Heasley et al., 2010). Simultaneously, updates were being made to ARMPS (Mark, 2010) program. This included the addition of more deep cover case histories to the database, as well as 
adjusting a development load distribution calculation based on a pressure arch factor. This resulted in eliminating the depth as a statistically significant variable and changed the recommended design guideline to a constant stability factor of 1.5 regardless of depth.

Recently, other research in pillar design has included a shift toward combining elements of both empirical design and numerical modeling. For instance, in the AMSS program, a numerical model (LaModel) is used to determine the multiple-seam stress influence which is then combined with the empirical ALPS or ARMPS analysis to get a multiple-seam stability factor (Mark et al., 2007). In the LaModel calibration method for deep-cover mines, a database of deep-cover mines is used to define the required safety factor (Heasley et al., 2010). The research in this dissertation, similar to the previous deep-cover calibration, creates a crossroads between the two design methods by using numerical modeling analysis backed by a database of real world case histories to establish a practical design guideline.

\subsection{Objective}

The objective of this research is to improve mine safety by improving pillar design and entry stability for shallow cover room and pillar mines through developing a shallow cover calibration method in LaModel.

\subsection{Statement of the Problem}

The scope of the deep-cover calibration method (Heasley et al., 2010) was limited to cases deeper than $750 \mathrm{ft}$; however the injury/fatality statistics (Pappas and Mark, 2012) still show a need of improved pillar design and roof control in shallow cover mines. Additionally, while it is true that over time coal mining is being conducted at deeper depths, it is also true that more 
multiple-seam interaction scenarios are being encountered as the age of reserves progresses in this country. With time, the number of mines encountering multiple seam interactions is increasing. Logically, there is a corresponding need for improved multiple-seam ground control design as the occurrence of multiple-seam mining increases. This research attempts to address the need for improved ground control in shallow cover and/or multiple-seam mines by defining LaModel calibration and safety factor guidelines for shallow cover and/or multiple-seam pillar design.

\subsection{Scope of Work}

This research consists of gathering 40 case histories, determining a suitable calibration technique, analyzing the database, and determining design guidelines based on the statistical analysis of the database.

The scope of this study is mostly limited by the size of the database. Because it takes up to a week to do a detailed multiple-seam LaModel analysis with actually gridding the mine plan and topography; the initial shallow cover database is quite small (40 case histories). While this is a problem from a statistical point of view, it is acceptable as long as the number of independent variables is kept small. More importantly, the shallow-cover database is nearly the same size as the LaModel deep cover database which yielded reasonable results. And, it is hoped that in the future additional case histories will be added to the shallow cover database.

Because the size of the database limited, the breadth is also of necessity limited. A narrow range of pillar sizes, overburden depths, panel widths, etc. can only be included. The variability of input parameters in the LaModel program is also limited in this study. Coal materials are analyzed as elastic-plastic materials and the gob is strain-hardening, as was the case with the 
deep-cover study. Specifically, strain-softening coal, elastic coal, and linear-elastic gob materials will not be considered in this study, although there is certainly potential for some of these material types in future research. 


\section{Chapter 2}

\section{Literature Review}

\subsection{Introduction}

Prior research in the field of pillar design spans more than a century with a huge increase in the literature occurring in the last 50 years. To adequately introduce the subject, recent advances in the topical areas of empirical pillar design and numerical modeling for pillar design will be discussed in detail below. Empirical pillar design relies primarily on experiment and observation (Mark, 1999) while numerical design relies primarily on the mathematical and mechanical analysis of the structure (Heasley, 1998). Both design methods are not static and have evolved over time. Specifically, the pillar design methods ARMPS and LaModel are continually being modified and "upgraded" based on current needs and research trends.

Empirical design, the first relevant technique to see widespread usage, relies on large databases of past observations in an attempt to create a statistical design "average" minimizing the likelihood of failure within the domain of the database. In other words, future designs are statistically compared to past designs with less regard for the actual mechanics at work.

Numerical analysis, on the other hand, is the result of the mathematical analysis of one or more physical properties presented in the model. Traditionally, it is used at a site specific level and allows for future designs to be compared to an initial calibrated model.

Both design methods facilitate designing an engineered system without fully understanding or incorporating all of the physical mechanisms at work. While numerical modeling techniques and empirical design both attempt to attain the result of suitable and stable pillar design, a rift between "average" design and site specific design has existed between the two. The focus of this 
literature review, in addition to showing the progression of pillar design, is to show how these two methods are recently coming closer together and being combined, and how this combination approach relates to the objective of this research. It should be noted that equations in this literature review retain the notation provided by the author except where there is a conflict with the notation in other sections of this thesis.

\subsection{Empirical Pillar Design}

Empirical pillar design methods have seen use in the U.S. mining industry for over a century (Bunting, 1911). Until the emergence of numerical methods in the 1970's, it was the only pillar design method available. All empirical pillar design techniques use the same basic design methodology (after Mark, 1999):

1. Estimate the pillar load

2. Estimate the pillar strength, then

3. Calculate the pillar safety factor.

Initially, the basic room-and-pillar load was calculated using the tributary area method (Mark, 1999). That is, each pillar supports the full overburden load above it and half the entry width on every side. With the development of the ARMPS program (Mark and Chase, 1997), estimates of the pillar load now included both the tributary area load and the abutment loads associated with retreat mining techniques. Taking into account the additional load from multiple-seam stress transfer is difficult using pure empirical analysis techniques. The development of the AMSS program utilized existing numerical modeling techniques, which naturally incorporated the important parameters and applied them according to the mechanics involved to calculate the multiple-seam stresses. 
Early pillar strength formulas were determined based on either lab testing (Holland and Gaddy, 1957; Obert and Duvall, 1967) or large-scale insitu tests (Bieniawski, 1968). To estimate the pillar strength, the laboratory coal strength is typically modified based on the pillar size and shape. It is generally accepted that as the size of the rock specimen increases, the strength decreases until a critical size is reached at which point the specimen strength does not decrease any more. The shape effect on coal strength is typically incorporated by considering the width and height of the pillar in the pillar strength formula. As the width to height ratio increases, it is generally accepted that the pillar strength increases.

The problem is that while all of the methods using lab tested specimens de-rate the pillar strength based on specimen size, extreme extrapolation is typically required to estimate the strength of actual pillars from laboratory sized specimens. Mark and Barton (1996) concluded that the laboratory-derived uniaxial compressive strength (UCS) provided little assistance in pillar design in the field and also, that the size effect is not constant, but varies considerable from seam to seam (Mark, 1999). More importantly, designs derived strictly from lab-tested specimens, and even large-scale insitu tests lack design guidelines determined from actual fullsize pillar case histories.

The concept of developing pillar design criteria based on the statistical analysis of a database was first introduced by Salamon and Munro in 1967 and has been used for several decades with relatively good results. In fact, the most widely used empirical pillar design program in the U.S., Analysis of Retreat Mining Pillar Stability or ARMPS (Mark et al., 1995; Mark and Chase, 1997; Mark, 2010), which is based on a statistical analysis of a database, has become a design standard in the U.S. (MSHA, 2010). 
The major strength of empirical design lies in the database itself. Results from empirical design are directly supported by actual, either successful or unsuccessful, designs. Its major weaknesses include: the riskiness of extrapolating outside the database and a limited ability, or inability, to adjust for site-specific conditions while still retaining statistical significance.

\subsubsection{Salamon and Munro}

Salamon and Munro (1967) provided the first attempt at designing coal pillars using the statistical analysis of actual full scale, insitu, case histories. They assumed that if one could adequately calculate the strength of coal pillars then the critical safety factor $\left(\mathrm{S}_{\mathrm{c}}\right)$ formed a frequency distribution centered on unity. The probability of a pillar failing is then indicated by its position on the curve, in other words, they used the notion that the nature of a safety factor is probabilistic. This implies that the inputs (strength, loading, etc.) are also probabilistic in nature.

Salamon and Munro's initial database included 125 cases from the Transvaal and Orange Free State in South Africa. The data focused solely on square pillar failures and was subdivided into stable and collapsed cases. This research neglected stress related failures that did not involve failure of the pillar itself, such as roof/floor failure. The pillar load was assumed to be the tributary area and only cases where pillar workings were extensive enough to meet this assumption were considered for the database.

For their work, the safety factor $(\mathrm{S})$ was defined as:

$$
\mathrm{S}=\frac{\mathrm{S}_{\mathrm{P}}}{\mathrm{L}_{\mathrm{P}}}
$$

Where:

$\mathrm{S}$ is the pillar safety factor

$\mathrm{S}_{\mathrm{P}}$ is the strength of the pillar

$\mathrm{L}_{\mathrm{P}}$ is the load applied to the pillar 
Here, the strength is the total strength of the coal pillar itself rather the strength of the insitu coal and the load is the total load applied to the pillar.

Assuming the strength and the load are exactly known; if the safety factor is less than 1, then the structure will fail. Conversely, if the safety factor is greater than 1 it will not fail (Salamon and Munro, 1967). If a database of failed structures is generated using a single method of predicting strength, then the observed critical safety factors can be plotted as a frequency distribution of the critical safety factor, $\mathrm{f}\left(\mathrm{S}_{\mathrm{c}}\right)$. Three fictitious curves are presented in figure 2.1 and 2.2 as an example (after Salamon and Munro, 1967). Curves A, B, and C represent less and less reliable methods of design. Asymmetry and increasing the amount the curves are skewed represent increasing scatter and decreasing accuracy of the critical safety factors.

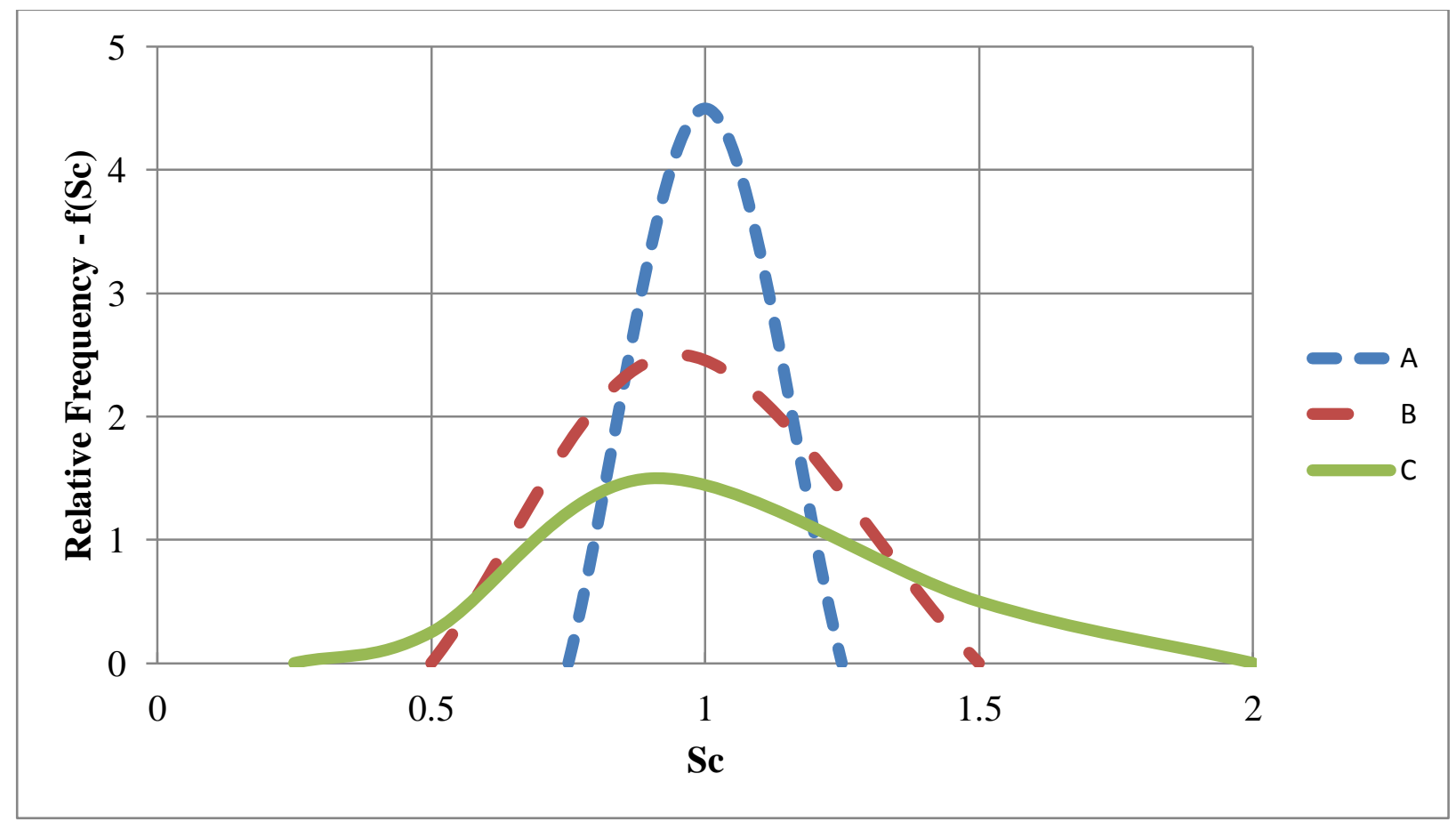

Figure 2.1: Example of relative frequency, $\mathrm{f}\left(\mathrm{S}_{\mathrm{c}}\right)$, distribution of critical safety factors (after Salamon and Munro, 1967). 


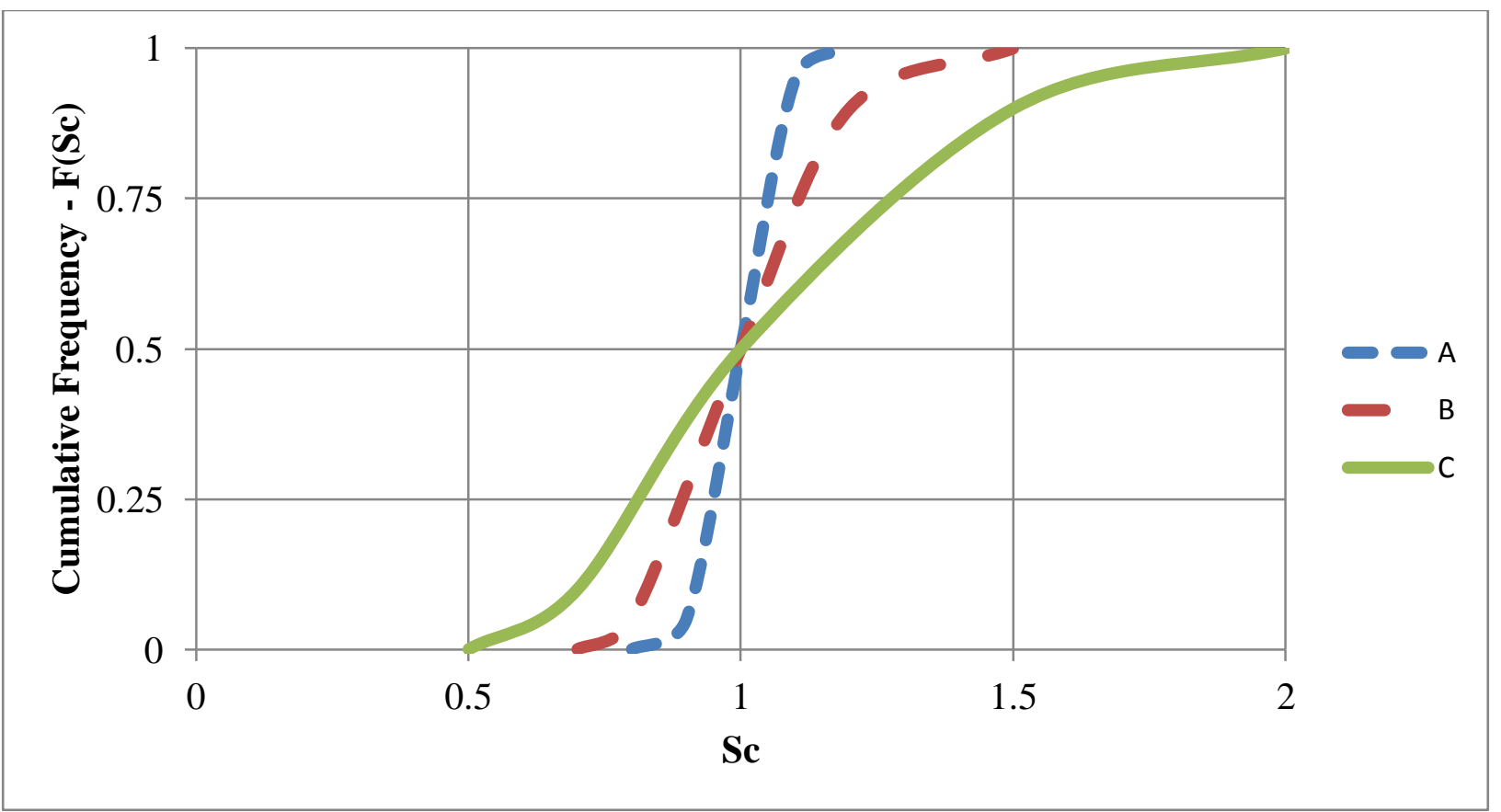

Figure 2.2: Example of cumulative frequency, $\mathrm{F}\left(\mathrm{S}_{\mathrm{c}}\right)$, distribution of critical safety factors (after Salamon and Munro, 1967).

In order for the design criteria to be considered reliable, the scatter of the critical safety factors should be minimized and centered on unity (See Figure 2.1). (Looking forward, this is the same reason for attempting to minimize the "grey area", or overlap area, in both the deep cover and shallow cover databases.) The cumulative distributions, Figure 2.2, represent the probability that the critical safety factor of a randomly selected structure is between 0 and S. Additionally, it represents the probability that a structure designed with a safety factor of $\mathrm{S}$ will be stable.

Because the cumulative curves range from 0 to 1 , the probability of a failure at $S=0$ is $100 \%$ while the probability of a success at $\mathrm{S}=\infty$ is $100 \%$. By creating a design procedure using this methodology, a 50\% failure rate would be achieved with a median value of $\mathrm{S}=1$.

In order to used this probabilistic approach, the safety factor for coal pillars must be defined. Salamon defined the strength of a pillar as: 


$$
S_{P}=K h^{\alpha} w^{\beta}
$$

Where:

$\mathrm{K}$ is the strength of a one foot cube of coal

$\mathrm{h}$ is the pillar height

$\mathrm{w}$ is the pillar width

$\alpha$ and $\beta$ are appropriately chosen constants

Combining equation 2.1 and 2.2 the safety factor for a coal pillar can be written as:

$$
\mathrm{S}=\frac{\mathrm{K} \mathrm{h}^{\alpha} \mathrm{w}^{\beta}}{\mathrm{p}}
$$

Where:

$\mathrm{p}$ is average stress acting on a pillar (psi)

Salamon and Munro (1967) specifically chose case histories with working areas large enough for the tributary area to be considered applicable. If, it is assumed that the pillars carry the full load of the overburden at a rate 1.1 psi per foot of depth, then the average pillar stress can be taken as:

$$
\mathrm{p}=1.1 \mathrm{H}\left(\frac{\mathrm{w}+\mathrm{B}}{\mathrm{w}}\right)^{2}
$$

Where:

$B$ is the entry width

In order to estimate the parameters of K, $\alpha$, and $\beta$; Salamon and Munro (1967) suggests the values be chosen using the probabilistic approach. Therefore, choosing parameters that concentrate the distribution of critical safety factors as densely about $\mathrm{S}=1$ as possible.

Assuming that the $\log \mathrm{S}$ follows a normal distribution with mean zero $(\mathrm{S}=1)$ and standard deviation $\sigma$, the frequency distribution of the $\log \mathrm{S}$ is given as Salamon and Munro (1967):

$$
f_{1}(\log S)=\frac{1}{\sqrt{2 \pi} S_{d}} \exp \left[-\frac{1}{2}\left(\frac{\log S}{S_{d}}\right)^{2}\right]
$$


This distribution is symmetric in the logarithmic scale. The standard deviation, $S_{d}$, is simply a measure of the spread about the mean, zero (See Figure 2.3). The frequency distribution of S on the natural scale is:

$$
f(S)=\frac{\log e}{\sqrt{2 \pi} S_{d} S} \exp \left[-\frac{1}{2}\left(\frac{\log S}{S_{d}}\right)^{2}\right]
$$

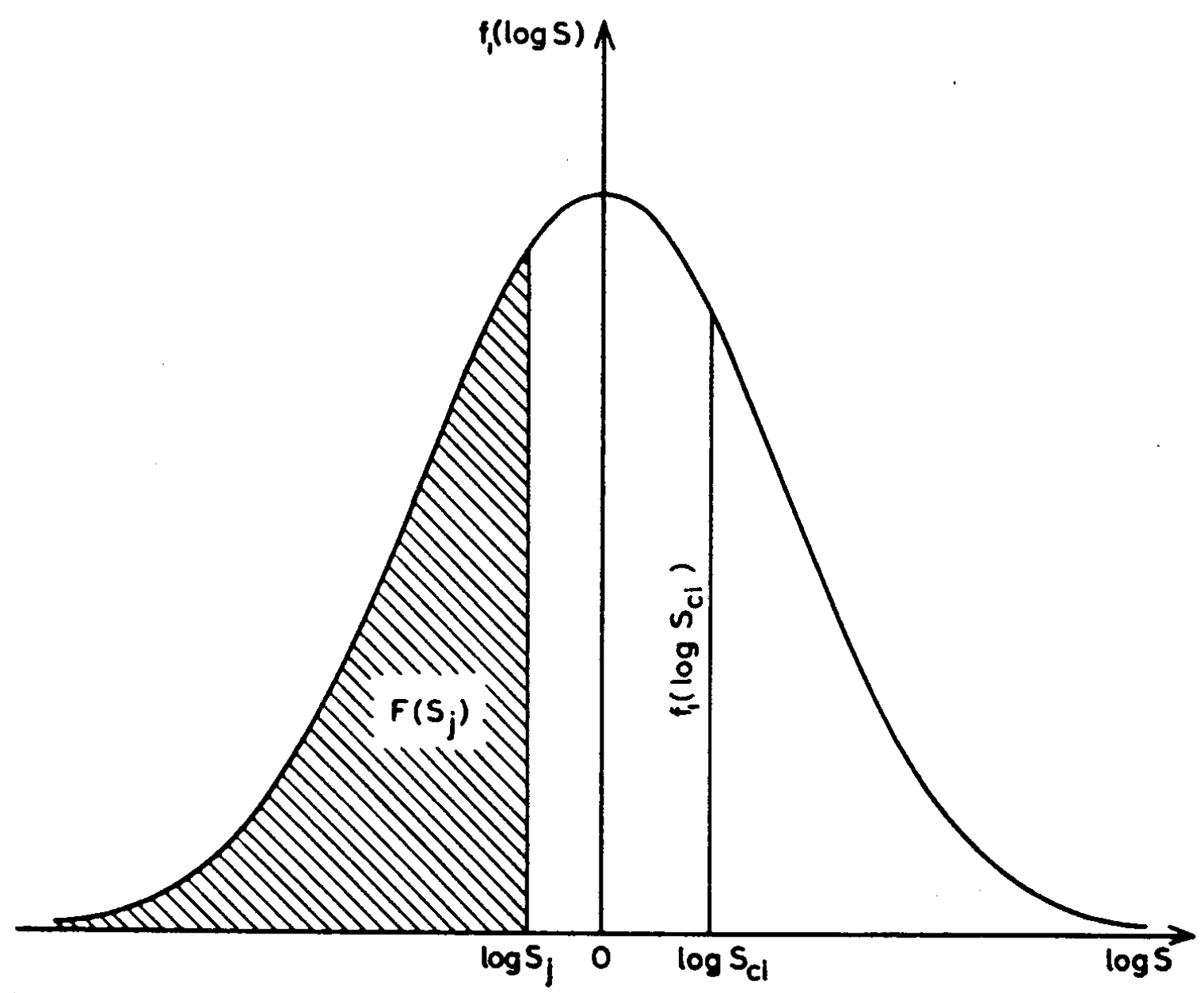

Figure 2.3: Log-normal distribution in the logarithmic scale (after Salamon and Munro, 1967) From Figure 2.3, the cumulative normal distribution function, $\mathrm{F}(\mathrm{S})$, is the area under the curve (integral) of $f(S)$ and was defined as: 


$$
\mathrm{F}(\mathrm{S})=\Phi\left(\frac{\log \mathrm{S}}{\mathrm{S}_{\mathrm{d}}}\right)
$$

Where:

$$
\Phi\left(\frac{\log S}{S_{d}}\right) \text { is the cumulative normal distribution function. }
$$

Estimating the unknown constants is related to the collapsed cases only and chosen such that it maximizes the clustering of the observed critical safety factors about the median $S=1$. This is expressed by requiring that the product of the frequency function $\mathrm{L}_{1}$ be maximized:

$$
L_{1}=f_{1}\left(\log S_{c 1}\right) \cdot f_{1}\left(\log S_{c 2}\right) \ldots f_{1}\left(\log S_{c i}\right) \ldots f_{1}\left(\log S_{c m}\right)
$$

Where:

$\mathrm{S}_{\mathrm{cl}}, \mathrm{S}_{\mathrm{c} 2}, \ldots \mathrm{S}_{\mathrm{cm}}$ is the critical safety factors of the $\mathrm{m}$ failure cases.

In this method, the estimates of the critical parameters are the same as those which could be derived by the method of least squares.

In the subset of successful cases, the safety factor is greater than the critical safety factor, meaning, $S_{j}>S_{c j}(j=1,2, \ldots n)$. This suggests that at $S_{j}$ the probability of successful geometry, $\mathrm{F}\left(\mathrm{S}_{\mathrm{j}}\right)$, should be as great as possible within the limits of equation 2.3. Salamon and Munro (1967) define the probability of a stable case with a safety factor of $S_{j}$ as the area under the frequency distribution curve to the left of $S_{\mathrm{j}}$, see Figure 2.3. Estimation of the critical parameters requires maximization of the product function where:

$$
\mathrm{L}_{2}=\mathrm{F}\left(\mathrm{S}_{1}\right) \cdot \mathrm{F}\left(\mathrm{S}_{2}\right) \ldots \mathrm{F}\left(\mathrm{S}_{\mathrm{j}}\right) \ldots \mathrm{F}\left(\mathrm{S}_{\mathrm{n}}\right)
$$

Salamon and Munro (1967) determined the critical parameters based on evidence from both the successful and failure cases. Where, a solution required maximizing the function L:

$$
\mathrm{L}=\mathrm{L}_{1} \cdot \mathrm{L}_{2}
$$

with respect to $K, \alpha, \beta$, and $\sigma$. 
Here, the product function $\mathrm{L}$ represents the likelihood function in statistics and the critical parameters derived from it are called the "maximum likelihood estimators." The function $\mathrm{L}$ is maximized at the same values of the critical parameters. Due to mathematical simplification, Salamon and Munro (1967) maximize the natural log of L instead:

$$
\ln \mathrm{L}=\ln \mathrm{L}_{1} \cdot \ln \mathrm{L}_{2}
$$

Substitution of equation 2.6 and 2.8 results in:

$$
\ln \mathrm{L}_{1}=\text { const. }-\mathrm{m} \ln \sigma-\frac{1}{2 \sigma^{2}} \sum_{\mathrm{i}=1}^{\mathrm{m}}\left(\log \mathrm{S}_{\mathrm{ci}}\right)^{2}
$$

and based on equations 2.7 and 2.9:

$$
\ln \mathrm{L}_{2}=\sum_{\mathrm{j}=1}^{\mathrm{n}} \ln \Phi\left(\frac{\log \mathrm{S}_{\mathrm{j}}}{\sigma}\right)
$$

The function $\mathrm{L}$ has a stationary value where the first partial derivatives with respect to the critical parameters are 0.

$$
\frac{\partial(\ln \mathrm{L})}{\partial \mathrm{K}}=\frac{\partial(\ln \mathrm{L})}{\partial \mathrm{x}}=\frac{\partial(\ln \mathrm{L})}{\partial \beta}=\frac{\partial(\ln \mathrm{L})}{\partial \sigma}=0
$$

Looking at the behavior of the second derivative of $\ln \mathrm{L}$ confirms the stationary value to be a maximum (Salamon and Munro, 1967).

The four equations given in equation 2.14 are complex with roots determined using an iterative process. The initial values of the critical parameters were determined by considering only the failed cases. That is, by maximizing the function $\ln \mathrm{L}_{1}$ in equation 2.12.The final parameters determined using this method result in a pillar strength formula of: 


$$
S_{p}=1320 \frac{\mathrm{w}^{0.46}}{\mathrm{~h}^{0.66}}
$$

Where:

$\mathrm{h}$ is the pillar height ( $\mathrm{ft}$ ).

Pillar design requires a statistical focus on the unsuccessful case histories. The reason for the focus on the unsuccessful case histories is because no one gets injured from major ground failures when a panel is retreated successfully. The key to increasing safety is to correctly predict the unsuccessful cases acceptably well, even if it is at the expense of over design. Using this pillar strength formula, $99 \%$ of the collapsed cases had a SF between 0.65 and 1.48 . The recommended SF of 1.6 would correctly classify practically all of the collapsed cases in the database.

While Salamon and Munro (1967) provided the mining community with a statistical approach to determining the pillar strength, their method lacked one important feature required for modern room and pillar mining. Namely, their database was designed only to include the tributary area loading. It does not provide a means of calculating the load applied to the pillars if the assumption of tributary area loading isn't met. Additionally, this method only applies to square pillar failure; it lacks the ability to address more complex mining geometries and barrier pillars or situations where stress related failure occurs due to the roof/floor.

\subsubsection{The Bieniawski Pillar Strength}

To set the stage for the more recent advances in pillar design, a slight digression is required. Although the discussion will involve statistical methods of pillar design, a different pillar strength formula will be used. This formula will be applied to the empirical and numerical 
design methods that are pertinent to this research and although it is not a statistical approach, this equation has seen widespread use in the United States (Bieniawski, 1981).

The Bieniawski (1981) pillar strength formula began in South Africa as research investigating the size effect on pillar strength using large (but not full) scale insitu testing of coal specimens (Bieniawski, 1968). A total of 60 cubic specimens ranging from 0.75 in to $6.6 \mathrm{ft}$ were tested. It was determined that, for coal, once the specimen reached a critical size of about $5 \mathrm{ft}$, reduction in specimen strength was negligible and an approximation of the insitu coal strength is reached. It is then assumed that strength of a cubic specimen of at least $5 \mathrm{ft}$ can be extrapolated to full scale pillar design.

Bieniawski (1981) determined the effective pillar strength formula to be:

$$
\mathrm{S}_{\mathrm{p}}=\sigma_{1}\left(0.64+0.36 \frac{\mathrm{w}}{\mathrm{h}}\right)
$$

Where:

$\sigma_{1}$ is the insitu coal strength (psi)

Here, the width to height ratio takes into account the pillar shape effect, but the size effect was ignored due to all of the specimens being rectangular. It is assumed that the pillar is either square, or in the case of a rectangular pillar that the additional length provides a negligible increase in strength. Early versions of ALPS and ARMPS program used this formula (Mark and Chase, 1997).

A need to better approximate the strength of rectangular pillars and noting the nonuniformity of stress within a coal pillar leads directly to the Mark-Bieniawski pillar strength equation as derived by Mark and Chase (1997). By integrating the Bieniawski (1981) pillar strength equation and understanding that the vertical stress applied is a continuous function, a linear stress gradient $\left(\sigma_{\mathrm{v}}\right)$ is implied (Mark and Chase, 1997). 


$$
\sigma_{\mathrm{v}}=\sigma_{1}\left(0.64+2.16 \frac{\mathrm{x}}{\mathrm{h}}\right)
$$

Now that the stress gradient is known, a second integration over the load bearing area results in the strength of any rectangular shaped pillar (Mark and Chase, 1997).

$$
\mathrm{S}_{\mathrm{p}}=\sigma_{1}\left(0.64+0.54 \frac{\mathrm{w}}{\mathrm{h}}-0.18 \frac{\mathrm{w}^{2}}{\mathrm{lh}}\right)
$$

Where:

1 is the pillar length.

The Mark-Bieniawski pillar strength equation is used from this point forward. This is because it allows for the use of square and rectangular pillars and is widely used and is universally accepted for use in U.S. coal fields. The equation is used in several empirical design techniques with very large databases and numerical analysis techniques which will be discussed in the following.

\section{$\underline{\text { 2.2.3 ARMPS }}$}

The ARMPS program (Mark et al., 1995, Mark and Chase, 1997) provided a much needed upgrade for coal pillar design in the United States. Based on the previous ALPS program (Mark, 1990; Mark, 1992), ARMPS considers not only the tributary area loads but also the abutment loads associated with retreat mining pillar geometries. More importantly, it is backed by an extensive database of U.S. case histories. Initially, this database included 130 case histories and has now been expanded to nearly 650 .

A portion of the expansion of the database was directed at solving the pillar design problems associated with deep cover pillar extraction after the Crandall Canyon Mine collapse discussed previously (Mark, 2010). The deep cover LaModel database will be discussed in detail later, but it should be noted that the "upgrades" to both the ARMPS and the LaModel program were 
performed around the same time using some of the same case histories. Using these case histories and a new calibration procedure led directly to comparisons between the ARMPS and LaModel programs.

The ARMPS program considers/evaluates the overall stability of the section, and therefore calculates the stability factor ( $\left.\mathrm{SF}_{\mathrm{ARMPS}}\right)$ as an "average safety factor" over the section instead of considering individual pillar safety factors. A case study was successful when an entire panel was recovered without any significant ground failures, and a case was a failure when the pillars collapsed or a ground failure occurred that necessitated leaving pillars or altering the original mine plan (Mark, 2009). This technique accounts for cases where some pillars on the face line may have a low safety factor, but the overall stability of the section is not compromised. This can be due to the outby and barrier pillars sharing load transferred from the yielded/yielding pillars on the face line (Mark, 2010). Using this definition of the SFARMPS is the direct result of moving beyond classification of failures as purely pillar failures in Salamon and Munro (1967) and shifting to a consideration of the success of the panel as a whole.

To calculate the average stability factor, the area over which the average is taken is defined as the active mining zone (AMZ). The width of the AMZ is the panel width, and the breadth of the AMZ (see Figures 2.4 and 2.5) is defined as the abutment extent that contains $90 \%$ of the abutment load (Mark, 1990).

$$
\mathrm{B}_{\mathrm{AMZ}}=5 \sqrt{\mathrm{H}}
$$

Where:

$\mathrm{B}_{\mathrm{AMZ}}$ is the breadth of the AMZ

$\mathrm{H}$ is the depth 


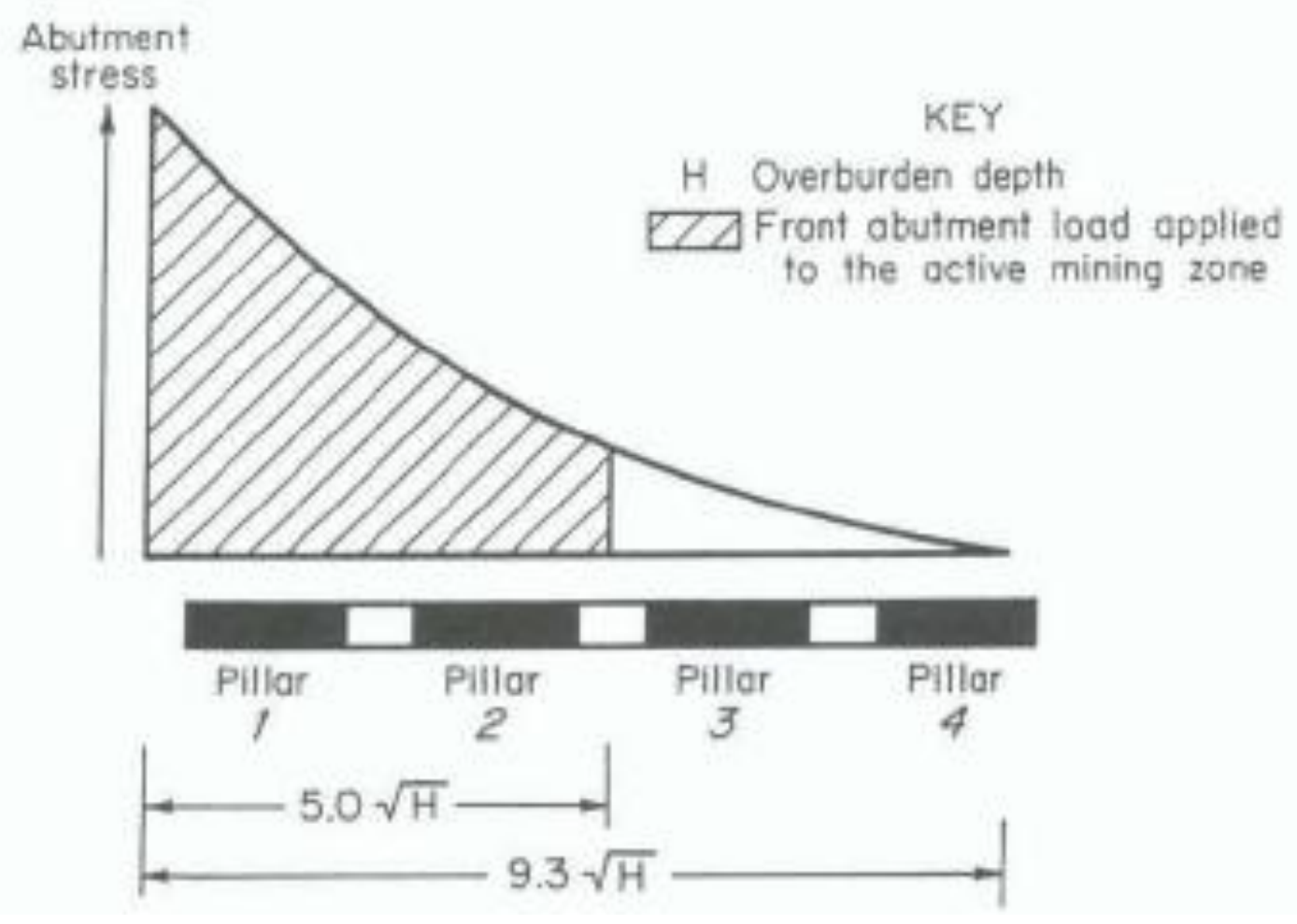

Figure 2.4: Distribution of the abutment stress (after Mark et al., 1995).

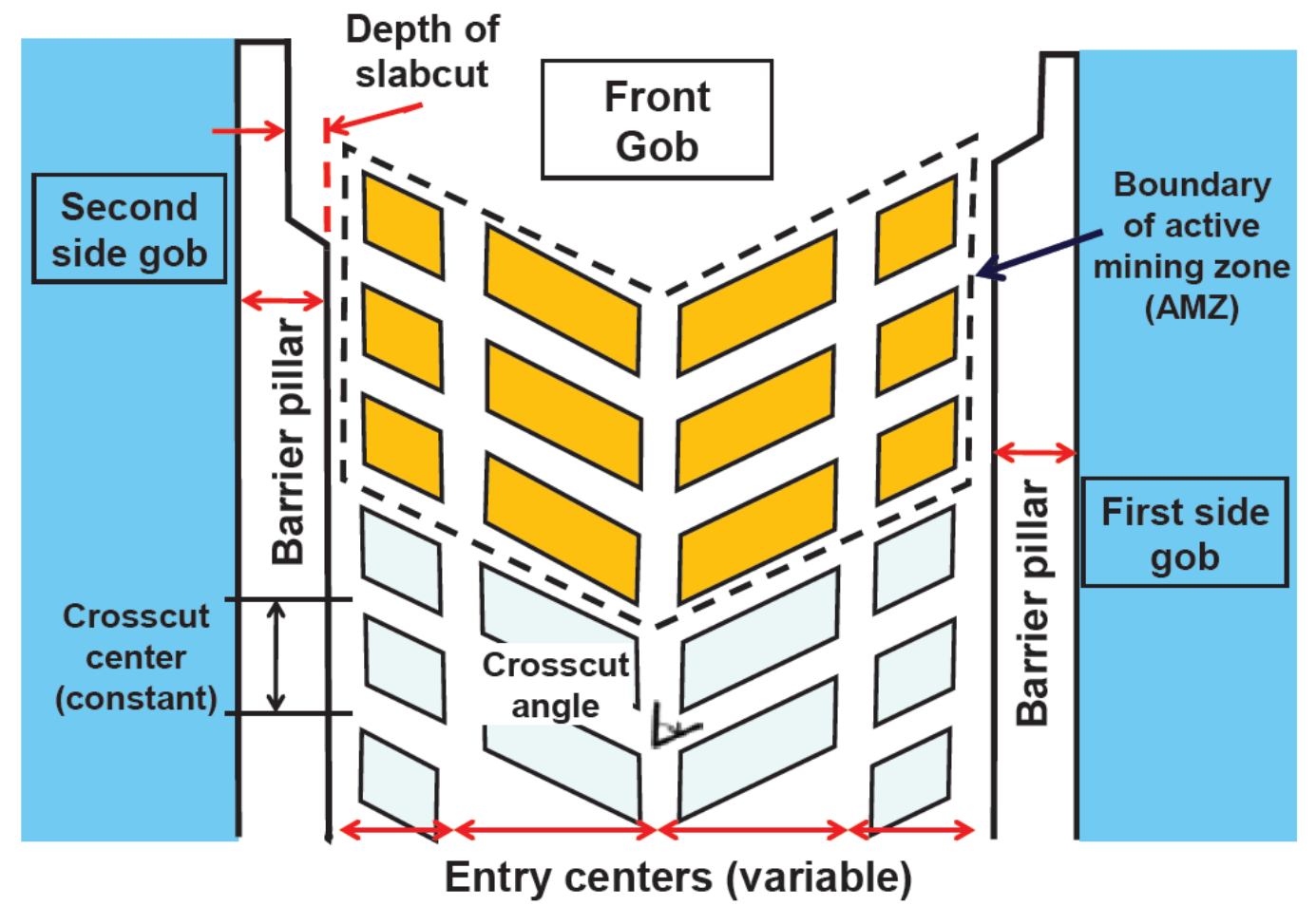

Figure 2.5: Geometry of typical retreat mining panel showing the ARMPS input parameters (after Mark et al., 2011). 
The $\mathrm{SF}_{\mathrm{ARMPS}}$ is then calculated as:

$$
\mathrm{SF}_{\mathrm{ARMPS}}=\frac{\mathrm{L}_{\mathrm{BC}}}{\mathrm{L}_{\mathrm{T}}}
$$

Where:

$\mathrm{L}_{\mathrm{BC}}$ is the load bearing capacity of pillars within the $\mathrm{AMZ}$

$\mathrm{L}_{\mathrm{T}}$ is the load applied to pillars within the AMZ.

The load bearing capacity of the pillars or portions of pillars in the AMZ is then calculated as the sum of individual pillar strengths using the Mark-Bieniawski equation (2.18) and typically assuming an insitu coal strength $\left(\sigma_{1}\right)$ of 900 psi (Mark et al., 1995). Now that the load bearing capacity of the AMZ has been determined, the load applied to the pillars must be estimated (See Figure 2.6).

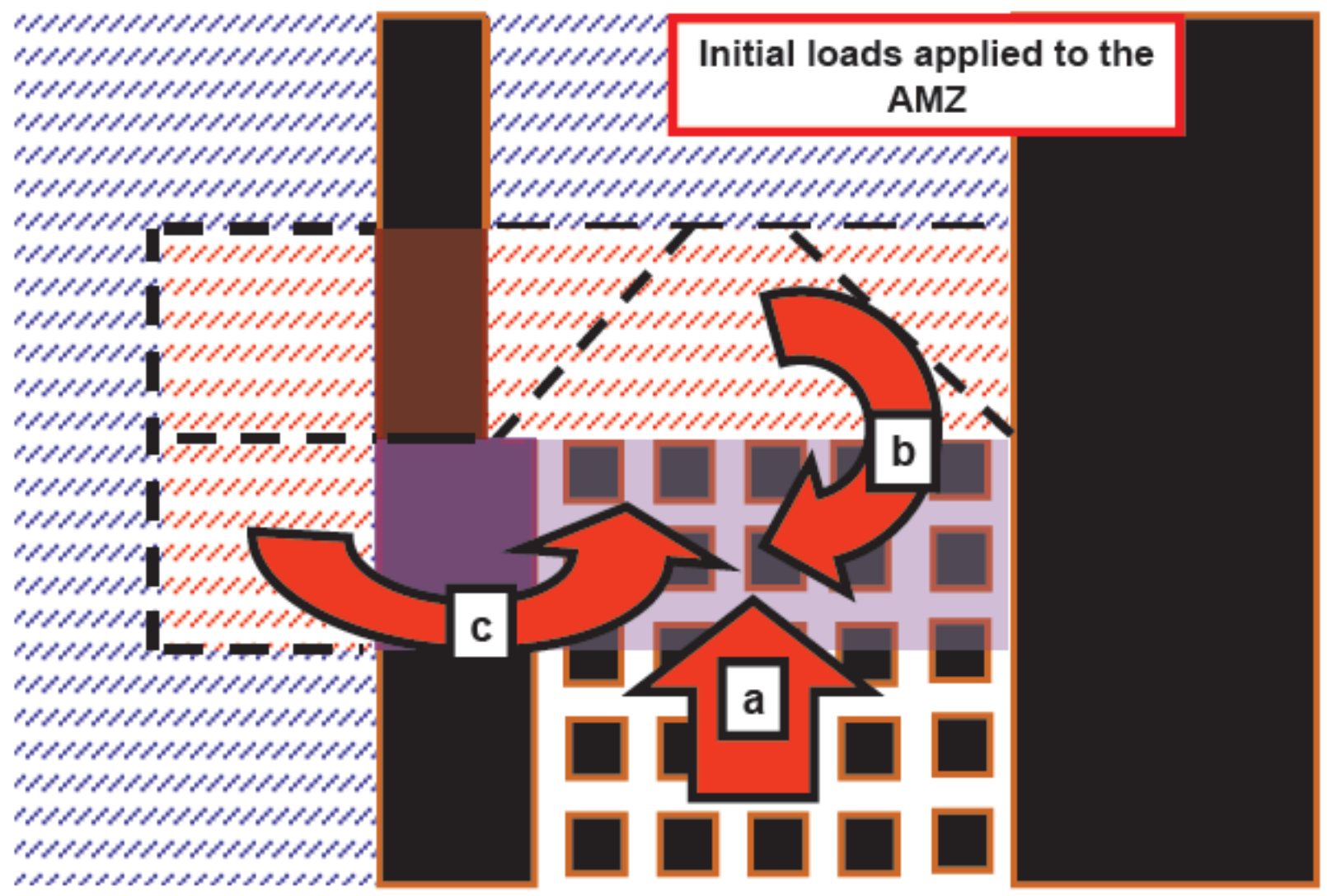

Figure 2.6: The initial loads applied to the AMZ (after Mark et al., 2011). 
Loads applied to the AMZ consist of the development or tributary area load (a), the front abutment load (b), and the side abutment load (c) utilizing the abutment angle concept (see Figure 2.7).
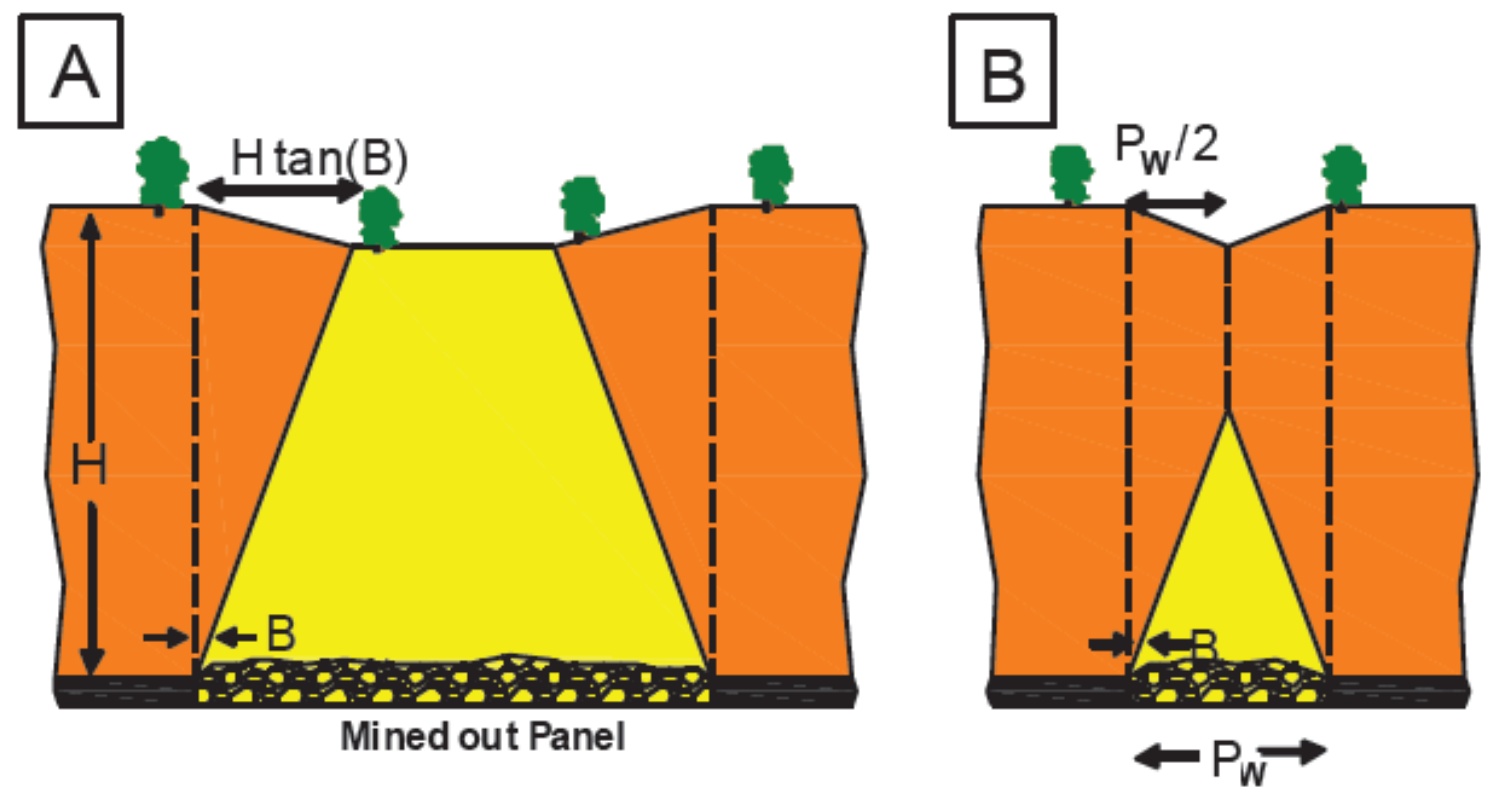

Figure 2.7: The "abutment angle" concept used to estimate loads in ARMPS. (A) Supercritical panel. (B) Subcritical panel (after Mark et al., 2011).

The abutment angle, B, determines what portion of the total overburden load is applied to the gob and what portion is transferred to the abutments. As the panel approaches critical width, the percentage of the load applied to the abutments decreases and the percentage applied to the gob increase. At the critical width, the load is split evenly between the gob and the abutments. Once the panel exceeds the critical width, the magnitude of the load applied to the abutments and the peak stress on the gob remains constant. For ARMPS and ALPS, the default abutment angle is $21^{\circ}$ (Mark, 1992), but is a user modifiable parameter.

New features of ARMPS 2010 (Version 6) include the pressure arch factor: 


$$
\mathrm{F}_{\mathrm{pa}}=1-\left[0.28\left(\ln \left(\frac{\mathrm{H}}{\mathrm{P}_{\mathrm{w}}}\right)\right)\right]
$$

Where:

$\mathrm{F}_{\mathrm{pa}}$ is the pressure arch factor

$\mathrm{H}$ is the depth of cover (for $\mathrm{H}<\mathrm{P}_{\mathrm{w}}$ )

$\mathrm{P}_{\mathrm{w}}$ is the panel width

which is applied to subcritical panels (where the panel width is less than the depth of cover) and shifts some of the load from the AMZ to the barrier pillars (see Figure 2.8). The quantity of load shifted is determined by simple multiplication of the load applied to the AMZ by the pressure arch factor. If the barrier pillars are undersized, a portion of the load is transferred back to the AMZ (see Figure 2.8). 

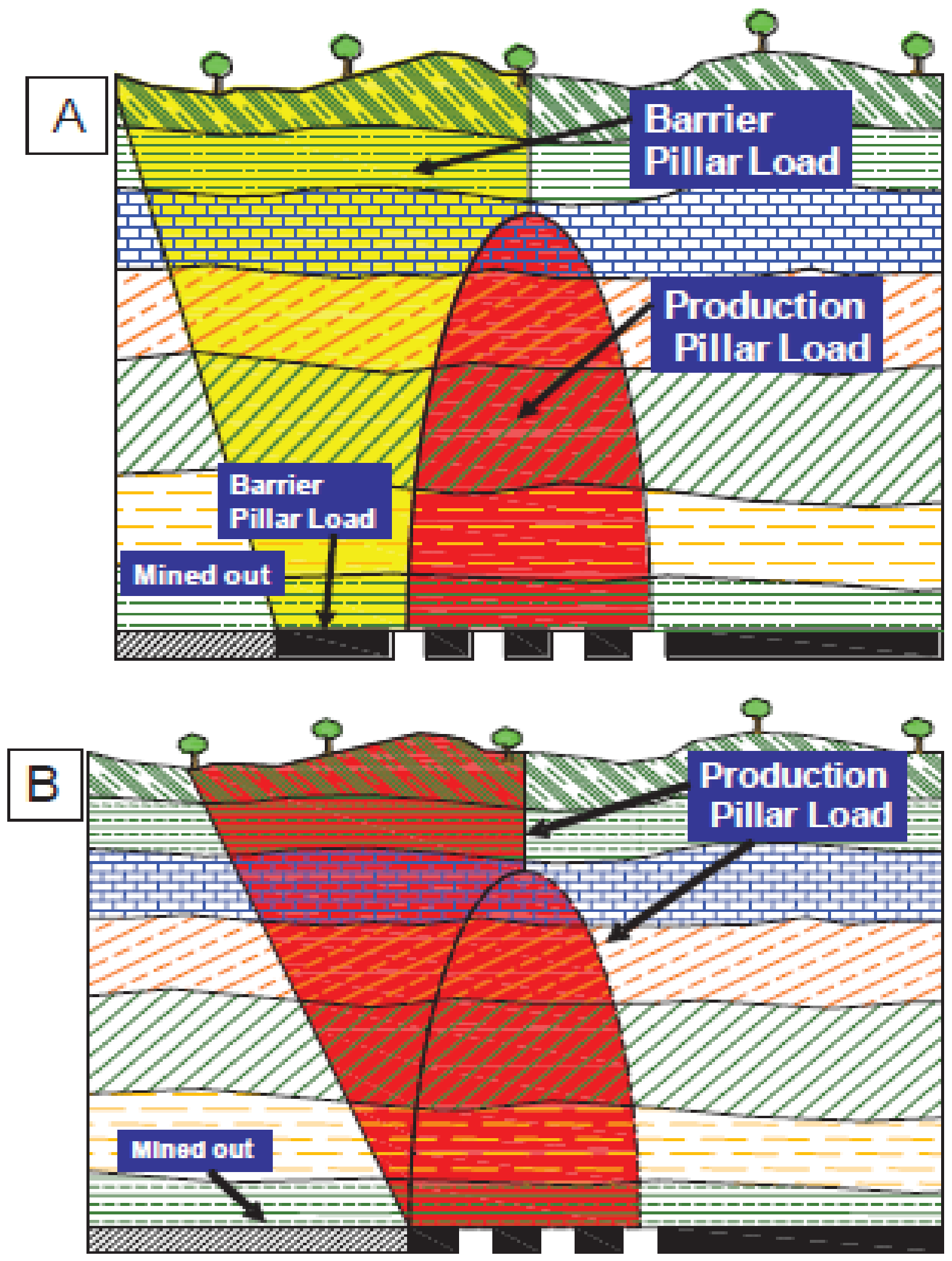

Figure 2.8: The pressure arch in ARMPS. (A) The initial pressure arch. (B) The transfer of loads from (A) back to AMZ with undersized barrier (after Mark et al., 2011). 
The ARMPS 2010 program finalizes the loading condition based on other considerations including leave blocks and composite barriers (necking down of entries mouth of the panel). An ARMPS stability factor is then calculated. Design guidelines for the required stability factor to use with the ARMPS program were then determined based on the aforementioned database of case histories using logistic regression techniques (see Figures 2.9 and 2.10).

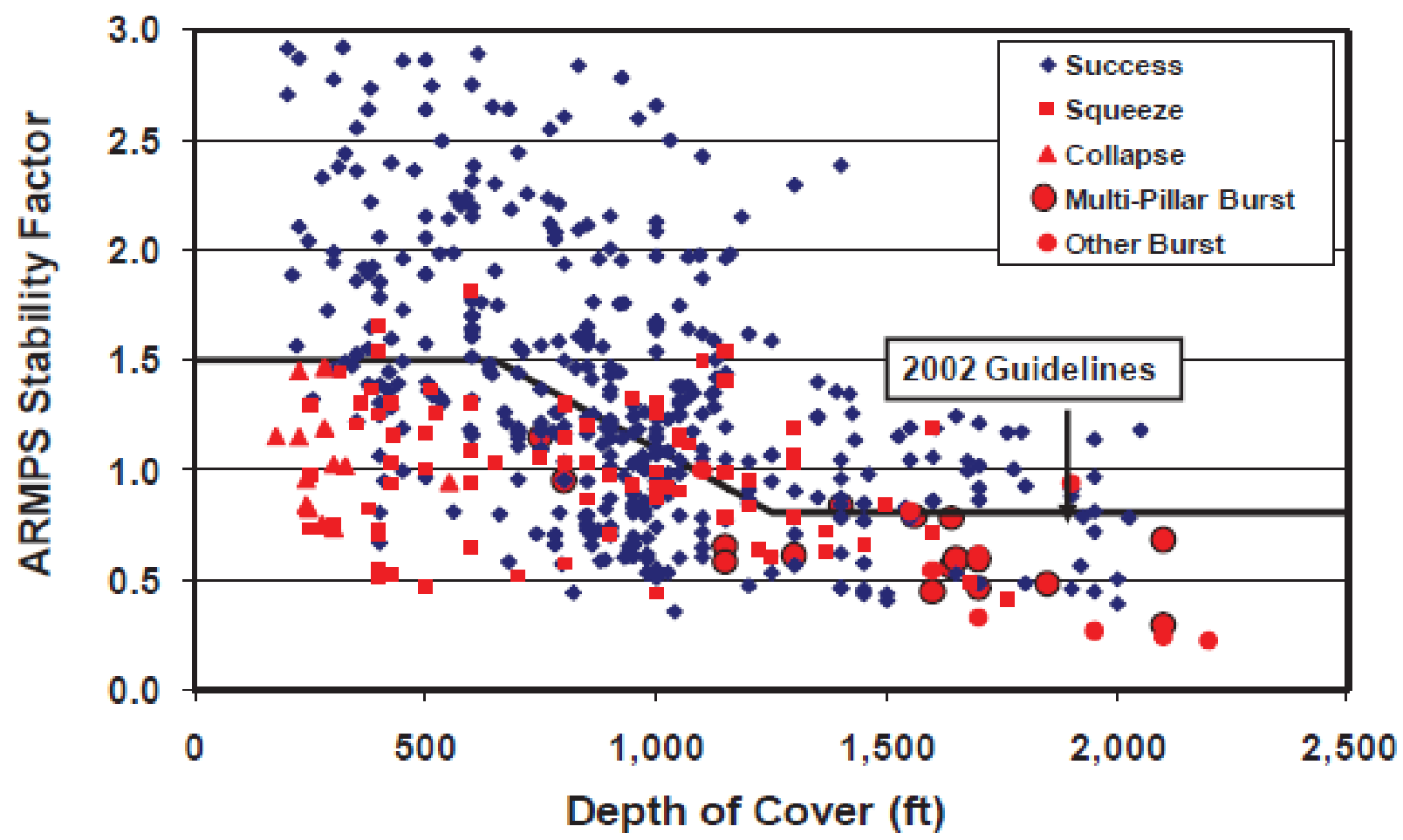

Figure 2.9: ARMPS 2002 stability factors vs. depth for the deep cover database showing the standard design criteria (after Mark, 2010). 


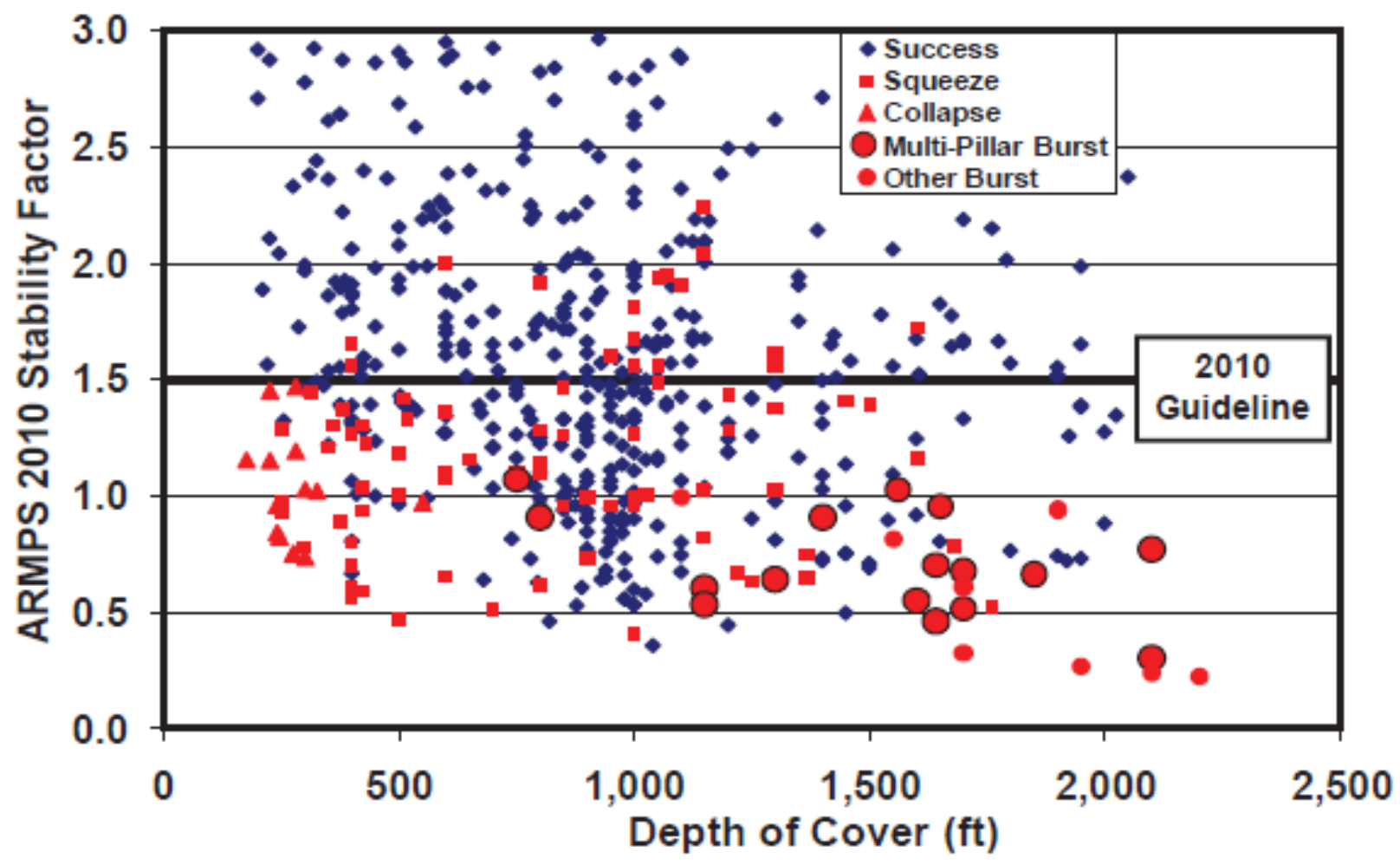

Figure 2.10: ARMPS 2010 stability factors vs. depth for the deep cover database showing the standard design criteria (after Mark, 2010).

The development of the ARMPS program provided huge strides in the advancement of empirical pillar design, especially with retreat mining. The ARMPS method goes a step beyond the tributary area assumption and provides a means of estimating the abutment load on the pillars. However, research was lacking in the ever-growing problem area of multiple seam mining.

\subsection{Numerical Modeling}

Multiple seam pillar design usually requires use of some form of numerical modeling, or a combination of empirical design accompanied with local past experiences. For this literature review, only the LaModel program (Heasley, 1998) will be discussed in detail. Other numerical methods, such as the finite element method (FEM), fall outside the scope of this thesis. 
The major strength of numerical design lies in the ability to analyze complex mining situations. The flexibility of the input parameters allows nearly any situation to be modeled. Numerical models allow analyzing complex multiple seam mining situations and calculating the overburden stress from the actual topography, but are limited by the accuracy of the input parameters. Difficulty obtaining or estimating the input parameters is the major weakness of numerical modeling. Because of the uncertainty in input parameters, calibration of numerical models is required and therefore the method more easily lends itself to site-specific design rather than the "average" design of empirical models.

\subsubsection{The LaModel Program}

The LaModel program (Heasley, 1998) is used to model the stresses and displacements on thin tabular deposits such as coal seams. It uses the displacement-discontinuity (DD) variation of the boundary-element method and is able to analyze large areas of single or multiple-seam coal mines (Heasley, 1998). Using LaModel, the total vertical stresses and displacements in the coal seam are calculated; and also, the individual effects of multiple-seam stress interactions and topographic relief can be separated and analyzed individually.

The LaModel program was first developed in 1996 and it has been continually modernized and upgraded with new features as operating systems and programming languages have evolved over time and new uses for the program have been developed (Hardy and Heasley, 2006; Heasley and Agioutantis, 2001; Heasley et al., 2003; Heasley et al, 2010; Sears and Heasley, 2009).

The LaModel program allows the user to choose between 6 material models (see Figure 2.11). 


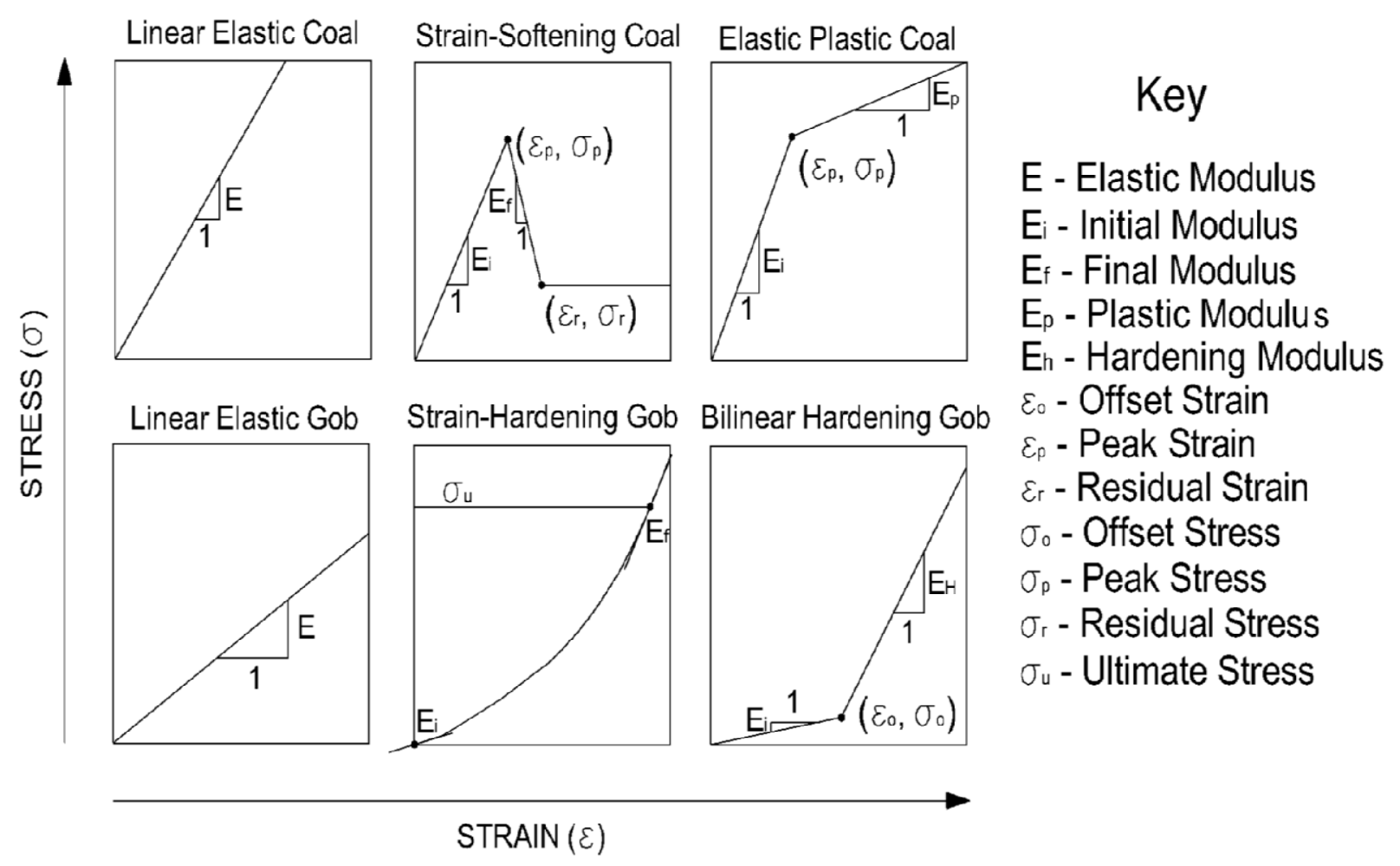

Figure 2.11: The six material models used in LaModel (after Heasley et al., 2011).

For the purposes of this and previous research, Elastic-Plastic materials were used to model the coal pillars assuming a Mark-Bieniawski pillar strength (see Equation 2.18) and the gob materials were modeled as Strain-Hardening materials.

The LaModel program allows the user to directly control the strength and stiffness of the overburden and the seam materials. Generally speaking, the overburden stiffness is controlled by the lamination thickness and the rock mass modulus while the strength and stiffness of the seam materials are controlled by the insitu coal strength and their respective coal moduli. The ability to change these stiffness parameters allows for calibration of the model to site-specific conditions, or in the case of this study, a standardized calibrations procedure.

For the purposes of this research, the lamination thickness will be used to control the stiffness of the overburden. The laminated model shown in Figure 2.12 allows the user to adjust the rock 
mass stiffness (bending of the overburden) by adjusting this lamination thickness. In particular importance to multiple-seam analysis, changing the overburden stiffness changes the multiple seam stress applied to surrounding coal seams.

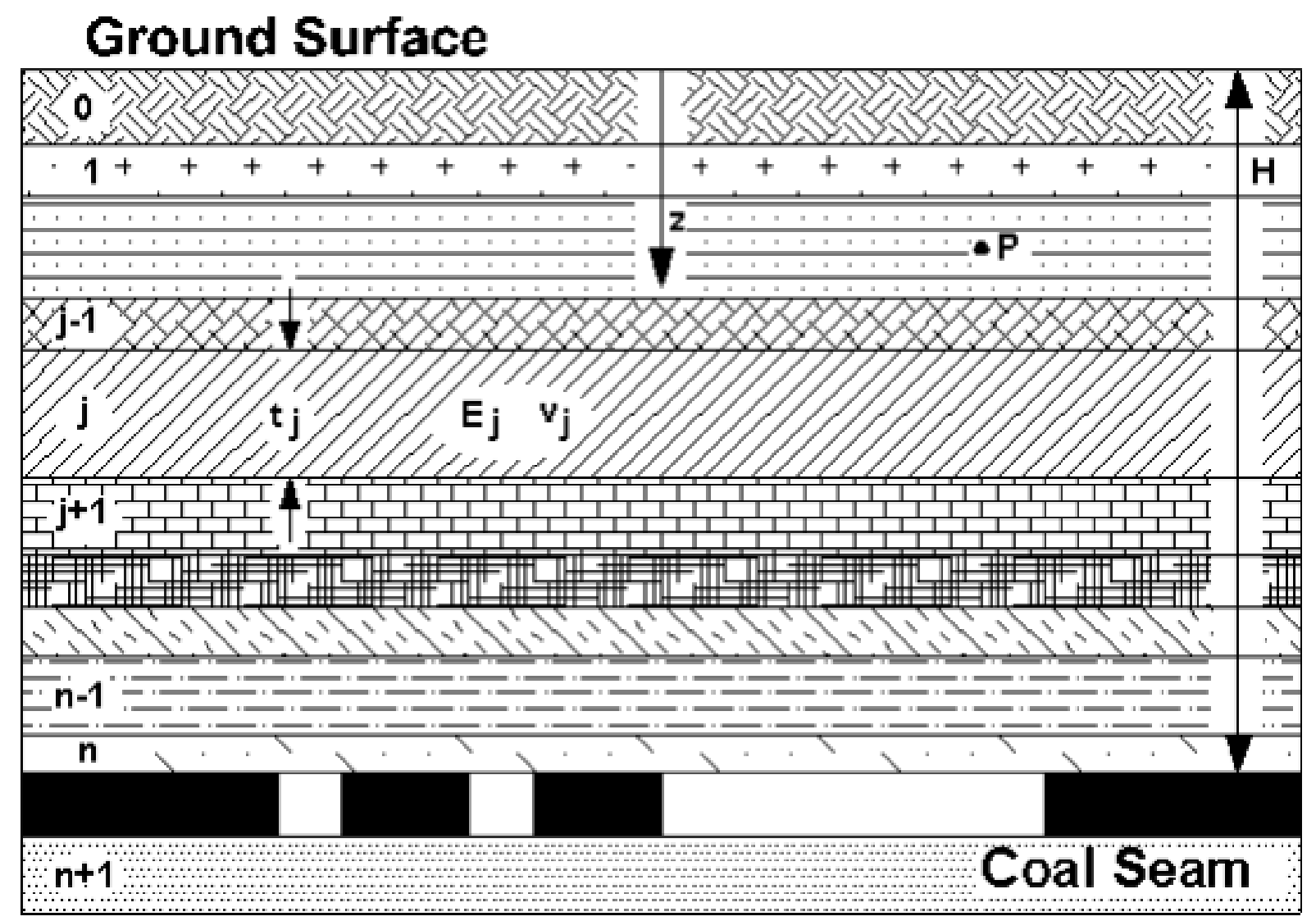

Figure 2.12: The laminated overburden (after Heasley, 1998).

The simplifying assumption of the laminated model is that each lamination in overburden has the same thickness, modulus, and poison's ratio in addition to being frictionless. To assist the user in calibrating an appropriate lamination thickness, the lamination thickness wizard (Figure 2.13) was implemented into LamPre 3.0 (Heasley et al., 2010). 


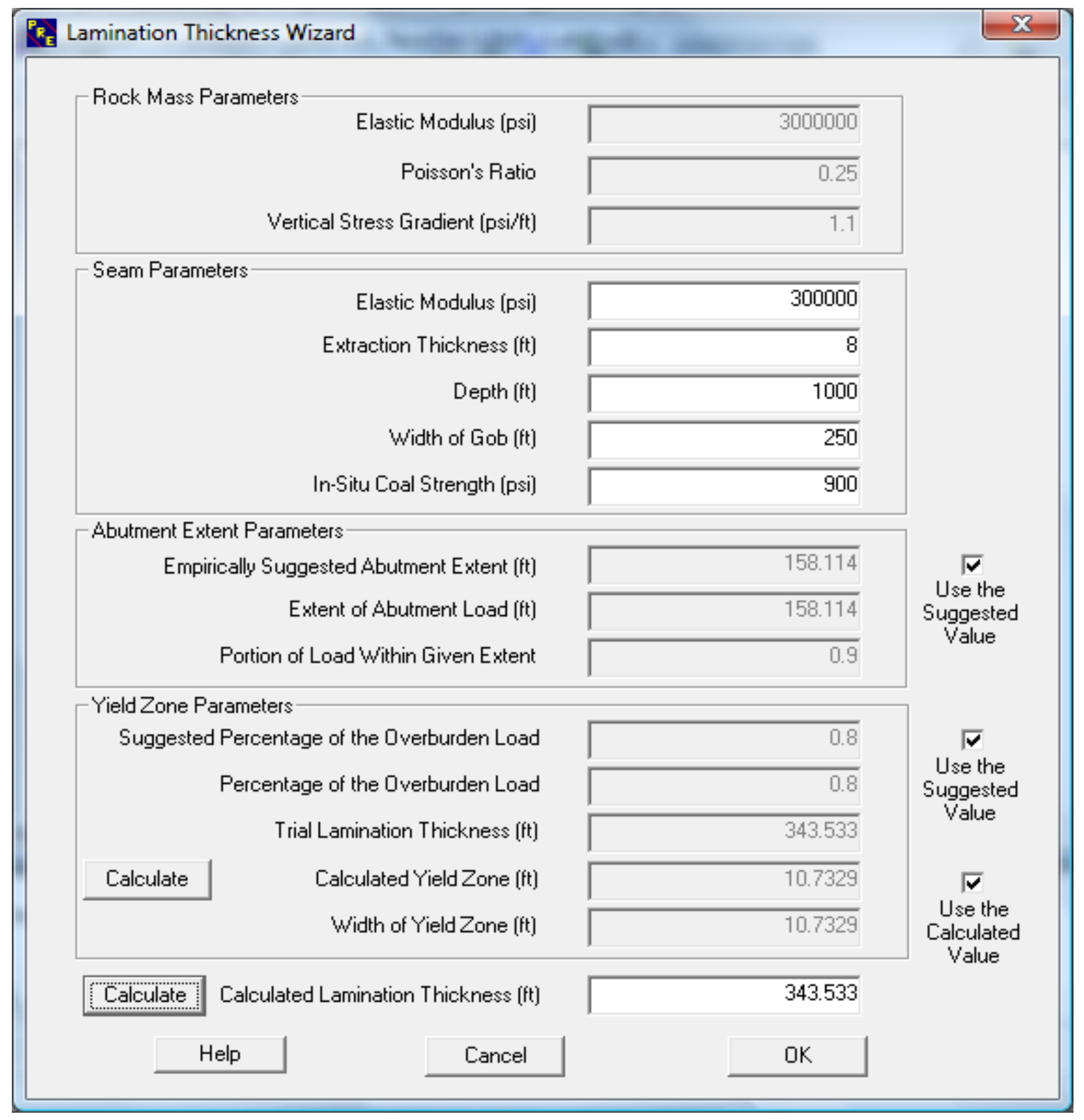

Figure 2.13: The lamination thickness wizard in LamPre 3.0 (after Heasley et al., 2010).

The wizard allows the user to automatically calculate the required lamination thickness to correspond to a given set of rock mass and seam parameters and to match a known abutment extent. 
The stiffness of the seam materials (See Figure 2.14) is determined by the modulus of the respective material.

\section{Seam Element Approximation}

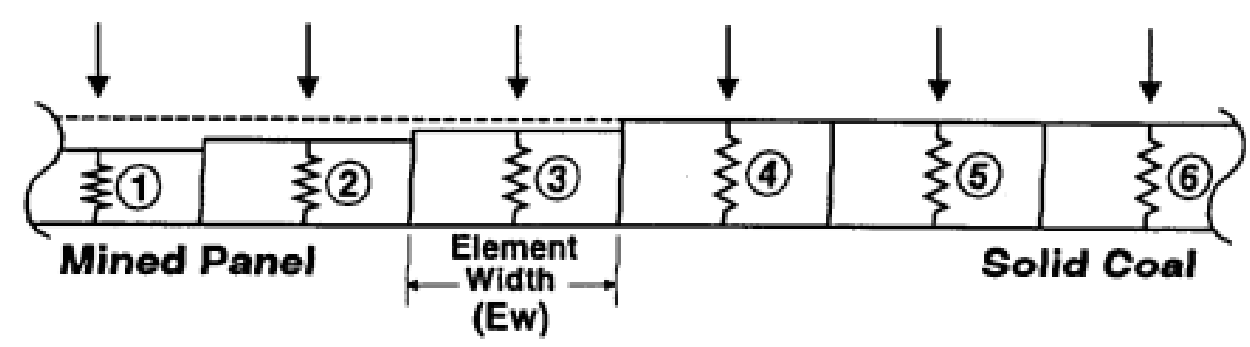

Figure 2.14: Seam elements with stiffness depicted as springs (after Heasley, 1998).

For this study, the seam modulus will be intentionally held constant while the gob modulus will change in relation to the appropriate lamination thickness. This allows the user to manipulate the stress applied to the gob, and therefore, the stress applied to the abutments. To assist the user in calibrating an appropriate gob modulus, the gob wizard (Figure 2.15) was implemented into LamPre 3.0 (Heasley et al., 2010).

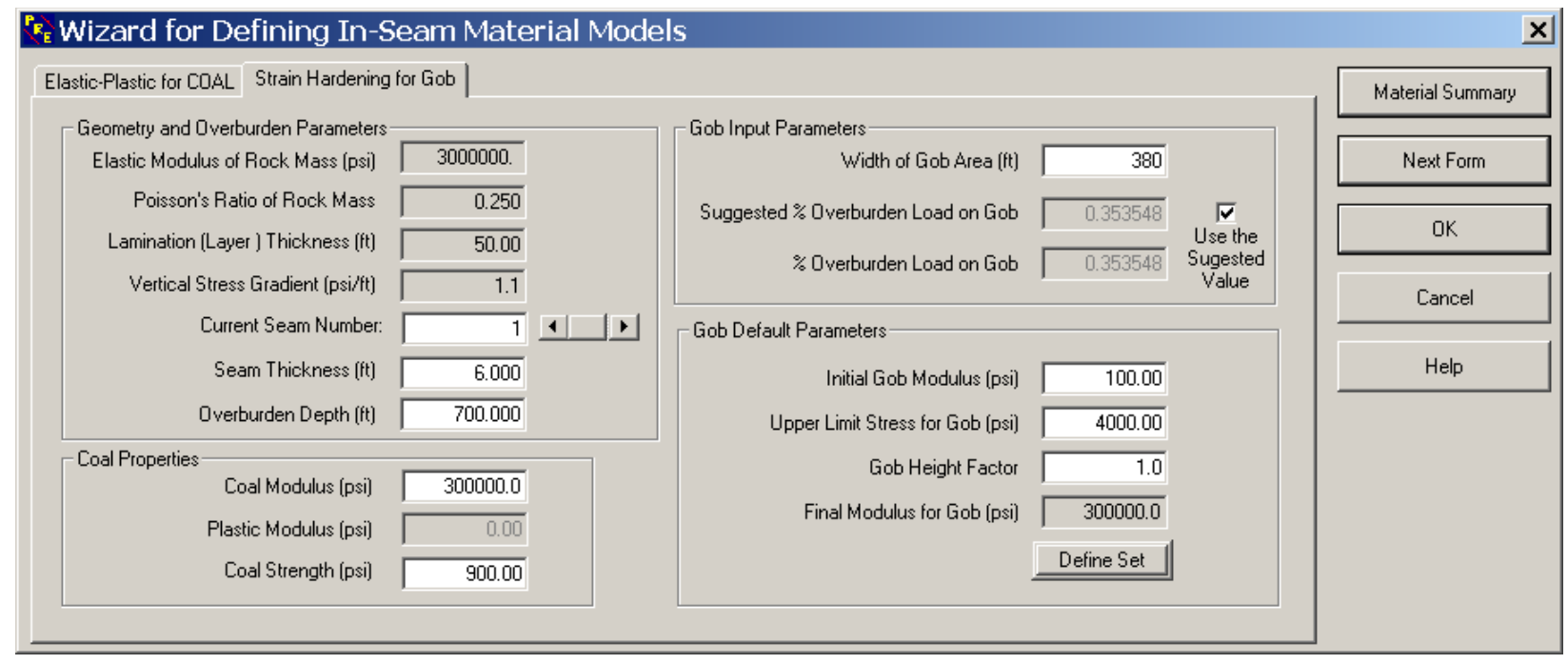

Figure 2.15: The gob wizard in LamPre 3.0 (after Heasley et al., 2010).

The gob wizard allows the user to calibrate the final gob modulus based on a given set of input parameters and the desired percentage of load on the gob. Both the lamination thickness 
wizard and the gob wizard were used in the deep cover calibration of LaModel, which will be discussed later. It will then be applied to the calibration of the shallow cover database as well.

As previously mentioned, the final important attribute of LaModel to be discussed is the ability to analyze multiple seam interactions. The LaModel program currently allows the user to input up to four coal seams, each with independent seam parameters. This allows the LaModel program to be used to analyze complex multiple seam interactions and will be a necessity for analysis of the shallow cover database.

Once appropriate input parameters and seam grids are input into the model, the convergence of the seam is calculated as (after Heasley, 1998):

$$
\left(\frac{\partial^{2}}{\partial \mathrm{x}^{2}} s(x, y)+\frac{\partial^{2}}{\partial y^{2}} s(x, y)=\frac{4 \sqrt{3\left(1-v^{2}\right)}}{E t} \sigma_{i}\right)
$$

Where:

$\mathrm{s}$ is the convergence

$v$ is the Poisson's ratio

$\mathrm{E}$ is the elastic modulus

$\mathrm{t}$ is the lamination thickness

$\sigma_{\mathrm{i}}$ is the induced stress

This means that seam convergence (and ultimately stress) is a function of the overburden parameters including the lamination thickness detailed above and the induced stress. The induced stress is simply a sum of the overburden, coal, surface effect, and multiple-seam stresses. This stress determine from this seam convergence is then used to calculate the pillar safety factors which are used in the current research. 


\subsection{Fusion of Empirical and Numerical Modeling}

As discussed previously, empirical and numerical modeling each has inherent advantages and disadvantages. The major practical advantage of empirical modeling is the linkage to a database of real world case histories backing up their "average" design equations/guidelines while the major disadvantage is limited flexibility to analyze complex geometry, multiple seam interactions, etc. Numerical modeling on the other hand has tremendous geologic and geometric flexibility but requires the user to provide many accurate and difficult-to-obtain input parameters.

However, the empirical and numerical methods can be fused to take advantage of the strengths of each as seen in the Analysis of Multiple Seam Stability, or AMSS program, (Mark et al., 2007) and the LaModel deep cover calibration (Heasley et al., 2010). These methods attempt to combine the strengths of empirical design with the strengths of numerical modeling while simultaneously minimizing the weaknesses. The AMSS program uses a two dimensional (2-D) laminated model (Akinkugbe and Heasley, 2007) to calculate the complex multiple seam stresses to add with the simply determine single-seam stresses. On the other hand, the deep cover calibration was applied to a database of case histories to develop appropriate design guidelines. This research proposes to use a similar approach as the deep cover calibration, by using numerical modeling simplified by a standardized calibration procedure and backed by a database of case histories to develop design guidelines.

\section{$\underline{\text { 2.4.1 AMSS }}$}

The Analysis of Multiple Seam Stability (AMSS) program was created to aid engineers and mine planners in pillar design and mine layout in simple multiple seam conditions (Mark et al., 
2007). The AMSS program picks up where the ARMPS program left off in regard to the loading applied to multiple-seam pillars. Where the ARMPS program combined abutment loading with the tributary area loading for single-seam retreat pillars, the AMSS program allows the user to include multiple seam loading (calculated using a idealized 2-D model). AMSS then uses empirical methods to compare the calculated results to a database of successful and unsuccessful case histories.

For the AMSS program, the final database consisted of 344 case histories from 36 mines including 92 retreat mining cases. Most of these cases were from the central Appalachian and western coal fields. A case was considered successful when there was minimal or no interaction, while the case was considered a failure when there were moderate to severe interactions from the multiple seam mining (Mark et al., 2007).

To order to determine the multiple seam stability factor $\left(\mathrm{SF}_{\mathrm{ARMPS}-\mathrm{MS}}\right)$, just like most other pillar design method, the pillar strength must first be calculated. In AMSS, the pillar strength is determined the same was as it is in ARMPS and ALPS, by using the Mark-Bieniawski pillar strength equation (2.18).

Once the pillar strength is estimated, the pillar load must be determined. The AMSS program goes a step beyond the ARMPS program in terms of estimating the pillar load. Initially, Salamon and Munro (1967) only considered the tributary area load. ARMPS then added the estimation of the abutment load. Now, the AMSS program adds the estimation of the multiple seam stress.

To calculate the pillar load, first the single seam load must be determined. The single seam load is then calculated the same way as it is in ARMPS or ALPS. The tributary area stress is calculated, a percentage of the abutment stress is applied to the AMZ, and the total represents the 
load on the AMZ. At this point, the single-seam ARMPS or ALPS stability factor is calculated. At this point, the maximum abutment stress applied to the critical pillar in the target seam is used for subsequent calculations.

Due to the complexity of determining a simplistic empirical mechanism for calculating multiple seam stress, empirical estimation techniques were abandoned in favor of numerical modeling techniques. The Lam2D program (Akinkugbe and Heasley, 2007) was integrated into the AMSS program and runs a two-dimensional (2-D) analysis using the laminated overburden model. The maximum multiple-seam stress determined by LaM2D is added with the single seam stresses from ALPS or ARMPS to determine the final multiple-seam loading. The LaM2D results are then used to determine the multiple-seam stability factor (after Mark, et al., 2007):

$$
\mathrm{SF}_{\mathrm{ARMPS}-\mathrm{MS}}=\mathrm{SF}_{\mathrm{ARMPS}}\left[\frac{\mathrm{L}_{\mathrm{SS}}}{\mathrm{L}_{\mathrm{SS}}+\mathrm{L}_{\mathrm{MS}}}\right]
$$

Where:

$\mathrm{SF}_{\text {ARMPS-MS }}$ is the multiple seam stability factor

$\mathrm{SF}_{\mathrm{ARMPS}}$ is the ARMPS (single seam) stability factor

$\mathrm{L}_{\mathrm{SS}}$ is the single seam load

$\mathrm{L}_{\mathrm{MS}}$ is the multiple seam load.

Because of the numerical modeling component of the analysis, additional parameters including total vertical stress, multiple-seam stress, convergence and differential convergence were included in the initial statistical analysis.

In this study, the binomial dependent variable (i.e. successful or unsuccessful) required the use of Logistic Regression. Initially, 26 cases where the $\mathrm{SF}_{\text {ARMPS-MS }}$ criteria were not met were excluded from the database (Mark, et al., 2007). If one considers the cases where the pillars were not adequately sized, then comparison between two statistical populations is being attempted simultaneously. Therefore, the pillar (global) stability must be satisfied first. The 
following list summarizes the independent variables, or variables thought to contribute to the dependent variable (success or failure):

- Overmining or undermining

- Development or retreat

- Longwall or room-and-pillar

- Depth

- Interburden thickness

- Mining heights

- Time lag between mining the two seams

- Angle of mining where the remnant structure was intercepted

- Supplemental support (yes or no)

- Pillar stability factors

- Type of remnant structure (isolated remnant or gob/solid boundary)

- The CMRR and its log transform

- Percentage of competent rock

- The number of beds in the interburden.

The values for the following variables were taken directly from the LaM2D analysis:

- Average total vertical stress applied to the critical pillar,

- Average multiple-seam stress on the critical pillar,

- Maximum convergence in the entry adjacent to the critical pillar, and

- Maximum differential convergence as defined as the difference in convergence at the edge of the critical pillar and the rib on the other side (Mark et al, 2007). 
Six of the initial potential variables were ultimately determined to be statistically significant. An important consideration in this decision is the correlation between independent variables. To minimize this effect, only one variable for stress was included, the total vertical stress.

Supplemental support is also significant and included as a binary variable (i.e. yes or no). This is because the vast majority of supplemental support was 8-12 ft cable bolts or resin-assisted mechanical bolts. The log transform of the CMRR-20 was determined to be better than using the CMRR. Scientifically, the explanation for this is that increasing the CMRR from 40 to 50 has a greater effect on entry stability than an increase from 80 to 90 . Statistically, the reason for using a $\log$ based transform is to alter a non-linear variable with a log-normal distribution into a normally distributed linear variable. Using a transformed CMRR implies that multiple seam effects are increased when the roof is weak and is more conservative for low CMRR values (Mark et al., 2007). The type of remnant structure was also included as a binary variable. Additionally, undermining vs. overmining and the interburden thickness were statistically significant. The final statistical model was chosen as (after Mark, et al., 2007):

$$
\begin{aligned}
\mathrm{g}(\mathrm{x})= & -0.81 \mathrm{~T} \sigma_{\mathrm{TV}}+1.79 \mu_{\mathrm{UO}}+0.0233 \mathrm{H}_{\mathrm{INT}}+2.02 \mathrm{~S}_{\mathrm{S}} \\
& -1.80 \mathrm{P}_{\mathrm{REM}}+1.95 \chi-6.47
\end{aligned}
$$

Where:

$\sigma_{\mathrm{TV}}$ is the total vertical stress on critical pillar (x1000 psi)

$\mu_{\mathrm{UO}}$ is 1 for undermining, 0 for overmining

$\mathrm{H}_{\mathrm{INT}}$ is the interburden ( $\mathrm{ft}$ )

$\mathrm{S}_{\mathrm{S}}$ is 1 for extra support, 0 for none

$\mathrm{P}_{\mathrm{REM}}$ is the 1 for isolated remnant pillar, 0 for gob-solid boundary $\chi$ is the $\ln (\mathrm{CMRR}-20)$.

A disadvantage of logistic regression is the lack of a well established measure of model fit.

There is no way to accurately say "the model explains $90 \%$ of the variability in the data because the $\mathrm{R}^{2}$ is 0.9 " like one can with least squares regression. One method to describe the degree of 
fit for logistic regression was recommended by Hosmer and Lemeshow (2000) and uses the Receiver Operating Characteristic, or ROC, curve (see Figure 2.16). The ROC curve plots the sensitivity vs. 1 - specificity for an entire range of cut points with the cut point defining the number of successes. Here, the sensitivity represents the proportion of correctly classified successes and the specificity represents the proportion of correctly classified failures. This means that 1 - specificity represents the proportion of incorrectly classified failures. The goal of the model is to classify as many successes as possible while minimizing the chance of incorrectly classifying a failure. This means that the $(0,1)$ coordinate on the ROC curve implies perfect discrimination and an Area Under the Curve (AUC) of 1. Goodness of fit between models can then be compared by the area under the curve which ranges from 0.5 (no discrimination or same as chance) and 1 (perfect discrimination). The area under the ROC curve for equation 2.24 is 0.88 implying excellent discrimination.

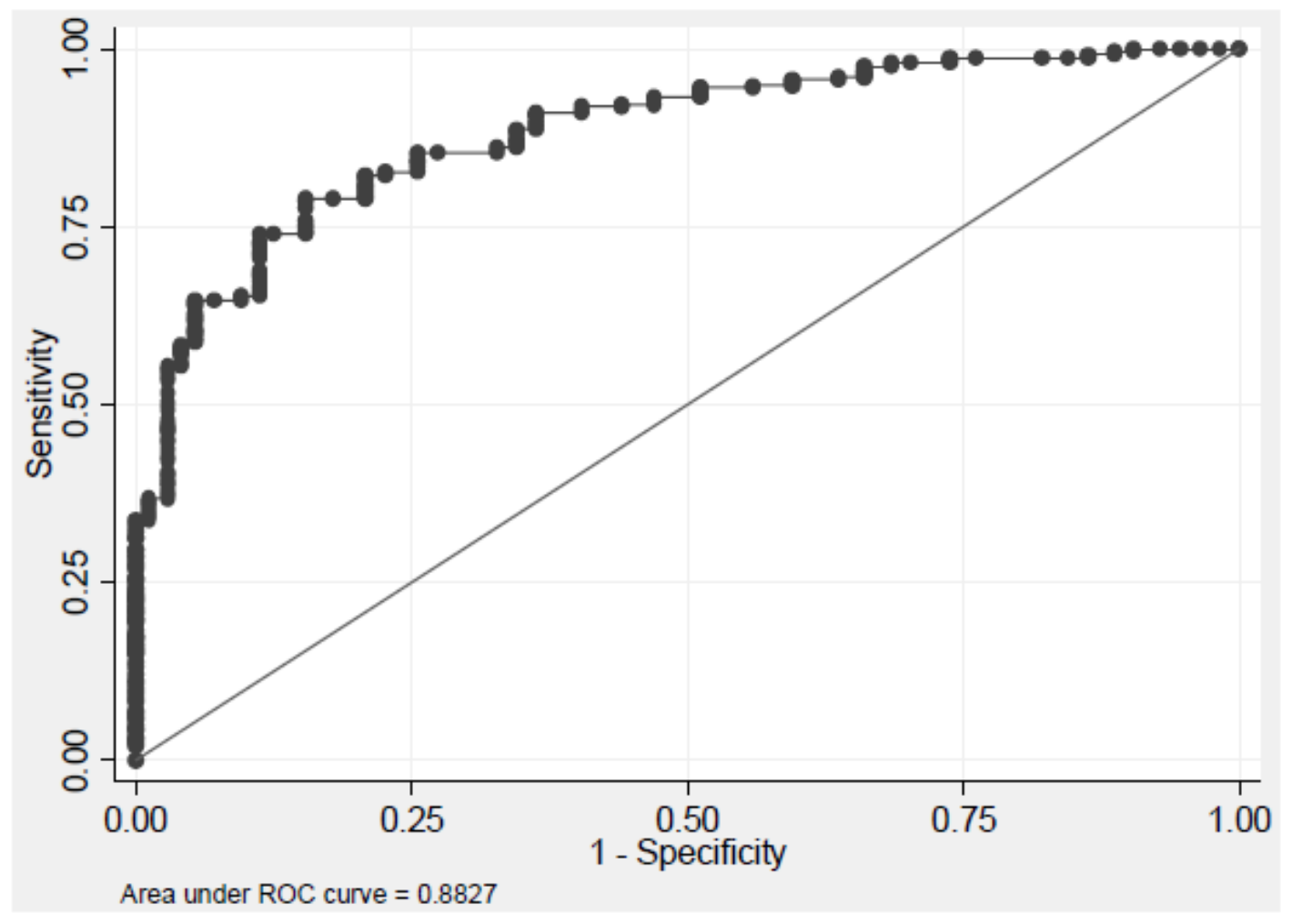


Figure 2.16: Receiver operating characteristic (ROC) curve for equation 2.17 (after Mark et al., 2007).

The model's optimum cut-point can be determined from plotting the sensitivity and specificity vs. the cut point (See Figure 2.17). Each point on the curve represents either the sensitivity or specificity at each individual cut point. As the cut point increases, the sensitivity decreases and the specificity increases. This means that the probability of correctly classifying a successful case decreases. More importantly, the probability of correctly classifying a failure case increases. The intersection of these two curves maximizes the overall classification accuracy resulting in the optimum cut-point for this data of $\mathrm{p}=0.86$.

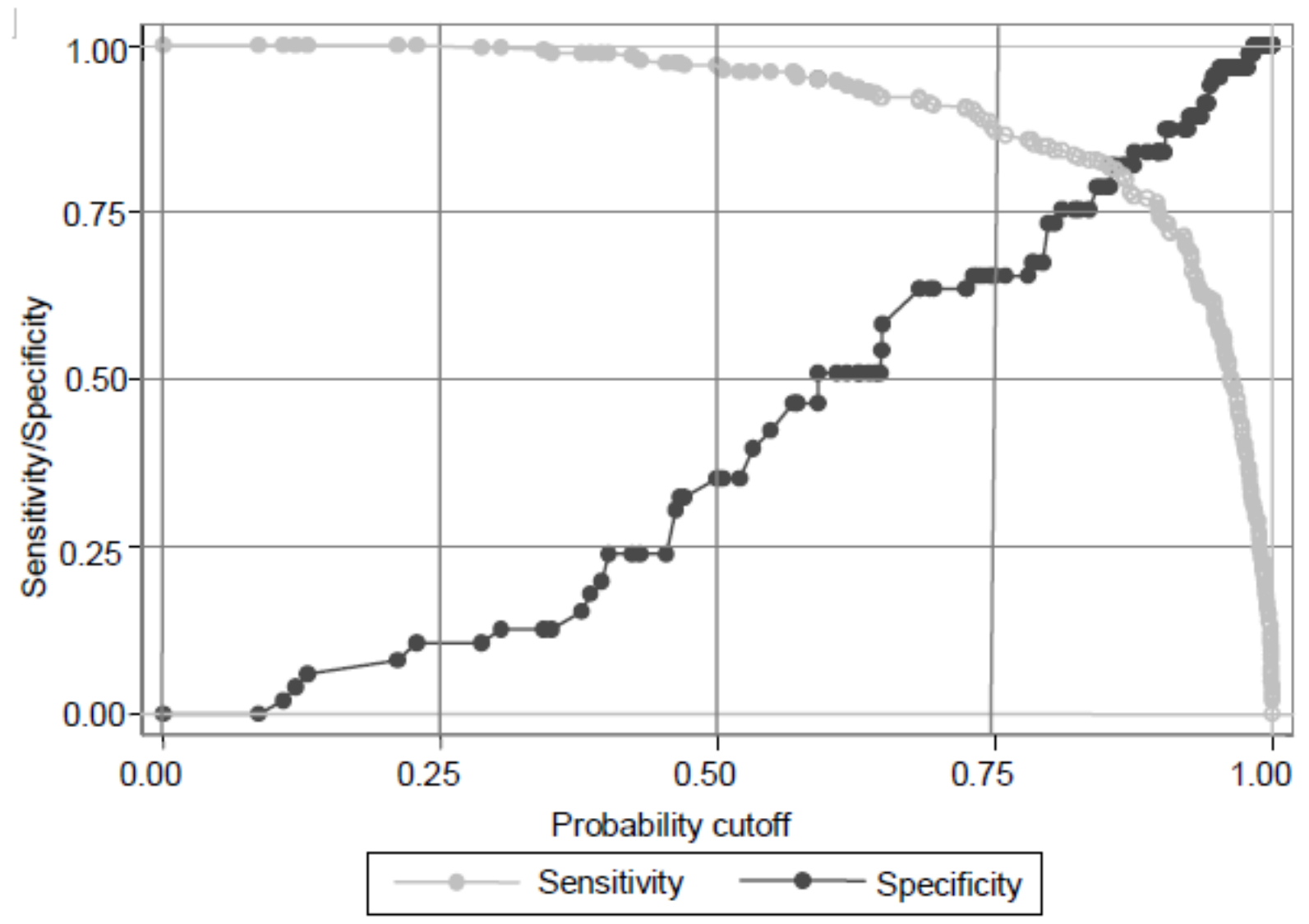

Figure 2.17: Plot of sensitivity and specificity versus cut-point (after Mark et al., 2007). 
For this model, using the optimum cut point correctly classifies approximately $80 \%$ of the overall cases, $81 \%$ of the successes, and $79 \%$ of the failures (more important from a ground control perspective).

For design purposes, equation 2.24 was corrected to correspond to the cut-point of 0.86 and transformed to predict the critical interburden thickness (after Mark et al., 2007):

$$
\begin{aligned}
\mathrm{H}_{\mathrm{INT}-\mathrm{CRIT}}= & 35 \sigma_{\mathrm{TV}}-77 \mu_{\mathrm{UO}}-87 \mathrm{~S}_{\mathrm{S}}+77 \mathrm{P}_{\mathrm{REM}} \\
& -83 \chi+359
\end{aligned}
$$

Where:

$\mathrm{H}_{\text {INT-CRIT }}$ is the critical interburden thickness ( $\mathrm{ft}$ ).

In some extreme cases, the equation could predict a negative critical interburden thickness in which case equation 2.26 is used.

$$
\begin{aligned}
\mathrm{H}_{\text {INT-CRIT }}= & \operatorname{EXP}\left[0.35 \sigma_{\mathrm{TV}}-0.74 \mu_{\mathrm{UO}}-0.99 \mathrm{~S}_{\mathrm{S}}\right. \\
& +0.74 \mathrm{P}_{\mathrm{REM}}-0.92 \chi+7.23
\end{aligned}
$$

Equation 2.25 provides several solid physical understandings of the value and importance of the individual parameters. For instance:

- Each additional 1000 psi of vertical stress is equivalent to subtracting 35 feet of interburden.

- Overmining requires 77 more feet of interburden than undermining for similar conditions.

- An isolated remnant requires pillar requires 77 more feet of interburden than a gob-solid boundary.

- A CMRR of 45 requires approximately 50 more feet of interburden than a CMRR of 65 . 
Although it is indicated that installing heavy supplemental support is equivalent to adding $87 \mathrm{ft}$ of interburden, the likelihood of rib spalling, floor heave, and/or hazardous roof conditions are also increased (Mark, et al., 2007).

The AMSS program provides a very important empirical design tool by providing what the ARMPS program is lacking in terms of support for multiple seam pillar analysis. Additionally, this is the first time one sees a widely accepted combination of empirical and numerical modeling techniques being used simultaneously for coal pillar design. With this technique, a method of pillar design where a numerical pillar design method (LaModel) is now supported by real world case histories is available to the on-site mine engineer who is looking for a simple, quick, and accurate method to model multiple-seam interactions. As mentioned previously, this fusion of empirical and numerical modeling is similar to the concept that will be used in this thesis.

\subsubsection{Deep Cover Calibration}

At the same time that the ARMPS program was being reevaluated, the LaModel program was being calibrated for deep-cover pillar retreat mining. Again, this course of action was the direct result of the Crandall Canyon Mine collapse. At the time, the empirical techniques incorporated into the ARMPS and ALPS programs provided the most widely accepted pillar design methods. Therefore, a process to calibrate LaModel to match reality as closely as possible, the pillar strength and loading concepts from the ARMPS and ALPS programs was implemented. It should be noted that it was not the intent to match the ARMPS and ALPS programs, but to calibrate the loading and pillar strength as accurately as possible. 
In LaModel, the critical input parameters controlling the model response and used for calibration are:

- The rock mass stiffness

- The gob stiffness

- The coal strength.

Calibration of these parameters (in this sequence) is detailed below.

The rock mass stiffness in LaModel is largely controlled by the rock mass modulus and the lamination thickness. Increasing either of these will result in a stiffer overburden and:

- The abutment extent increases

- The convergence over the gob areas will decrease

- The multiple seam stresses will be smoothed over a larger area.

(The last of these will be important with regard to current research where multiple-seam interactions will require consideration.)

\section{$\underline{\text { Abutment Extent }}$}

For the purpose of analyzing the deep cover database, the rock mass modulus was held constant in favor of calibrating the lamination thickness using the new lamination thickness wizard.

The derivation of the equation to calculate the required lamination thickness begins with an assumption. That is, the empirically determined distribution of the abutment stress within the abutment zone can be calculated with the following equation (after Mark, 1992). 


$$
\sigma_{\mathrm{a}}(\mathrm{x})=\left(\frac{3 \mathrm{~L}_{\mathrm{s}}}{\mathrm{D}^{3}}\right)(\mathrm{D}-\mathrm{x})^{2}
$$

where:

$\sigma_{\mathrm{a}}$ is the abutment stress

$\mathrm{L}_{\mathrm{s}}$ is the total side abutment load

$\mathrm{x}$ is the distance from the panel edge.

Based on the stress distribution generated by equation $2.27,90 \%$ of the abutment load should be within the distance ( $\left.\mathrm{D}_{.9}\right)$ from the edge of the panel (Mark and Chase, 1997):

$$
\mathrm{D}_{.9}=5 \sqrt{\mathrm{H}}
$$

where:

$$
\mathrm{H}=\text { depth. }
$$

This is the same assumption used in the ARMPS and ALPS programs. Once the extent of the abutment zone has been calculated, the lamination thickness that will match that abutment extent $\left(D_{.9}\right)$ is determined.

Heasley (1998) developed equation 2.29 which gives the magnitude of the abutment stress $\left(\sigma_{\mathrm{l}}\right)$ for the laminated model as a function of the distance $(\mathrm{x})$ from the panel rib for an elastic seam surrounding an unfilled opening (see Figure 2.18).

$$
\sigma_{1}(x)=q \frac{P}{2} \sqrt{\frac{2 E_{s} \sqrt{12\left(1-v^{2}\right)}}{E t h}} e^{-\sqrt{\frac{2 E_{s} \sqrt{12\left(1-v^{2}\right)}}{E t h}} x}
$$

where:

$\sigma_{1}$ is the magnitude of abutment stress

$\mathrm{q}$ is the insitu stress

$\mathrm{P}$ is the width of the panel

$\mathrm{E}_{\mathrm{s}}$ is the elastic modulus of the seam

$\mathrm{E}$ is the elastic modulus of the overburden

$v$ is the Poisson's Ratio of the rock mass

$\mathrm{t}$ is the lamination thickness in the rock mass

$\mathrm{h}$ is the seam thickness

$\mathrm{x}$ is the distance from the panel rib 
Figure 2.18 graphically compares abutment stress as calculated by the laminated model and the empirical model with the load matched at D.9.

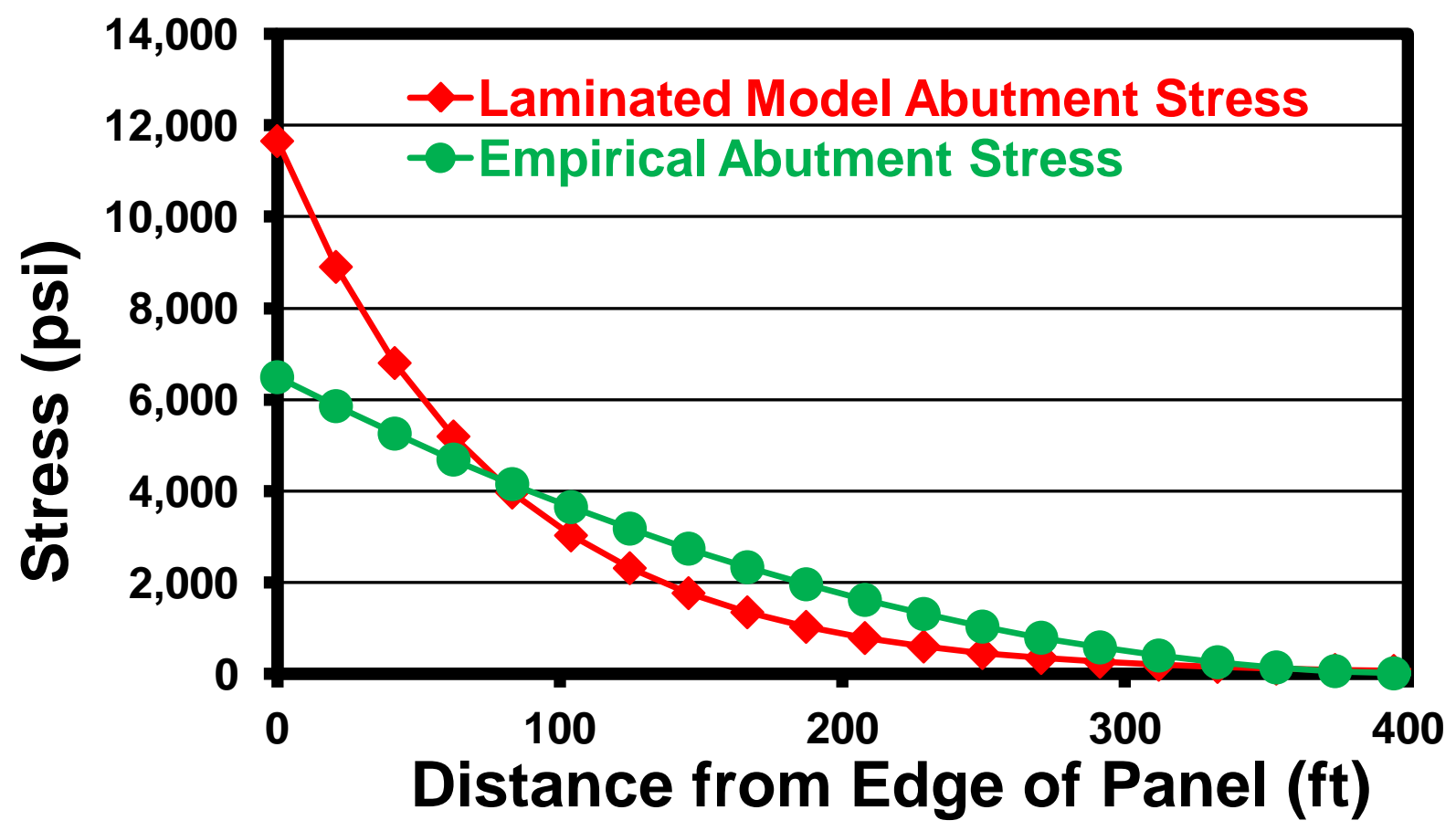

Figure 2.18: Abutment stress as a function of distance for the laminated model and the empirical data (after Heasley et al., 2011).

From this comparison, ignoring the yield zone, we see that the abutment stress determined by the laminated model naturally has a much higher peak stress than that calculated by the empirical model. Simultaneously, the slope of the curve is much steeper meaning more load it applied at the edges of the abutments and less is applied at the extremities.

The abutment distance for a given percent load as determined by the laminated model is:

$$
D_{n}=-\ln (1-n) \sqrt{\frac{E h t}{2 E_{s} \sqrt{12\left(1-v^{2}\right)}}}
$$

where:

$D_{n}$ is the abutment distance for given percent load (n). 
Equation 2.30 shows that the abutment extent is proportional to the square root of the rock mass modulus, seam thickness, and lamination thickness. It is also inversely proportional to the square root of the seam modulus.

Equation 2.30 can then be solved for the lamination thickness needed to result in a given abutment distance with required overburden and seam properties (Heasley et al., 2011):

$$
\mathrm{t}=\frac{2 \mathrm{E}_{\mathrm{s}} \sqrt{12\left(1-v^{2}\right)}}{\mathrm{Eh}}\left(\frac{\mathrm{D}_{\mathrm{n}}}{\ln (1-\mathrm{n})}\right)^{2}
$$

Equation 2.31 shows that the lamination thickness required to match a given abutment extent is proportional to the square of the abutment extent, linearly proportional to the seam modulus and inversely proportional to the rock mass modulus and seam thickness.

\section{$\underline{\text { Gob Load }}$}

In a retreat mining analysis, the stiffness for the gob (compared to the surrounding rock mass) is critical to accurately calculating the overburden load on the gob and, therefore, the remaining overburden load applied to the abutments. A stiffer gob material means more load is carried by the gob and less on the adjacent pillars while a softer gob material means more load is transferred to the surrounding pillars. In LaModel, the stiffness of the gob is calibrated by adjusting the "Final Modulus" of the strain-hardening gob material (Heasley, 1998) (see Figure 2.11).

To get a realistic gob loading, the same abutment angle concept as used in ARMPS and ALPS is used in the LaModel to calculate a desired gob loading for calibration. The abutment angle concept is used to calibrate the gob stress in LaModel to match the loading implemented in ARMPS and ALPS. The abutment angle concept calculates the average gob stress for a supercritical panel (see Figure 2.7) as: 


$$
\sigma_{\mathrm{g}-\mathrm{av}}=\left(\frac{\mathrm{H} \times \gamma}{144}\right)\left(\frac{\mathrm{P}-(\mathrm{H} \times \tan \beta)}{\mathrm{P}}\right)
$$

where:

$\sigma_{\mathrm{g} \text {-av }}$ is the average gob stress

$\gamma$ is the average overburden density

$\beta$ is the abutment Angle

Similarly, the average gob stress for a subcritical panel (see Figure 2.7) is:

$$
\sigma_{\mathrm{g}-\mathrm{av}}=\frac{\mathrm{P}}{4}\left(\frac{1}{\tan \beta}\right)\left(\frac{\gamma}{144}\right)
$$

In LamPre 3.0, the Strain Hardening Gob Wizard provides a means of automatically calculating the required final gob modulus. For the deep cover database, the empirical values calculated directly from equation 2.32 and 2.33 were used. Similar to the way the AMSS program works, in the Gob Wizard, a LaM2D analysis is performed in the background and iteratively calculates the modulus which produces the proper amount of load on the gob in a simplified 2D model.

\section{$\underline{\text { Pillar Strength }}$}

The final parameter that needs to be calibrated in the procedure used for the deep cover database is the insitu coal strength. Because the pillars in LaModel are modeled using a MarkBieniawski pillar strength (Equation 2.18), the insitu coal strength is directly related to the pillar strength. For the deep cover calibration, the default coal strength of $900 \mathrm{psi}$, as with ARMPS and ALPS (Mark, 1999), is used. Accurate pillar strength is critical to determining accurate pillar safety factors, and this is currently the most widely accepted method for determining pillar strength in U.S. coals. 
Mark and Barton (1997) found that it is more accurate to use an average empirically determined coal strength than to try and extrapolate specific laboratory test data to specific sites, and regardless, this data is rarely available. If the LaModel user chooses to change the default 900 psi coal strength, they should have a very strong justification, preferably a back analysis of a failure (Heasley, et al., 2010). Even with this data, comparisons between the users output and the deep cover database are no longer valid because the database was analyzed with the default 900 psi coal strength.

\subsubsection{The Deep Cover Database}

In order to evaluate and verify the LaModel calibration procedure detailed above, a database of deep cover retreat mining case studies was developed. The database consisted of 47 pillar retreat cases from 11 mines. Seven of the mines were in the Central Appalachian coal fields and 4 were in the Western coal fields. The depths of cover ranged from $750 \mathrm{ft}$ to $2200 \mathrm{ft}$ with an average of 1256. Extraction thicknesses ranged from a low of $3.6 \mathrm{ft}$ to a high of $9.0 \mathrm{ft}$ with an average of $6.9 \mathrm{ft}$. The number of entries in the sections ranged from 3 to 13 with an average of 6.2. Pillar widths ranged from 50 to $100 \mathrm{ft}$ centers and crosscut spacing ranged from 80 to $150 \mathrm{ft}$ centers with the average pillar size being $78 \mathrm{ft}$ by $101 \mathrm{ft}$. The panel widths ranged from $160 \mathrm{ft}$ to $940 \mathrm{ft}$ with an average of $410 \mathrm{ft}$.

Thirty of the case studies included loading from a single side gob, 14 only had an active gob, 2 had loading from two side gobs and 1 was development loading only. Sixteen of the cases were considered strength or pillar type failures, 28 were successful and 3 were marginal, or middlings. Failure was determined using the same guidelines for the ARMPS database. 
Like the ARMPS database, the LaModel deep cover database analysis does not specifically consider any additional parameters. As previously mentioned, all of these case histories were included in the ARMPS deep cover database, and therefore avoid multiple seam interactions. Additionally, the geology (CMRR) is not addressed because successful deep cover pillar retreat (read, high stresses) typically requires competent geology (high CMRRs).

\subsubsection{Analysis of the Deep Cover Database}

The deep cover database was analyzed using the ARMPS analysis, an idealized LaModel analysis, and a detailed LaModel analysis. When examining these results it is important to understand how the cases were obtained. For each failure case, the mine typically retreated the panel until the extent of active gob, overburden depth, ground conditions, etc. became so adverse that the face was abandoned. At this point, the failure is just below the stability factor that was previously successful. So, for each failure point on the graphs, one can infer that all stability factors above that point were successful and all of the stability factors below it were unsuccessful. Similarly, when a section was successful, the point with the deepest cover or most adverse conditions was analyzed to determine the minimum successful stability factor. Thus, for each of the successful points in the following graphs, one can consider all of the stability factors above that point to have been successful.

Figure 2.19 shows the analysis of the deep cover database using the ARMPS 2002 program and design guidelines. 


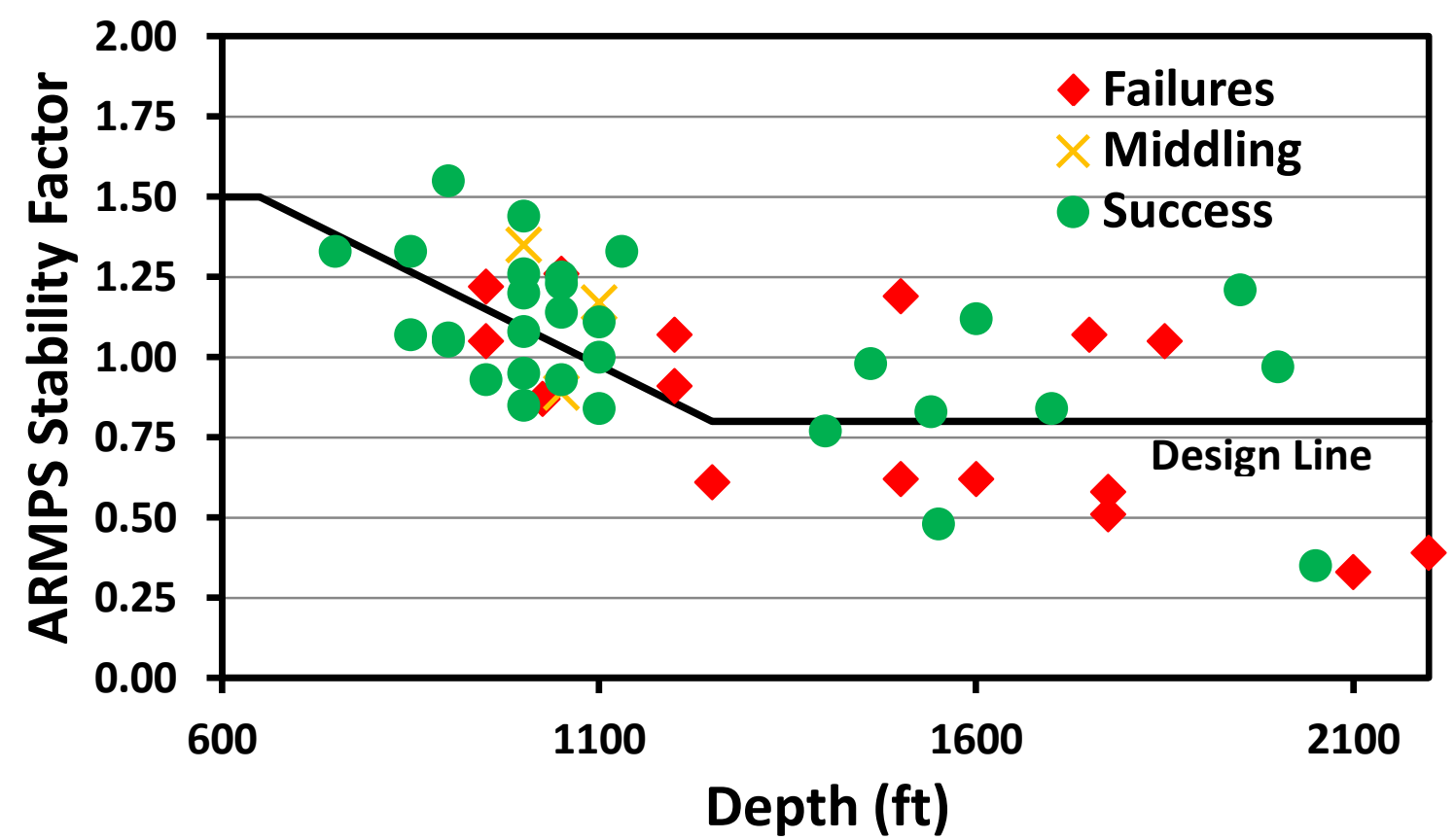

Figure 2.19: ARMPS (2002) stability factors for the case histories (after Heasley et al., 2011). The main reason for analysis using the ARMPS program was to allow for comparisons to the LaModel analysis to be made. For the most part, the ARMPS 2002 analysis evenly splits the failure cases in the database. More importantly, the "grey area," or the area of overlap between the successful and unsuccessful case histories can be seen. It can be imagined that all of the stability factors high than that of a successful case are successful and all of the stability factors lower than that of a failure would also be unsuccessful. The design line then splits this "grey area" where appropriate.

For the idealized LaModel analysis, the LaModel grid was built to exactly duplicate the idealized mining plan simulated in ARMPS for each case. The pillars were perfectly rectangular and the overburden was set at a constant depth. The stability factors for the idealized cases were calculated as the weighted average of the stress-based pillar safety factor for the area within the ARMPS Active Mining Zone (AMZ). 
The results from the idealized analysis are shown in Figure 2.20.

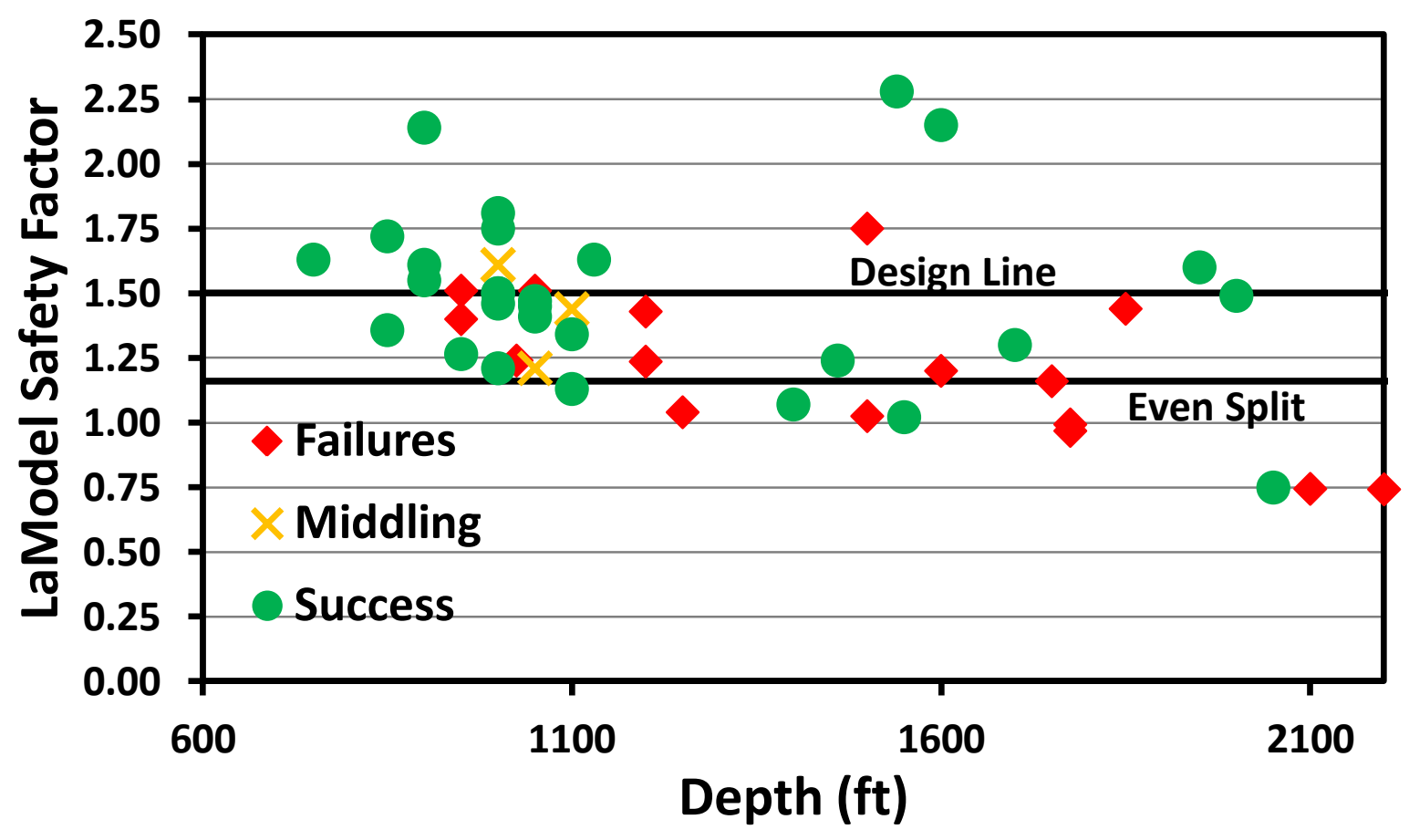

Figure 2.20: LaModel stability factors for the idealized cases (after Heasley et al., 2011).

The idealized LaModel stability factors ranged from 0.74 to 2.28 with an average of 1.39 . The area where the successful and failed designs overlap (the "grey area") ranges from 0.75 to 1.75 . With an average stability factor of 1.39 , this translates into an uncertainty of about $36 \%$.

Logistic regression was performed on data from the idealized LaModel analyses. The first outcome from his regression analysis was that the depth was not statistically significant. The analysis also determined that a safety factor of 1.16 provides the best overall classification of successes and failures with $86 \%$ of the successes correctly classified, $44 \%$ of the failures correctly classified, and an overall correct classification of $70 \%$. The area under the ROC curve for the idealized analysis was calculated to be 0.746 implying good discrimination.

The "detailed" LaModel analysis required the LaModel grid be built directly from the mine map and included all of the details associated with an actual mining map: variable pillar sizes, 
panel widths, surrounding rooms, pillar stumps, etc. Additionally, the actual topography was used in the analysis. Beyond this, the calibration and safety factor calculation method remained unchanged from the idealized analyses.

The results of the detailed LaModel analysis are shown in Figure 2.21.

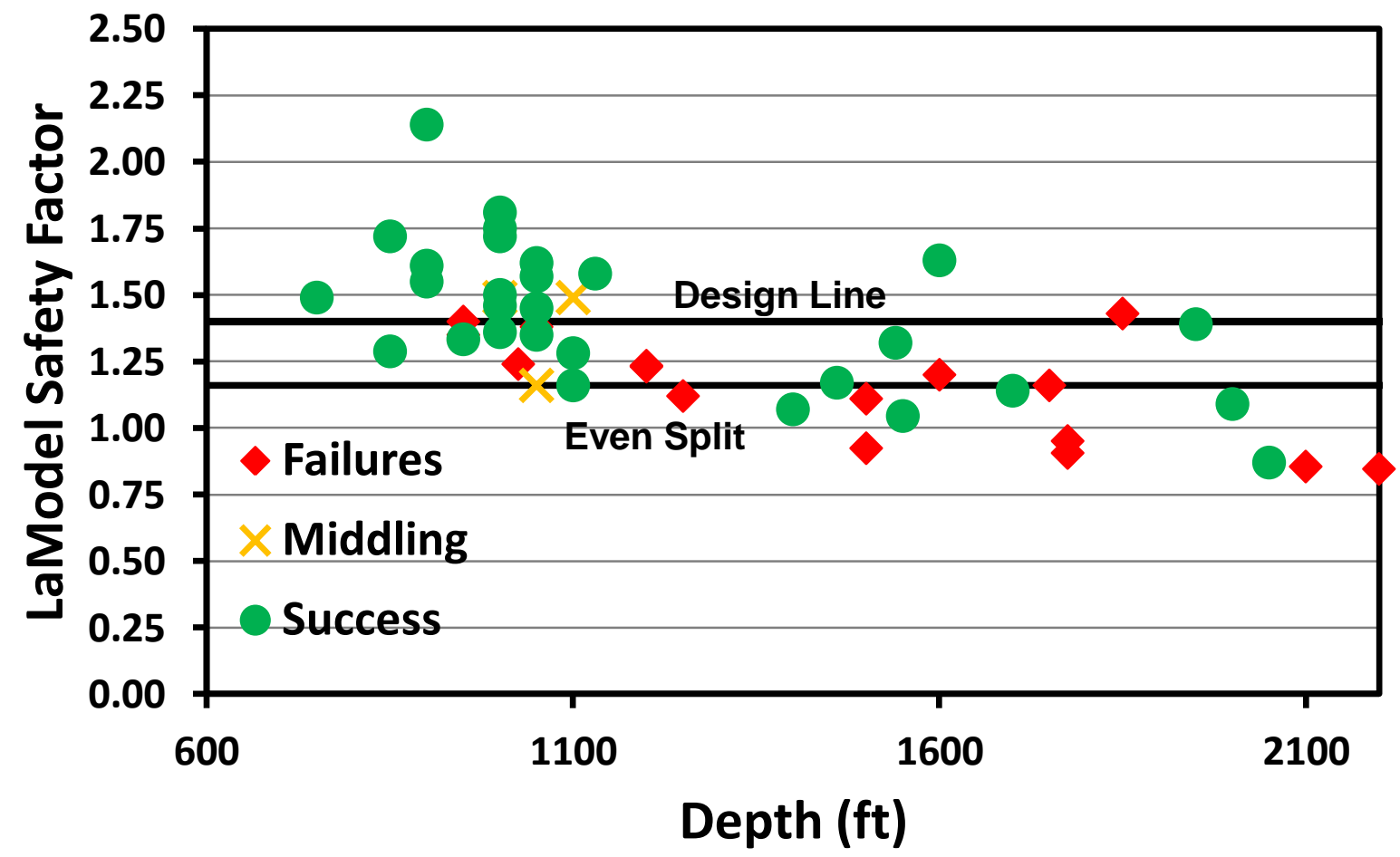

Figure 2.21: LaModel stability factors for the detailed cases (after Heasley et al, 2011).

The detailed LaModel stability factors ranged from 0.85 to 2.14 with an average of 1.33 . The separation of the successes and failures was improved a bit with the detailed analysis. Including the real geometry and topography in the LaModel analysis changes the safety factors for the specific case studies about $11 \%$ on average with a range from $0 \%$ to $58 \%$. The grey area for the detailed analysis ranges from a stability factor of 0.86 to 1.50 . With an average stability factor of 1.33 , this translates into an uncertainty of about $24 \%$. This $24 \%$ uncertainty implies that the detailed analysis provides a better discrimination than the idealized analysis (36\%) or the ARMPS (41\%) analysis. 
A logistic regression was also performed for the detailed LaModel analysis. Again, depth was not found to be statistically significant and the even split was at a stability factor of 1.16. The 1.16 stability factor correctly classified $79 \%$ of the successful case histories and $50 \%$ of the failures with an overall correct classification of $69 \%$. The area under the ROC curve for the detailed analysis was calculated to be 0.791 implying nearly excellent discrimination. The LROC value for the detailed analysis was $5 \%$ better at 0.791 . Overall, if a safety factor of 1.40 is used as a design objective, only 4 failures out of 47 case histories would be misclassified (or $8.5 \%)$.

Overall, the detailed LaModel analysis was somewhat better than the idealized LaModel analysis which was somewhat better than ARMPS 2002 analysis at correctly classifying the deep cover case histories. One reason that the detailed LaModel analysis is somewhat better than both of the other methods is because the detailed analysis more accurately reflects the mining geometries observed in the field. Specifically, actual variable pillar sizes and the introduction of variable topography. The fact that the detailed LaModel analysis classified these case histories better suggests that the underlying mechanics used in LaModel are more realistic than those used on ARMPS. This observation leads directly to this research, where the LaModel mechanics are expanded to include shallow-cover by expanding the case history database. 


\section{Chapter 3}

\section{The Shallow Cover Database}

In order to help evaluate and verify a "standardized" calibration method, a database of shallow cover $(<750 \mathrm{ft}$ deep) retreat mining cases was developed. The database consisted of 40 pillar retreat case studies from 12 different mines. Eight of these mines (the number in the red circles) are located in southern West Virginia, two are in central West Virginia, and two are in the Northern Appalachian coal fields (See Figure 3.1 and Table 3.1).

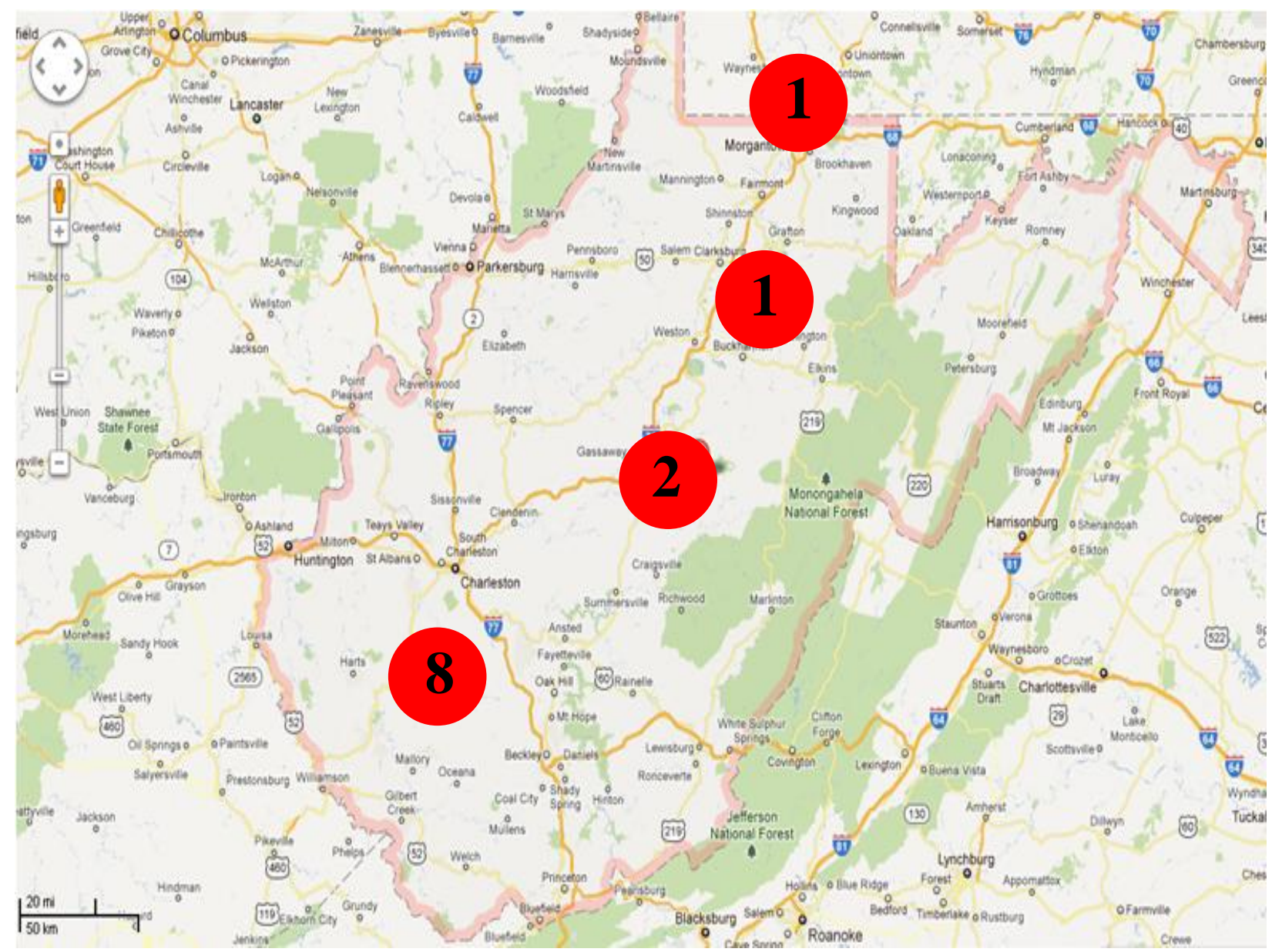

Figure 3.1: General location of case histories for the shallow cover database. 
Table 3.1: Details of the shallow cover database.

\begin{tabular}{|c|c|c|}
\hline \multicolumn{3}{|c|}{ Shallow Cover Database } \\
\hline Region & \# of Cases & \# of Mines \\
\hline Northern Appalachian & 11 & 2 \\
\hline Central West Virginia & 3 & 2 \\
\hline Southern West Virginia & 24 & 8 \\
\hline
\end{tabular}

The overburden depths ranged from $195 \mathrm{ft}$ to $700 \mathrm{ft}$ with an average of $439 \mathrm{ft}$. The mining height at the case study sites ranged from $4 \mathrm{ft}$ to $13 \mathrm{ft}$ with an average of $7.8 \mathrm{ft}$. The number of entries in the sections ranged from 4 to 17 with an average of 7.9 entries. (This number might appear high because of the number of cases histories where pillars were split, which resulted in twice the original number of entries for these cases.) Pillar widths ranged from $30-\mathrm{ft}$ to $85-\mathrm{ft}$ centers, and crosscuts spacing ranged from 50-ft to $110-\mathrm{ft}$ centers with the average pillar size being $56 \mathrm{ft}$ by $81 \mathrm{ft}$ center-to-center. (Again, pillar widths might seem low due to the number of cases where pillars were split resulting in pillars that were half their original size.) The panel widths ranged from $215 \mathrm{ft}$ to $570 \mathrm{ft}$ with an average of $405 \mathrm{ft}$. Twenty-three of the case studies included loading from an active gob, while 15 of the panels were development loading only. Of the active retreat cases, nine of these had additional loading from one side gob, but none of them had loading from two side gobs. Eighteen of the case study sites were considered failures, and 20 were considered successful.

\subsection{Database Parameters}

The most important variable in the database is the outcome: whether the shallow room-andpillar section was successful or unsuccessful (Mark et al., 2007). The determination of success or failure was made during mine visits and in conversations with the mine staff when possible, in 
some cases, the mine or mined section were not accessible or were cases found in the literature.. Essentially, determination of success or failure followed the same guidelines for the ARMPS and AMSS databases. A case study was considered a success when an entire panel was recovered without any significant ground control incidents, and a case study was considered a failure when the pillars collapsed or a ground failure occurred that necessitated leaving pillar or altering the original mine plan (Mark, 2009). In reviewing the database, it was noted that there were two separate populations of failures in the database. In one subset of the database, one or multiple pillars failed resulting in abandoning all or part of the panel. This is the pillar failure subset. In the other subset of the database, all or part of the panel was abandoned due to stress related issues with the roof, floor, or ribs; actual pillar failure did not occur. These cases histories are known as the entry failure subset.

In addition to dependent outcome variable, several other potential parameters were collected or extracted from the LaModel analysis. Independent geometric variables that were collected and considered for the statistical analysis included the following:

- Overburden depth

- $\quad$ Mining height

- $\quad$ Mining geometry (pillar sizes, gob widths, etc.)

- $\quad$ Coal Mine Roof Rating (CMRR)

- Interburden thickness

Independent variables that were calculated using LaModel included the following:

- $\quad$ LaModel stability factor (SF)

- $\quad$ Multiple-seam stress

- $\quad$ Total vertical stress 
- Maximum roof compression

- $\quad$ Maximum roof tension

Some of the variables used in the AMSS database, such as the usage of supplemental support, were not available and therefore unable to be included in this database. Additionally, the small size of the shallow cover database precludes the use of too many independent variables in the model; therefore, all of the variables listed above were not ultimately used. 


\section{Chapter 4}

\section{Methodology}

This research follows the same general methodology as that used to develop the LaModel deep cover calibration: a set of shallow cover and /or multiple-seam case histories (both successes and failures) was gathered; an "appropriate" calibration method with LaModel was developed; and then the required parameters for a successful design were determined using the calibrated LaModel and the database.

To perform the statistical analysis of the shallow-cover database, the statistical program $R$ ( $R$ Development Core Team, 2011) was used to apply logistic regression to the database. The R program uses a code based interface and allows great user flexibility. Logistic regression, in R, requires using the generalized linear model (glm) function which allows the user to move beyond least squares regression (the linear model, $\mathrm{lm}$ ) and introduce non-normal errors into the model. Setting the error family of the generalized linear model to binomial, and by default the link function to logit, tells the R program to perform logistic regression.

The shallow cover database, unlike the deep cover database, ultimately required the analysis of multiple-seam interactions because it was difficult to find unsuccessful cases, other than historic massive pillar collapses, where there wasn't some form of multiple-seam interaction. Adding these additional parameters resulted in a database with two distinct failure populations, similarly to the AMSS database. Specifically, there are failure cases where the pillars actually failed (global instability) and then there are failure cases where entry instability (local instability) resulted in failure of the mining plan. As a result of this dual failure nature, it was apparent that the database must be analyzed in two separate subsets. 
The known pillar failure cases were analyzed separately using logistic regression similarly to the ARMPS database and the deep-cover database. Once the optimum minimum stability factor for eliminating pillar failure in the database was determined, this value was used to remove cases from the database where the pillars were "obviously" undersized to create the entry stability subset of the data.

Then, the entry stability subset of the database was analyzed with a similar method to the AMSS database. Multi-variable logistic regression was used to first determine the critical independent parameters. Then, regression analysis was used to determine an optimum statistical model. This regression analysis attempts to answer the question, "why was this panel unsuccessful?" Was it due to weak roof, high stress, lack of support, or some definable combination of parameters? 


\section{Chapter 5}

\section{Calibration and LaModel Analysis}

\subsection{Relationship Between Rock Mass Stiffness and Stresses}

In order to more fully understand the calibration method detailed in the next section and applied to this database, a basic understanding of the relationship between the rock mass stiffness (Rock Mass Modulus and Lamination Thickness) and the Multiple Seam Stress is required. To accomplish this, a model was created using the average parameters for the database (Table 5.1).

Table 5.1: Input parameters for the average case.

\begin{tabular}{|c|c|c|c|c|}
\hline \multicolumn{5}{|c|}{ Average Seam Geometry } \\
\hline $\begin{array}{c}\text { Depth } \\
\text { (ft) }\end{array}$ & $\begin{array}{c}\text { Mining } \\
\text { Height (ft) }\end{array}$ & $\begin{array}{c}\text { Interburden } \\
(\mathbf{f t})\end{array}$ & $\begin{array}{c}\text { Pillars } \\
(\mathbf{f t}, \text { C-C) }\end{array}$ & $\begin{array}{c}\text { No. } \\
\text { Entries }\end{array}$ \\
\hline 300 & 8 & 135 & $60 \times 80$ & 8 \\
\hline
\end{tabular}

A seam with average pillar dimensions, an average number of entries, and an average seam height was created overlying an un-mined seam of average thickness with an average interburden at an average depth. Calibration methods matching the deep cover calibration procedure, adjusting the rock mass modulus to 6 million psi, and using the default $50 \mathrm{ft}$ lamination thickness were modeled separately (Table 5.2). Effects similar to those found by Heasley, 2012 were recorded and are detailed in the following. 
Table 5.2: LaModel input parameters for the three calibration techniques.

\begin{tabular}{|c|c|c|}
\hline \multicolumn{3}{|c|}{ Calibration } \\
\hline RMM (psi) & LamThk (ft) & Gob Modulus (psi) \\
\hline $3 \times 10^{\wedge} 6$ & 141 & $8 \times 10^{\wedge} 6$ \\
\hline $6 \times 10^{\wedge} 6$ & 71 & $8 \times 10^{\wedge} 6$ \\
\hline $3 \times 10^{\wedge} 6$ & 50 & $4 \times 10^{\wedge} 6$ \\
\hline
\end{tabular}

Figure 5.1 shows the effect on the abutment stress for an average model with calibrated rock mass moduli and for the default $50 \mathrm{ft}$ lamination thickness.

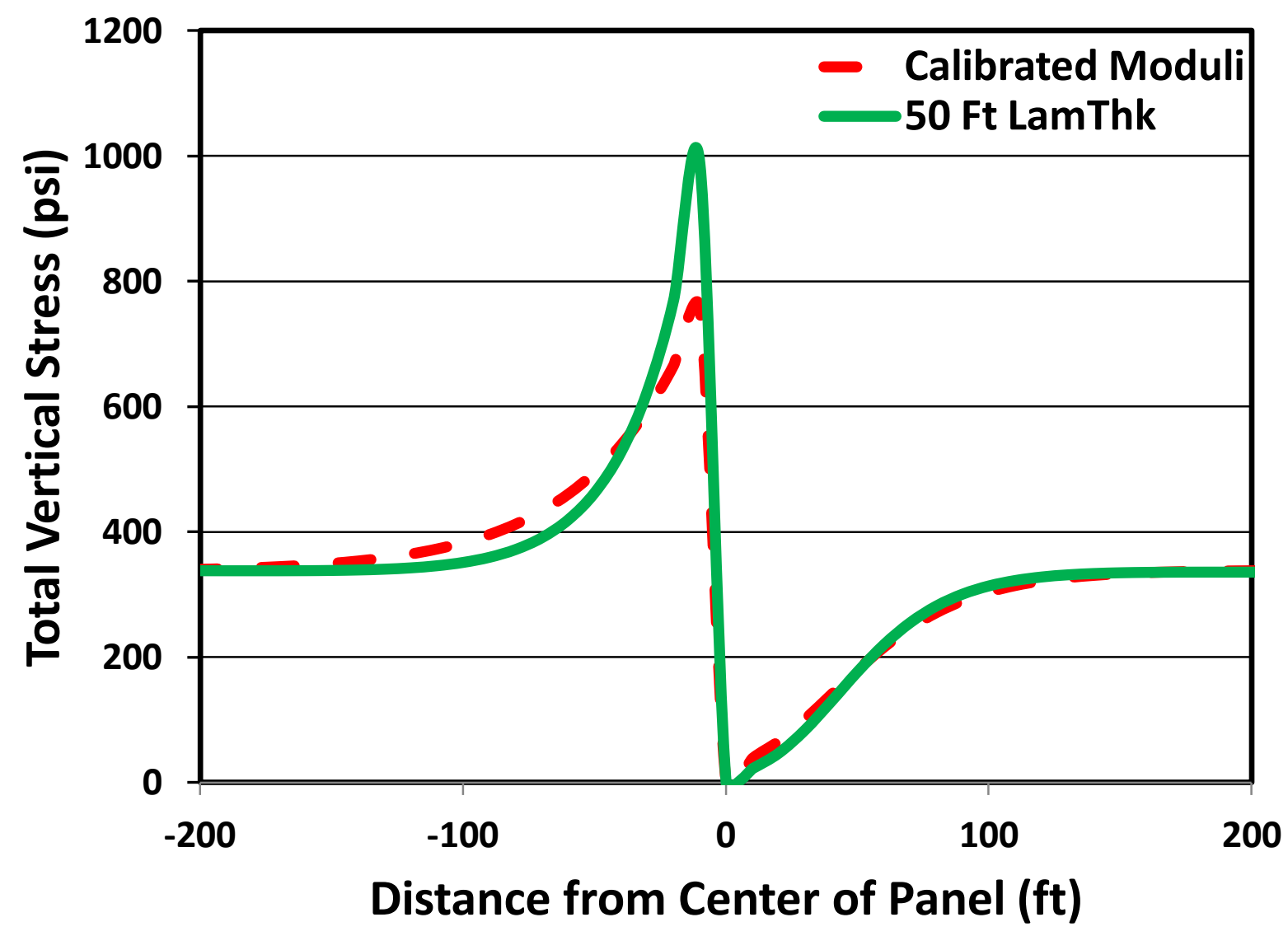

Figure 5.1: Side abutment stress for the average case by calibration method. 
Figure 5.1 shows that the abutment stress distribution in LaModel is the same regardless of the rock mass modulus used as long as the lamination thickness is calibrated to that specific modulus, and assuming the gob modulus is calibrated for the same gob loading. This means that it is possible to decrease the lamination thickness while keeping the same abutment stress profile by increasing the rock mass modulus. However, using the a smaller lamination thickness without adjusting the rock mass modulus increases the peak magnitude of the abutment stress and the steepness of its profile.

Figure 5.2 shows the multiple seam stress calculated by: using the deep cover calibration, changing the modulus to $6 \times 10^{6}$ psi and re-calibrating, and using the default $50 \mathrm{ft}$ lamination thickness and 3 million psi rock mass modulus. The results for the model show that increasing the modulus and decreasing the lamination thickness of the rock mass proportionally (which keeps the single-seam stiffness the same) significantly increases the multiple seam stress. However, just decreasing the lamination thickness causes and even bigger increase in multipleseam stress. 


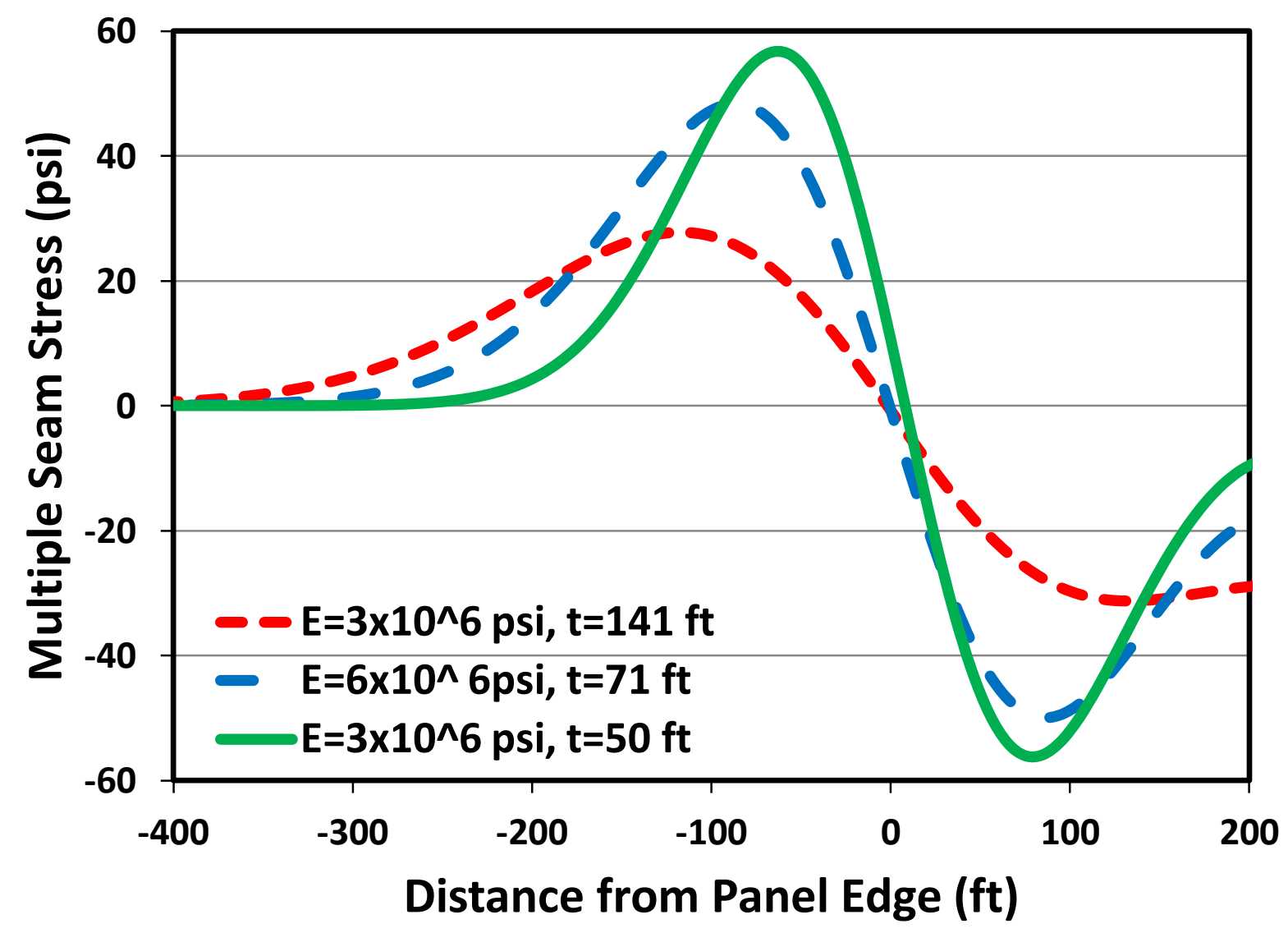

Figure 5.2: Multiple seam stress on the underlying seam.

Figure 5.2 shows that increasing the rock mass modulus, and therefore decreasing the calibrated lamination thickness or decreasing the lamination thickness and keeping the same rock mass modulus results in an increased multiple seam stress from the overlying abutment. The act of softening the surrounding rock mass results in an increase of the multiple seam stress transferred to the average underlying seam. (The reason that the multiple seam stress in Figure 5.2 appears small in comparison to the cases found in the database is because of the relatively shallow cover, $300 \mathrm{ft}$, and the relatively large interburden thickness, $135 \mathrm{ft}$.) 


\subsection{Calibration Method}

The 38 case histories in the database were analyzed using the LaModel3.0 program. The majority (25) of these case histories allowed for using mine maps to create input grids based on the actual mine plan and creating overburden grids based on the actual overburden. Thirteen case histories required using an "idealized" analysis due to the fact that they were historic massive pillar collapses taken from the literature (Chase et al., 1994) where no detailed mine map or overburden data was available. In these "idealized" cases, perfectly rectangular pillars and an average constant overburden depth were used in the LaModel analysis.

Once the seam grids and overburden grids were completed, the input parameters needed to be calibrated. Initially, a small subset of the database (10 case histories) was analyzed using three different trial calibration approaches in addition and prior to the analysis of the average case history detailed in the previous section

The first approach was to exactly follow the deep cover calibration procedure (Heasley et al., 2010). The second approach involved changing the rock mass modulus from 3,000,000 to 5,000,000 psi, thereby lowering the lamination thickness and increasing the multiple-seam impact while keeping the same abutment extent. The final approach was to use a thinner lamination thickness (the default of $50 \mathrm{ft}$ ) to increase the multiple-seam impact while letting the abutment extent decrease.

The deep cover calibration procedure produced maximum multiple-seam stresses in the 200 psi range. Increasing the rock mass modulus and decreasing the lamination thickness produced multiple-seam stress in the $400 \mathrm{psi}$ range, while fixing the lamination thickness at $50 \mathrm{ft}$ resulted in multiple-seam stresses in the 1400 psi range. I believe that the 200 to 400 psi multiple-seam stress values were very low, because in many situations, it appeared that the multiple-seam 
interactions were causing the observed failures. Therefore, it was decided to continue with the third approach and to hold the lamination thickness constant at $50 \mathrm{ft}$ for the subsequent analysis of the database. Other than fixing the lamination thickness, the procedure used to calibrate the gob material and generate the coal pillar strength for the shallow cover database followed the same procedure as the deep cover database. The gob properties, specifically the final gob modulus, were determined based on the expected gob load assuming an empirically suggested 21 degree abutment angle. The pillar strength was calculated as having a Mark-Bieniawski pillar strength assuming a 900 psi insitu coal strength.

There are several reasons for using the standard elastic-plastic and strain hardening materials. Use of the elastic-plastic coal material is typical procedure with LaModel and it results in exactly a Mark-Bieniawski pillar strength. This approach is consistent with both the ARMPS analysis and the deep-cover LaModel analysis. Similarly, the strain-hardening gob material is typically used with LaModel and with the gob wizard; it provides a quick calibration of the expected abutment loads. Therefore, using these materials with the current calibration techniques appears to be the best available option at this time.

This calibration technique was chosen because it maximized the multiple seam stress for both the average case, as well as the small subset of the database. While, this method appeared to be the best for tackling multiple seam interactions, it raises some potential issues. By fixing the rock mass stiffness, we have moved to a variable abutment stress distribution. Meaning, the abutment stress profile no longer follows the empirically suggested abutment extent, which is that $90 \%$ of the load occurs within a distance of $5 \sqrt{ } \mathrm{H}$. Moreover, fixing the rock mass stiffness begs the question, what would have been the results of the deep cover analysis had this 
calibration technique been applied to it? Some potential solutions to these issues are discussed in greater detail in the suggestions for future research.

\subsection{Analysis of the Database}

The first step in analyzing the database (See Appendix A) was to calculate the LaModel stability factor of the pillar plan (Figure 5.3).

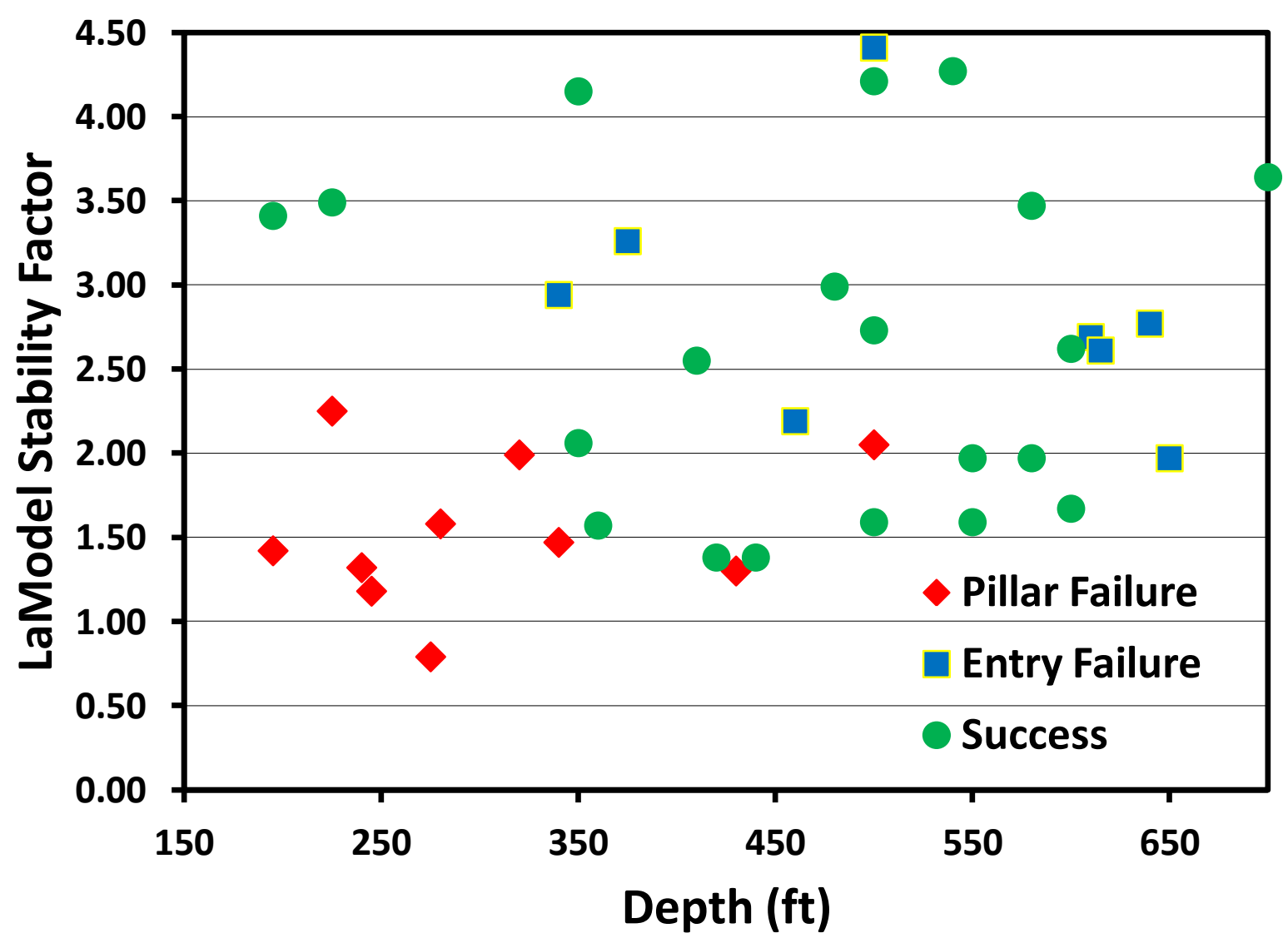

Figure 5.3: Depth versus LaModel stability factor.

For this database, the stability factor was calculated in the same manner as in the deep cover database (Heasley et al., 2010). Specifically, the stability factor was calculated as the element weighted average of the pillar safety factor over the Active Mining Zone (AMZ). Also, for the 
analysis of the LaModel pillar stability factor as shown in Figure 5.3, the failure cases were broken into two groups based on the observed failure mode: pillar failures or entry failures.

Looking at the LaModel results in Figure 5.3, first, we see that the majority of the pillar failure case histories cluster at the lower stability factors and lower depths. The pillar failure stability factors ranged from 0.79 to a high of 2.25 , and the grey area where the failures overlap with the successful cases ranges from 1.30 to 2.25 . With an average stability factor of 2.40 , this translates into an uncertainty of about $40 \%$. Looking at the entry failures, as might be expected, we see significant scatter of the stability factors, where the entry failures are occurring with a stability factor as high as approximately 4.5 and intermixed with the successful case histories in regard to the stability factor. Observing only the entry failures, it is clear that the pillar stability factor is not the most significant parameter in predicting success or failure for this subset of failures; however, on the other hand, the majority of the pillar failure cases appear to be readily explained by low stability factor.

This situation where the pillar stability factor was not the most significant independent variable was also encountered when the database for the AMSS program was analyzed (Mark et al., 2007). In the AMSS analysis, a combination of the independent parameters - total vertical stress, interburden thickness, CMRR, undermining vs. overmining, existence of supplementary support, and remnant pillar vs. gob-solid boundaries — was ultimately used to determine entry stability, after a minimum required pillar stability factor for the pillars had been met. The statistical analysis in this research followed a similar approach. First, a minimum allowable stability factor was determined to cover the pillar failure subset of the data. Then, a logistic regression of the remaining independent variables was performed in an attempt to predict the entry failure subset of the data. 


\section{Chapter 6}

\section{Results of the Logistic Regression Analysis}

Logistic regression is the most common statistical technique for models where the dependent variable is binary (in this case, success or failure). Fortunately, for the geo-mechanical analysis of small databases, the assumptions of linear regression such as: normality, constant variance, etc. are not required for logistic regression analysis. The basic assumption of logistic regression is that continuous independent variables must be "linear in the logit (Mark et al, 2007)." This means that the regression equation should have a linear relationship with the logistic (logit or log-odds) form of the dependent variable (success or failure). The following summarizes the results of the logistic regression for the shallow cover database. A detailed discussion of the statistical analysis can be seen in Appendix B.

\subsection{Single Variable Pillar Failure Subset}

First, the pillar failure subset (global stability) of the data was analyzed. To accomplish this, two models were performed. First, the single variable (SF) model using the LaModel SF was created and the results are presented in Table 6.1 .

Table 6.1: Logistic regression table for the single variable (SF) model.

\begin{tabular}{|c||c|c|c|c|}
\hline \multicolumn{5}{|c|}{ Summary Table } \\
\hline Coefficients: & Estimate & Std. Error & Z Value & P Value \\
\hline \hline Intercept & -3.631 & 1.783 & -2.037 & 0.0417 \\
\hline LaModel SF & 2.243 & 1.006 & 2.229 & 0.0258 \\
\hline
\end{tabular}


Based on the estimates of the coefficients in the above table generated using the summary function in the R program, the model equation can be written as:

$$
g(x)=2.243 S F-3.631
$$

and solving equation 6.1 for the critical SF results in:

$$
\mathrm{SF}=1.62
$$

As previously discussed, one disadvantage of logistic regression is the lack of a well established measure of model fit. Mark et al. (2007), as recommended by Hosmer and Lemeshow (2000), uses the receiver operating characteristic or ROC curve as an alternate to an $\mathrm{R}^{2}$ parameter. The cut point is defined as the probability which separates the predicted values into categories. In this case, the predicted values will be classified as either successful (higher than the cut point) or failures (lower than the cut point). The default cut point used in the epicalc package (see Appendix B) in R, and most statistical packages is 0.5. By changing the cut point, the corresponding intercept of the logistic model is adjusted to move the design line in relation to the desired classification. The area under the ROC curve for equation 6.1 (see Figure 6.1) is 0.84 implying excellent discrimination. 


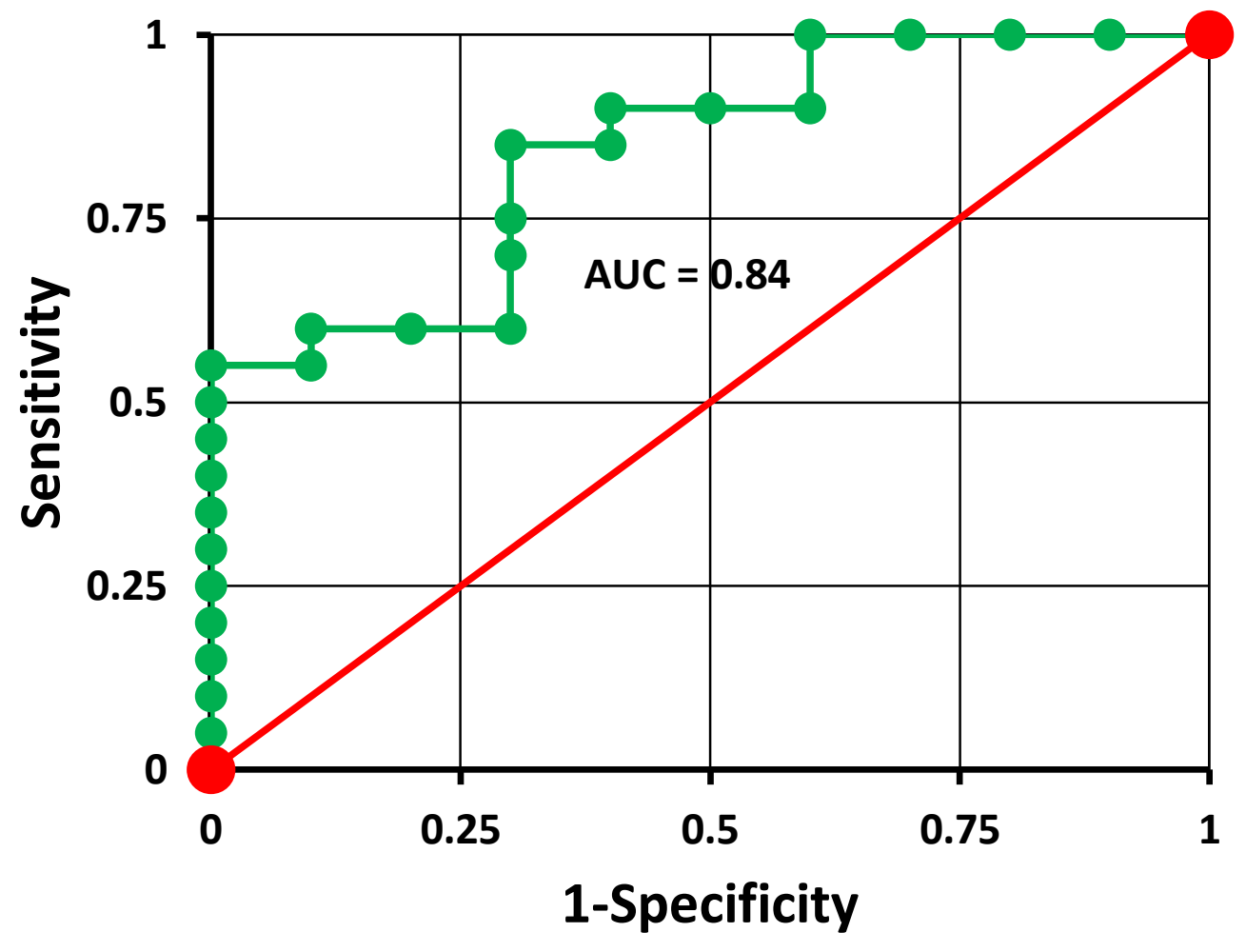

Figure 6.1: ROC curve for equation 6.1.

Further, the logistic regression model's optimum cut-point can be determined from plotting both the sensitivity and specificity vs. the cut point (See Figure 6.2). 


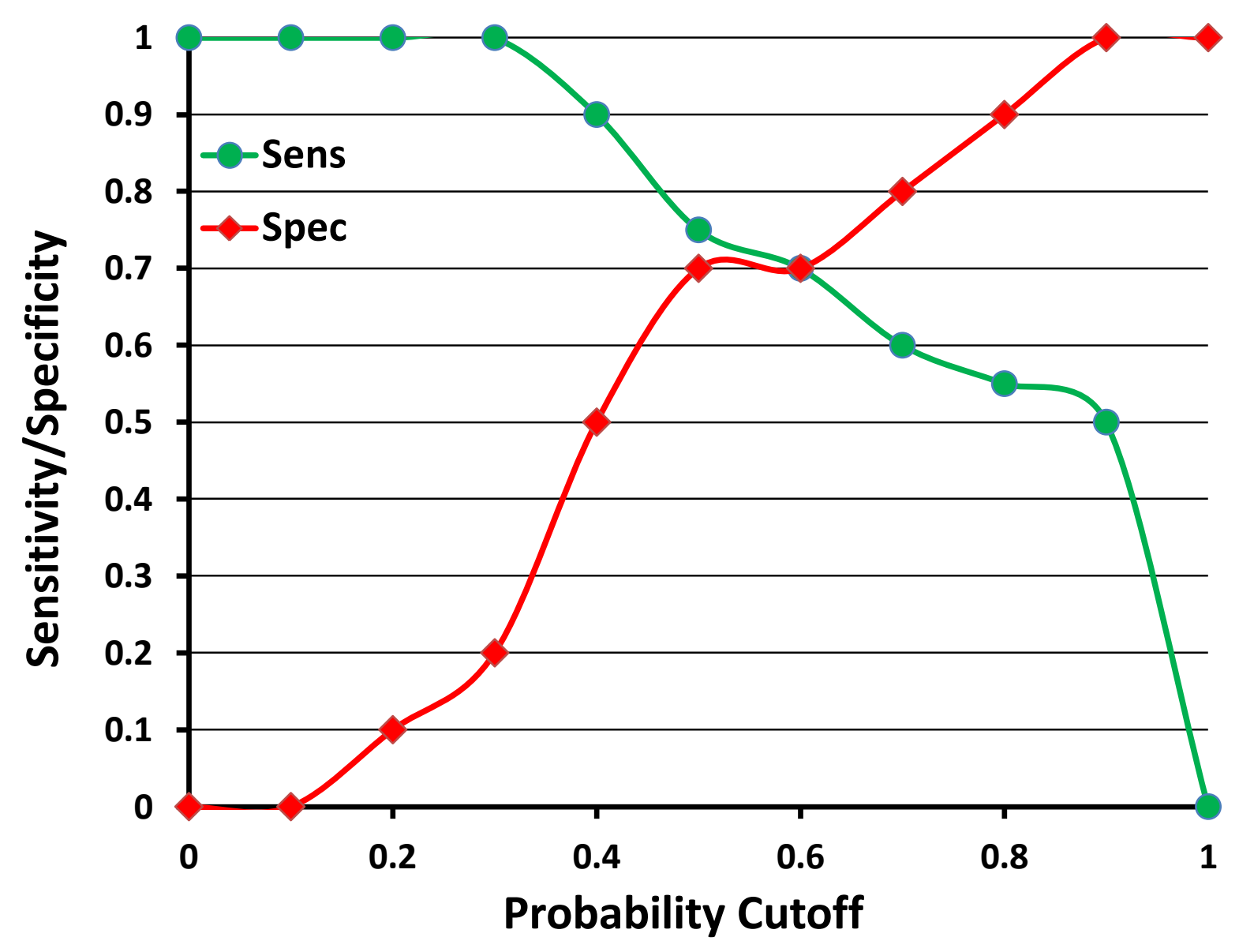

Figure 6.2: Plot of specificity and sensitivity vs cut-point for equation 6.1 showing the optimum cut-point to be between 0.5 and 0.6 .

Each point on the curve represents either the sensitivity (correctly classified successes) or specificity (correctly classified failures) at each individual cut point. As the cut point increases, the probability of correctly classifying a successful case decreases while the probability of successfully classifying a failure increases. Or in logistic regression terminology, the sensitivity decreases and the specificity increases. The intersection of these two curves maximizes the overall classification error resulting in the optimum cut-point of $\mathrm{p}=0.5$ to 0.6 .

The original model assumes a cut-point of 0.5 ; therefore, no modification of the intercept in equation 6.1 is required. The following classification chart (Table 6.2) show the percent correct classification for the optimum cut-point. 
Table 6.2: Performance of the design equation against the database at a cut point of 0.5 .

\begin{tabular}{|c||c|c|}
\hline & \# Correct & \% Correct \\
\hline \hline Successes & 15 & $75 \%$ \\
\hline Failures & 7 & $70 \%$ \\
\hline Overall & 22 & $73 \%$ \\
\hline
\end{tabular}

From Table 6.2, we see that if we use the optimum cut point of 0.5 and the resulting design SF of 1.62 the model correctly predicts $70 \%$ of the failure cases. Of less importance, since we are primarily designing to prevent failure, the model also correctly predicts $75 \%$ of the successes and $73 \%$ of the overall cases.

To improve the classification of the failure cases to $90 \%$, the cut point must be changed to a value between 0.7 and 0.8 as seen in the specificity curve in Figure 6.2. The QuantPhyc package (see Appendix B) in $\mathrm{R}$ was used to determine that a cut point of 0.725 resulted in the desired failure classification rate while retaining the highest classification of successes. Using this new cut point modifies the intercept in the model equation to:

$$
g(x)=2.243 \mathrm{SF}-4.6
$$

Solving equation 6.3 for the critical SF results in:

$$
\mathrm{SF}=2.05
$$

The following classification chart (Table 6.3) shows the percent correct classification for the cutpoint of 0.725 .

Table 6.3: Performance of the design equation against the database at a cut point of 0.725 .

\begin{tabular}{|c||c|c|}
\hline & \# Correct & \% Correct \\
\hline \hline Successes & 12 & $60 \%$ \\
\hline Failures & 9 & $90 \%$ \\
\hline Overall & 21 & $70 \%$ \\
\hline
\end{tabular}


Here we see that if we use a cut-point of 0.725 and the resulting design SF of 2.05, the model correctly predicts $90 \%$ of the failure cases. But the accuracy of the model for the successful cases drops to $60 \%$ and the overall accuracy drops to $70 \%$. The design guidelines shown with the pillar failure subset of the data for equations 6.2 and 6.4 can be seen in Figure 6.3.

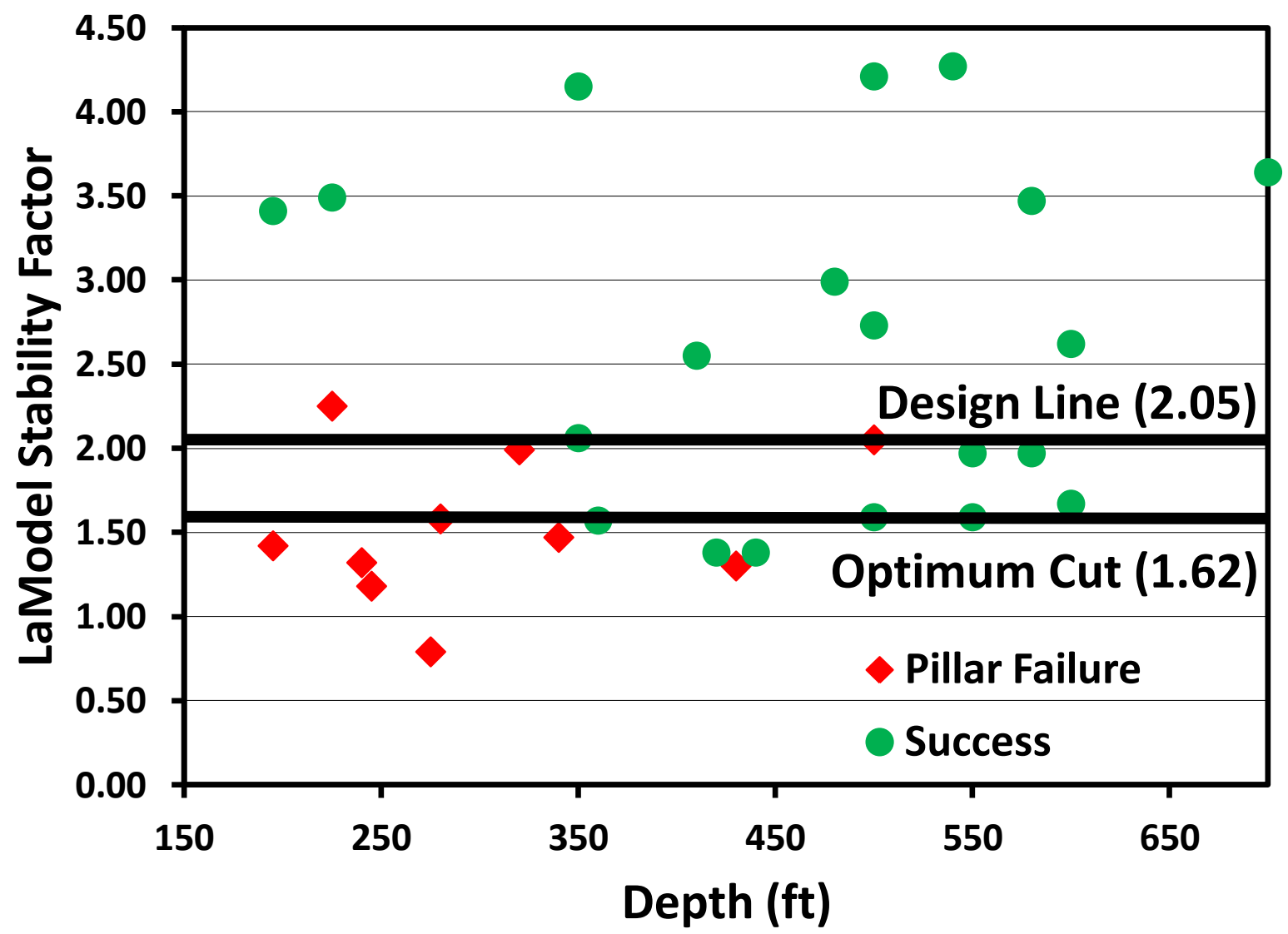

Figure 6.3: Design guidelines for $70 \%$ correct failure classification $(\mathrm{SF}=1.62)$ and $90 \%$ correct failure classification $(\mathrm{SF}=2.05)$.

\subsection{Multi Variable Pillar Failure Subset}

The second model that was analyzed for the pillar failure subset of the data also considers the depth (which was the only other independent parameter to be determined as statistically 
significant from running numerous models). Table 6.4 shows logistic regression table for the multi-variable model with both the LaModel SF and the depth.

Table 6.4: Logistic regression table for the multi-variable (SF and $\mathrm{H}$ ) model.

\begin{tabular}{|c||c|c|c|c|}
\hline \multicolumn{5}{|c|}{ Summary Table } \\
\hline Coefficients: & Estimate & Std. Error & Z Value & P Value \\
\hline \hline Intercept & -10.306 & 4.205 & -2.451 & 0.014 \\
\hline LaModel SF & 2.554 & 1.161 & 2.200 & 0.028 \\
\hline Depth (H) & 0.016 & 0.007 & 2.199 & 0.028 \\
\hline
\end{tabular}

Based on the estimates of the coefficients in the above table, the model equation can be written as:

$$
\mathrm{g}(\mathrm{x})=2.554 \mathrm{SF}+0.016 \mathrm{H}-10.306
$$

and solving equation 6.5 for the critical SF with depth $(\mathrm{H})$ in hundreds of feet results in:

$$
\mathrm{SF}=4-0.6 \mathrm{H}
$$

The area under the ROC curve for equation 6.5 (See Figure 6.4) is 0.95 implying near perfect discrimination. 


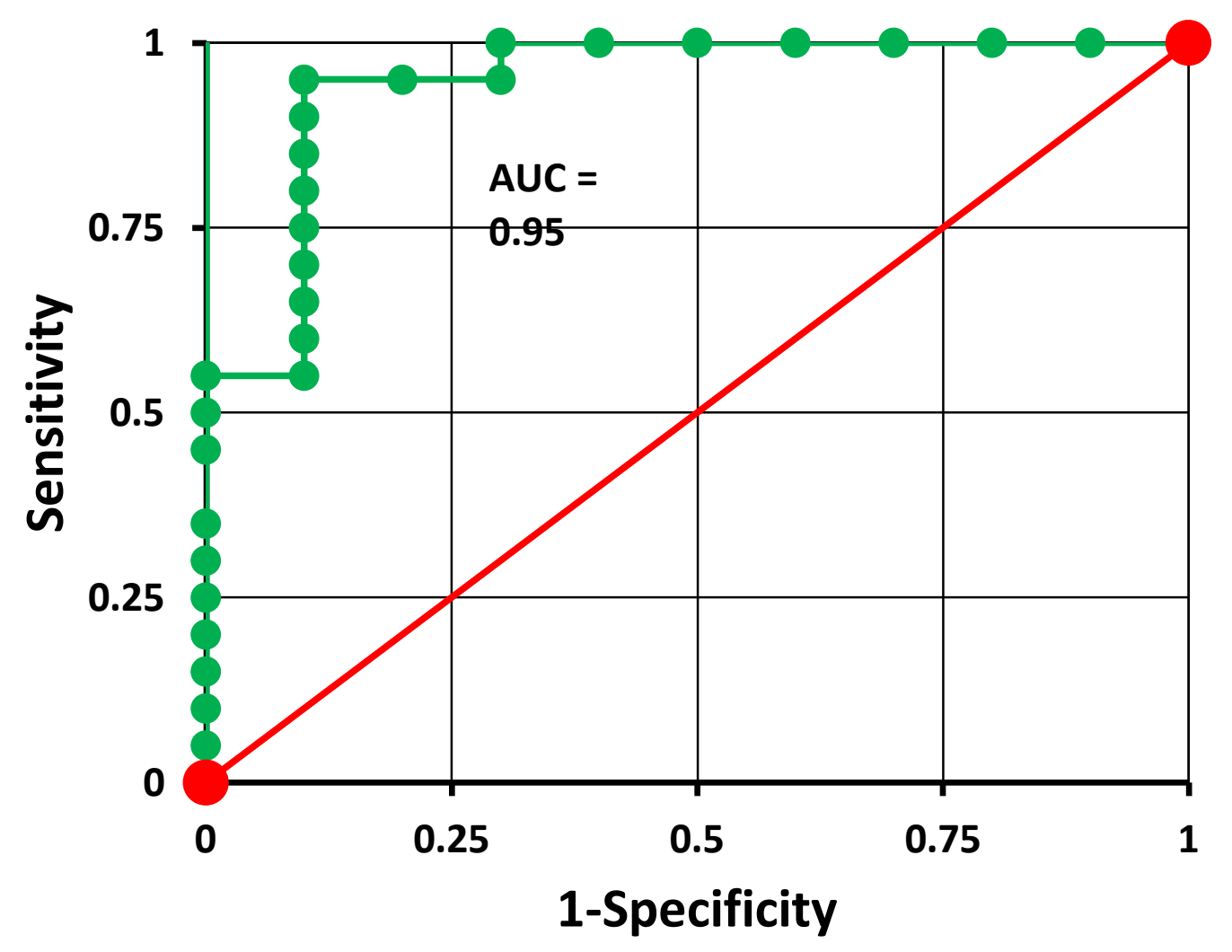

Figure 6.4: ROC curve for equation 6.5.

The multi-variable model's optimum cut-point can be determined from plotting the sensitivity and specificity vs. the cut point just like the single variable model (See Figure 6.5). 


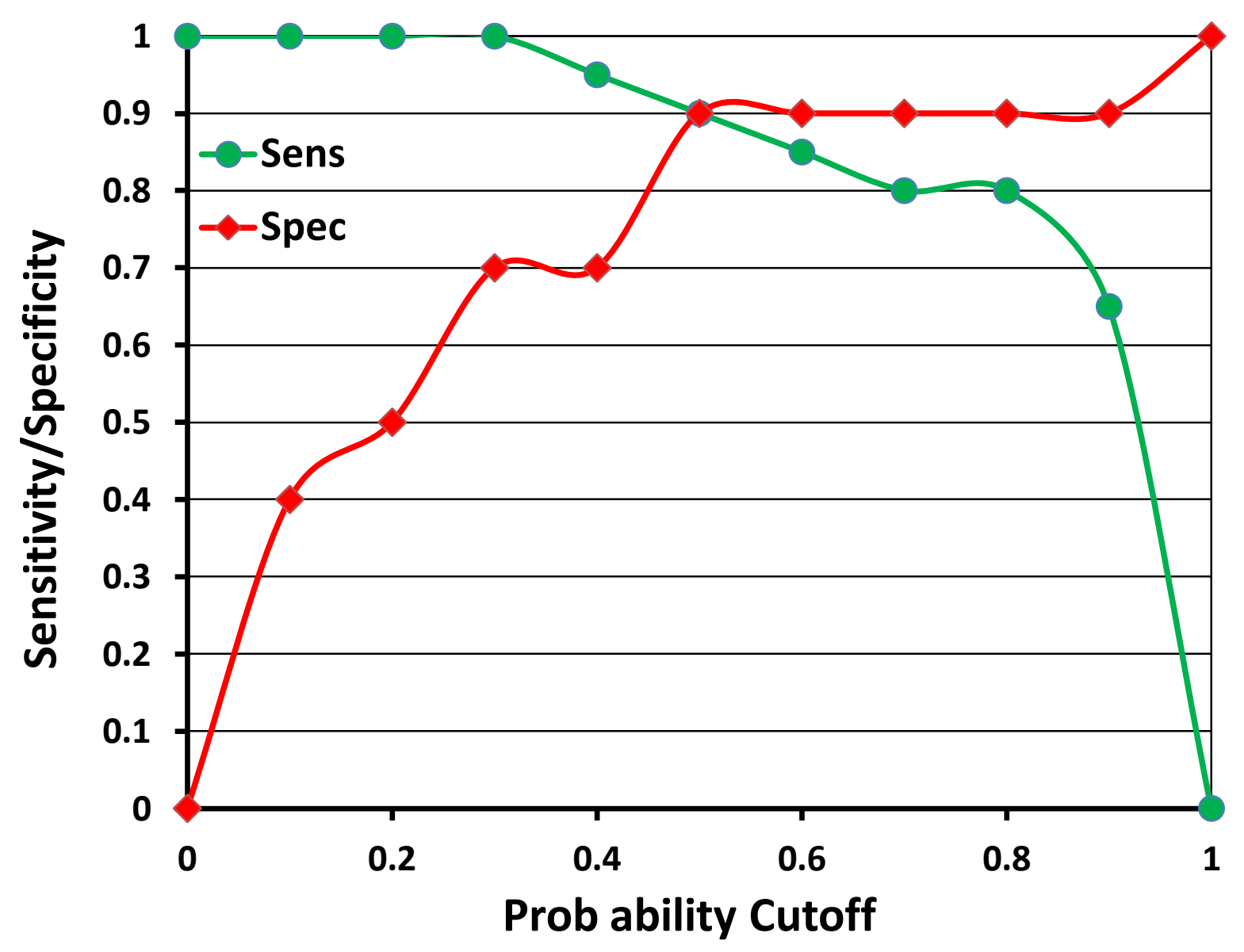

Figure 6.5: Plot of specificity and sensitivity vs cut-point for equation 6.5 showing the optimum cut-point to be 0.5 .

Again, because the model assumes a cut-point of 0.5 , no modification of equation 6.5 is required. The following classification chart (Table 6.5) show the percent correct classification for the optimum cut-point when considering both the LaModel SF and the depth.

Table 6.5: Performance of the multi-variable model against the database at the optimum cut point.

\begin{tabular}{|c||c|c|}
\hline & \# Correct & \% Correct \\
\hline \hline Successes & 18 & $90 \%$ \\
\hline Failures & 9 & $90 \%$ \\
\hline Overall & 27 & $90 \%$ \\
\hline
\end{tabular}


In this table, we see that with the optimum cut point of 0.5 and the resulting design equation (6.5), the model correctly predicts $90 \%$ of the failure cases, $90 \%$ of the successful cases, and $90 \%$ of the overall cases. Since the optimum cut-point correctly classifies $90 \%$ of the cases, there is no need to further modify the cut point as was done with the single variable model. The design guidelines shown with the pillar failure subset of the data for equation 6.5 can be seen in Figure 6.6. Here, engineering judgment determined that there should be some upper and lower bound to the stability factor in the design guidelines, hence starting the downward trend at a SF of 2.0 and stopping the downward trend at the deep-cover pillar retreat guideline of a SF of 1.4 (Heasley et al., 2010).

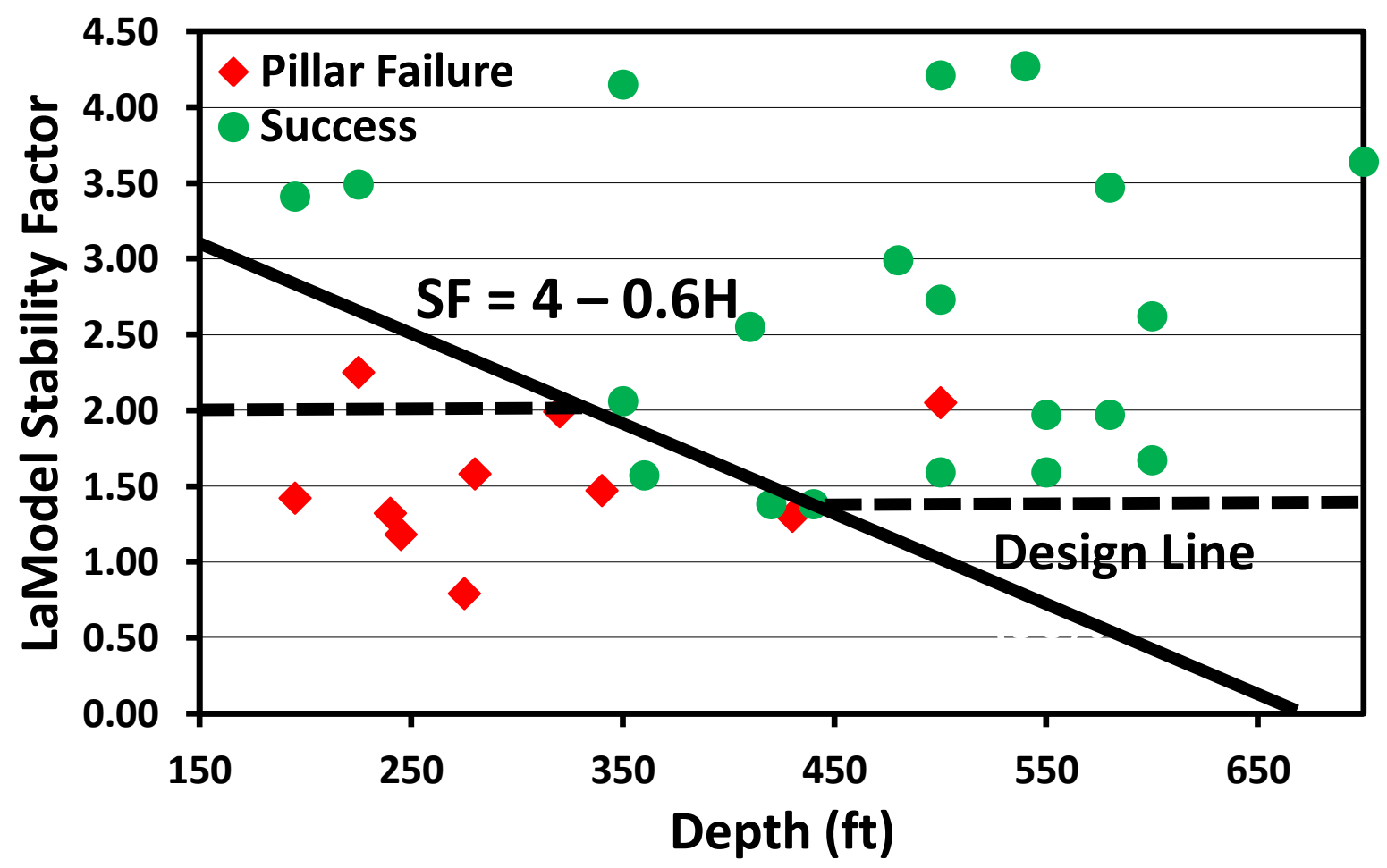

Figure 6.6: Design guidelines for $90 \%$ correct failure classification using equation 6.5. 


\subsection{Entry Failure Subset}

Finally, the entry stability failure (local stability) subset of the data was analyzed. Because this subset of the data is treated as a distinct population and a separate statistical analysis is being preformed, cases within this subset where the SF was found to be less than the recommended SF for global stability required removal from the database. These cases were removed from the database to eliminate the possibility of attempting to model a sample of the population where the entry stability failure was the result of inadequately designed pillars. These cases would be outside the population of this subset of the database and actually belong in the pillar failure subset, but where a determination of pillar failure was not obtainable. This required the removal of two cases which brought the total number of cases remaining in the entry failure subset to 28 .

A host of initial models were used to determine which few of the many possible independent variables contributed the most to the success or failure of the entry failure subset of the database. Ultimately, none of the variables were found to be statistically significant based on their pvalues. Instead of stopping at this point, it was determined that two variables with the most significance were the maximum multiple seam stress (MSS) within the AMZ and the coal mine roof rating (CMRR). Due to the nature of small databases, the multiple seam stress and CMRR were highly correlated and adding both variables into a statistical model was of minimal value. Additionally, using only one independent variable follows the rule of thumb "10 events per independent variable" required to minimize bias in logistic regression analysis (Peduzzi et al., 1996). Therefore, the most statistically significant variable, the multiple seam stress was chosen to pursue.

Table 6.6 shows logistic regression table for the single variable (multiple seam stress) model. 
Table 6.6: Logistic regression table for the MSS model.

\begin{tabular}{|c||c|c|c|c|}
\hline \multicolumn{5}{|c|}{ Summary Table } \\
\hline Coefficients: & Estimate & Std. Error & $\begin{array}{c}\mathbf{Z} \\
\text { Value }\end{array}$ & $\begin{array}{c}\text { P } \\
\text { Value }\end{array}$ \\
\hline \hline Intercept & 2.161 & 0.700 & 3.089 & 0.002 \\
\hline MulSeamStress & -0.0046 & 0.002 & -2.399 & 0.016 \\
\hline
\end{tabular}

Based on the estimates of the coefficients in the above table, the model equation can be written as:

$$
g(x)=2.161-0.0046 M S S
$$

Solving equation 6.7 for the critical multiple seam stress results in:

$$
\mathrm{MSS}=470 \mathrm{psi}
$$

The area under the ROC curve for equation 6.7 (See Figure 6.7) is 0.85 implying excellent discrimination.

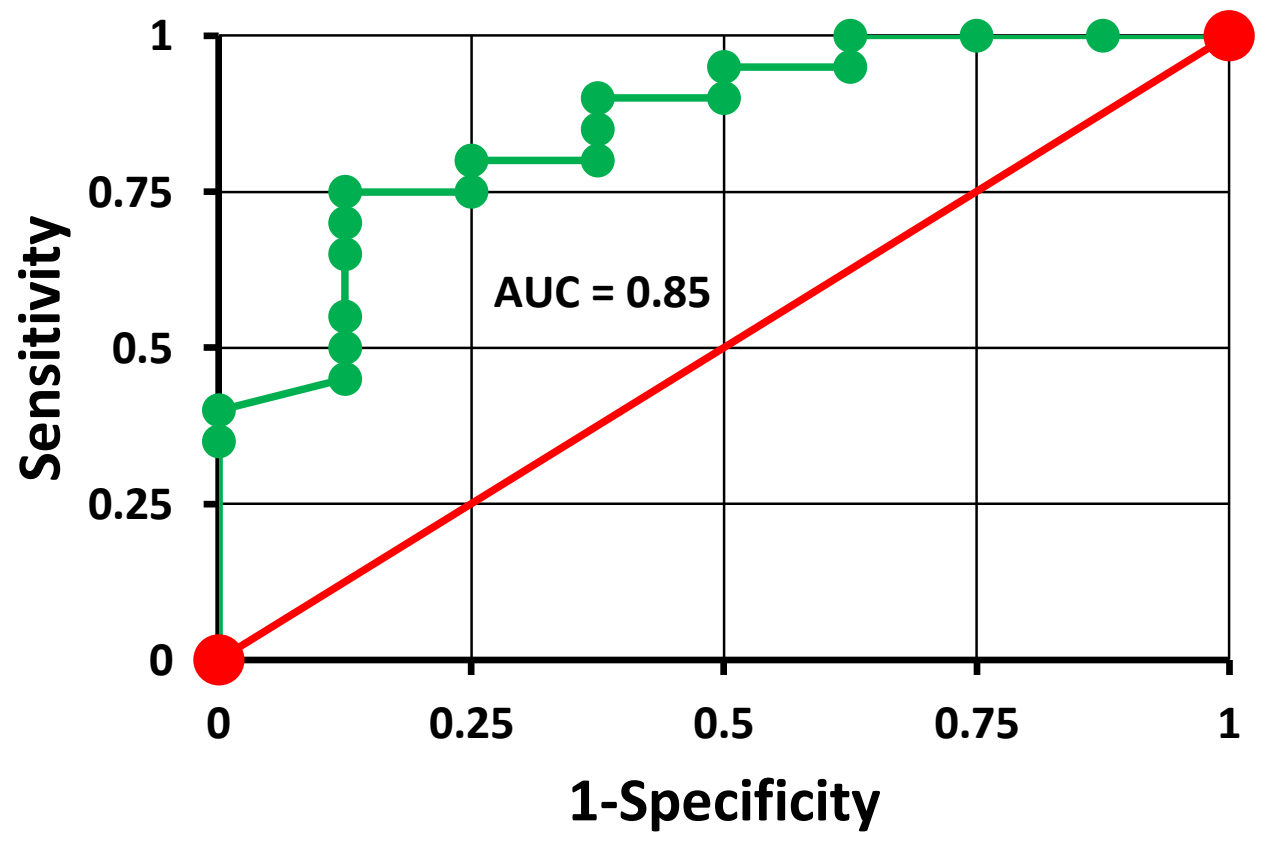

Figure 6.7: ROC curve for equation 6.7. 
Again, the model's optimum cut-point can be determined from plotting the sensitivity and specificity vs. the cut point just like the pillar failure subset of the data (See Figure 6.8).

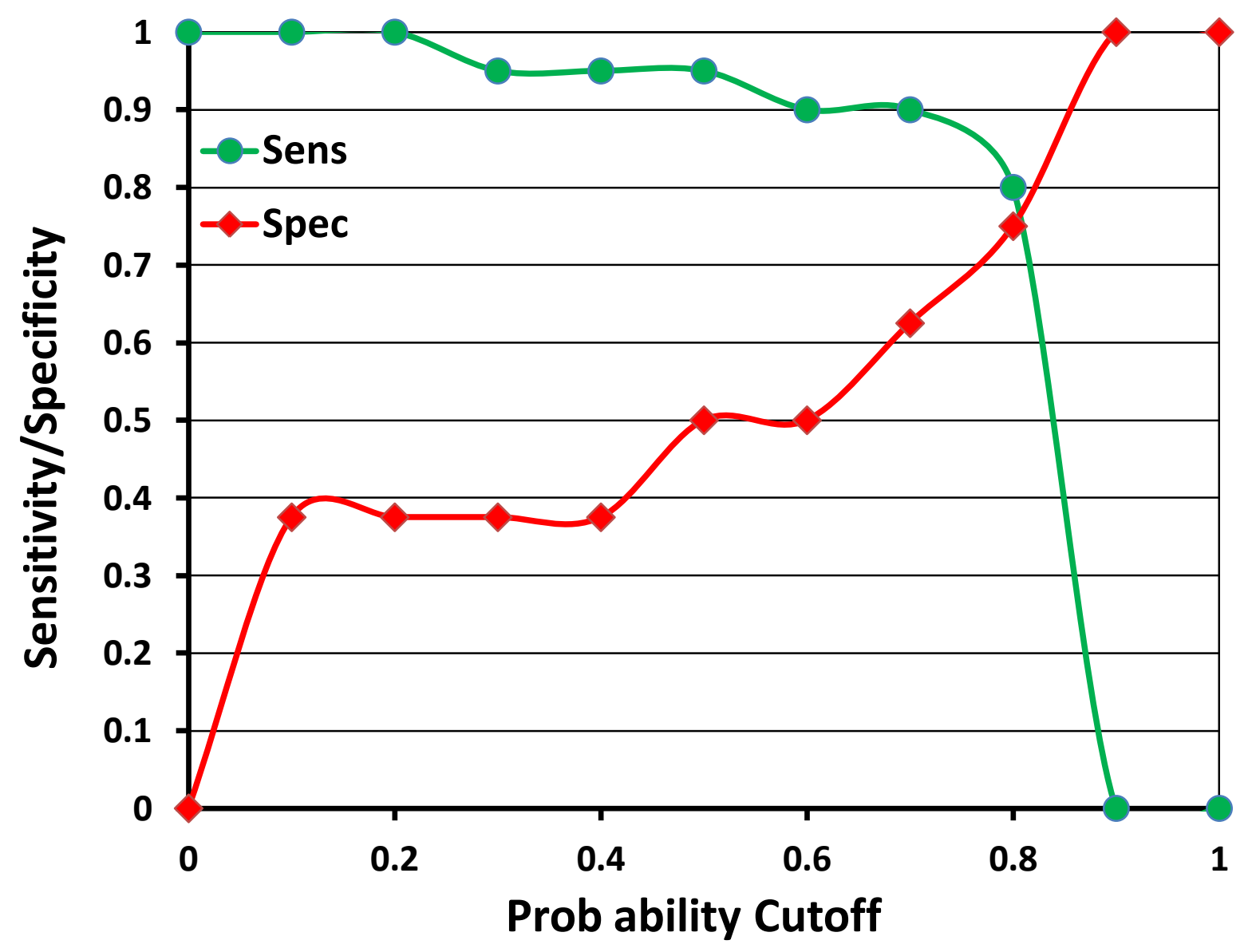

Figure 6.8: Plot of specificity and sensitivity vs cut-point for equation 6.7 showing the optimum cut-point to be about 0.8 .

This time, the optimum cut point chosen isn't 0.5 (the default model) and the design equation must be modified to fit the optimum cut-point of 0.8 . Based on the optimum cut point, the model equation can be written as:

$$
g(x)=0.775-0.0046 \mathrm{MSS}
$$

Solving equation 6.9 for the critical multiple seam stress results in:

$$
\mathrm{MSS}=168 \mathrm{psi}
$$


Based on the optimum cut-point of 0.8 , the following classification chart (Table 6.7) shows the percent correct classification for that optimum cut-point.

Table 6.7: Performance of the entry stability model against the database at the optimum cutpoint.

\begin{tabular}{|c||c|c|}
\hline & \# Correct & \% Correct \\
\hline \hline Successes & 16 & $80 \%$ \\
\hline Failures & 6 & $75 \%$ \\
\hline Overall & 22 & $79 \%$ \\
\hline
\end{tabular}

Here we see that if we use the optimum cut point of 0.8 and the resulting design equation (6.9), the model correctly predicts $75 \%$ of the failure cases, $80 \%$ of the successful cases, and $79 \%$ of the overall cases. In order to correctly classify $90 \%$ of the cases, a cut point of 0.85 must be used. Based on this cut point nearly a $90 \%$ correct classification of the failures is possible and the model equation can be written as:

$$
g(x)=0.426-0.0046 M S S
$$

Solving equation 6.11 for the critical multiple seam stress results in:

$$
\mathrm{MSS}=92 \mathrm{psi}
$$

The following classification chart (Table 6.8) shows the percent correct classification for a cutpoint of 0.85 .

Table 6.8: Performance of the entry stability model against the database at a cut point of 0.85 .

\begin{tabular}{|c||c|c|}
\hline & \# Correct & \% Correct \\
\hline \hline Successes & 11 & $55 \%$ \\
\hline Failures & 7 & $88 \%$ \\
\hline Overall & 19 & $64 \%$ \\
\hline
\end{tabular}

Here we see that if we use the a cut-point of 0.85 and the resulting design equation (6.11), the model correctly predicts $88 \%$ of the failure cases, $55 \%$ of the successful cases, and $64 \%$ of the 
overall cases. Based on this model, even though the statistical analysis says otherwise, there is no clear cut separation of the successful and unsuccessful case histories (see Figure 6.9).

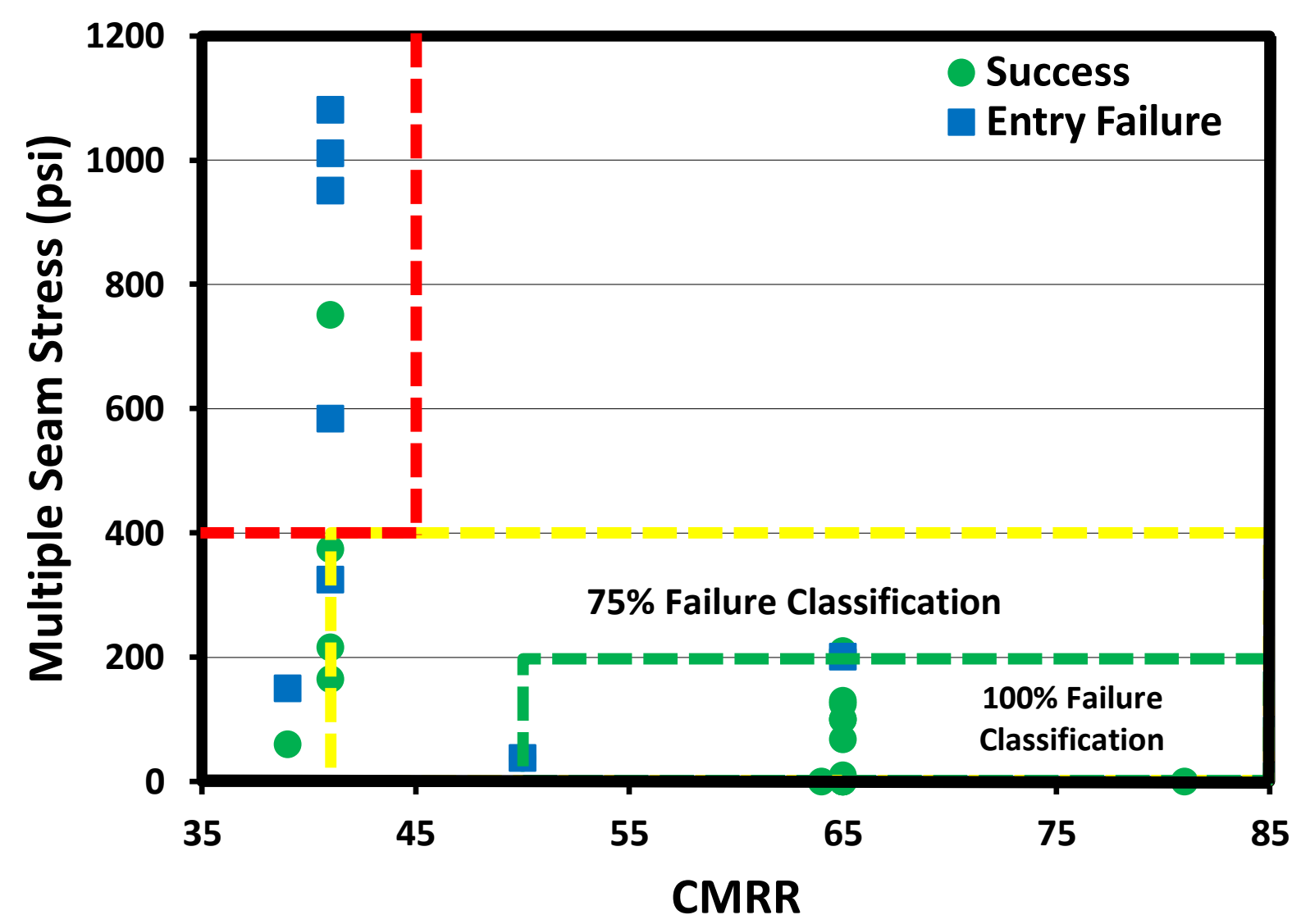

Figure 6.9: CMRR vs multiple seam stress.

However, what we do see in Figure 6.9 is that most of the cases have one of two CMRRs: a low value of about 40 and a high value of about 65 . This results in the clustering observed and the statistical correlation between the two values, and is a result of how the CMRR values were collected and the small size of the database. Instead of site specific values, which may have improved the analysis of database, only regional average values for the specific seam were available.

Of course, the design guidelines based only on the logistic regression analysis of the multiple seam stress could be used, but instead a visual analysis of the data suggests that a two parameter, 
observational approach with three categories of predicted design outcomes (similarly to AMSS) should be used in lieu of the direct statistics based approach.

\subsubsection{Green}

If the Multiple Seam Stress is less than or equal to 200 psi and the CMRR is greater than or equal to 50 then, based on observation of this database, the possibility of major local instability is considered unlikely.

\subsubsection{Yellow}

If the multiple seam stress is between 200 to $400 \mathrm{psi}$ or the CMRR is between 41 to 50 , then the possibility of major local instability is considered elevated. It is recommended that, at a minimum, additional supplemental support should be installed.

\section{$\underline{6.3 .3 \mathrm{Red}}$}

The area where the multiple seam stress is greater than 400 psi and the CMRR is less than 45 corresponds to the portion of the database where there was only one observed successful case history. Additionally, there are no successful case histories observed in the database when the multiple seam stress is greater than 800 psi. For these cases, significant local instability should be considered likely.

It should be noted that many of the parameters used to analyze the AMSS database such as the total vertical stress, overmining vs. undermining, the interburden thickness, supplemental support, and remnant pillar vs. gob-solid boundary were not used in the analysis of the shallow cover database. Some of the reasons for this are that the values for most of these parameters 
were unknown, the small size of the database, and cases where there were multiple simultaneous multiple seam interactions. For example, the determination that the interburden thickness was not statistically significant goes against the findings of both Mark et al. (2007) and Haycocks and Zhou (1990), on the other hand, the interburden thickness in incorporated into the multiple-seam stress. The fact of the matter is simple: The database is simply too small and not diverse enough to allow detailed, highly significant statistical inferences to be made about the entry failure subset of the data. Now that the shallow cover database has been analyzed, it would be logical to compare the shallow cover to the deep cover database.

\subsection{Combining the Shallow Cover and Deep Cover Databases}

The Deep Cover Database, as detailed in the literature review (Chapter 2) consisted of 47 pillar retreat cases from 11 mines and depths of cover ranging from $750 \mathrm{ft}$ to $2200 \mathrm{ft}$. Again, this resulted in less than a $10 \%$ chance of failure, based on the database, when using a stability factor greater than or equal to 1.4 (Heasley et al., 2010). This previous research provided the basis for ceasing the downward trend of the shallow cover design curve when the required stability factor reached the design stability factor required for the deep cover database. By using this preestablished minimum required stability factor for both results, both the deep cover database and the pillar failure subset of the shallow cover database can be displayed on the same chart (Figure 6.10) with a consistent design line. The result of combining the two databases increases the scope of the LaModel database to 77 case histories from 18 mines with depths ranging from 200 $\mathrm{ft}$ to $2,200 \mathrm{ft}$. 


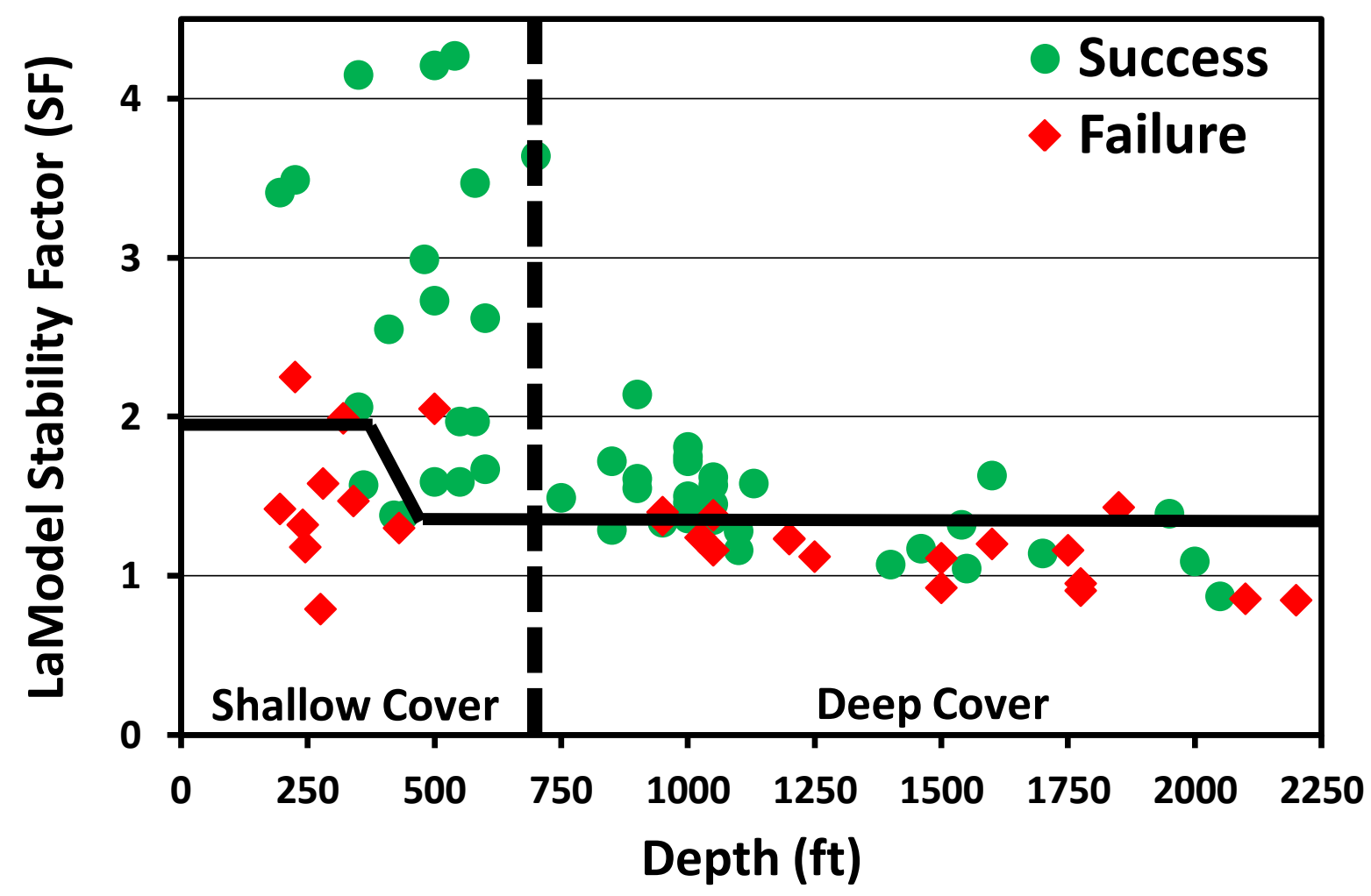

Figure 6.10: Design guidelines for approximately $90 \%$ correct failure classification.

Obviously, some caution must be observed when using the combined database of shallow cover and deep cover case histories. One must remember that two different LaModel calibration techniques were used to analyze the two databases. As mentioned in great detail, the shallow cover database was calibrated using a constant $50 \mathrm{ft}$ lamination thickness followed by a calibrated gob modulus based on the abutment angle concept. In contrast, the deep cover database used both a calibrated lamination thickness based on the abutment extent followed by a gob modulus that was calibrated based on the abutment angle concept. The vertical bold, dashed line at a depth of 725 feet represents the point where the shallow cover and deep cover databases are separated. It is imperative that one does not confuse the two calibration techniques. An additional limitation results from a lack of data at the ends of the two databases. Technically, there are no case histories from either database between depths of $700 \mathrm{ft}$ and $750 \mathrm{ft}$. Using 
values within this range would require extrapolation outside the range of the database.

Fortunately, this range is relatively small but, there are also no failure cases in either database between depths of $500 \mathrm{ft}$ and $950 \mathrm{ft}$. While this isn't technically considered extrapolation outside the bounds of the database, some degree of caution should be considered when using depth values within this range.

This combination of the two databases follows a similar trend to the ARMPS 2002 database where this 


\section{Chapter 7}

\section{Application}

The provide the end user with a case study demonstration, the average case history used to determine a suitable calibration method will be will be used. In order to calibrate the LaModel program using the method for shallow cover, multiple-seam mines, it is first assumed that the user has already completed the Project Parameters and the Seam Geometry forms. At this point, Rock Mass Parameters must be determined. Ensure that the default values for the Poisson's Ratio, Elastic Modulus, Lamination Thickness, and Vertical Stress Gradient are the same as those that appear in Figure 7.1.

\section{OrerBurden / Rock Mass Parameters}

- Overburden / RockMass Parameters
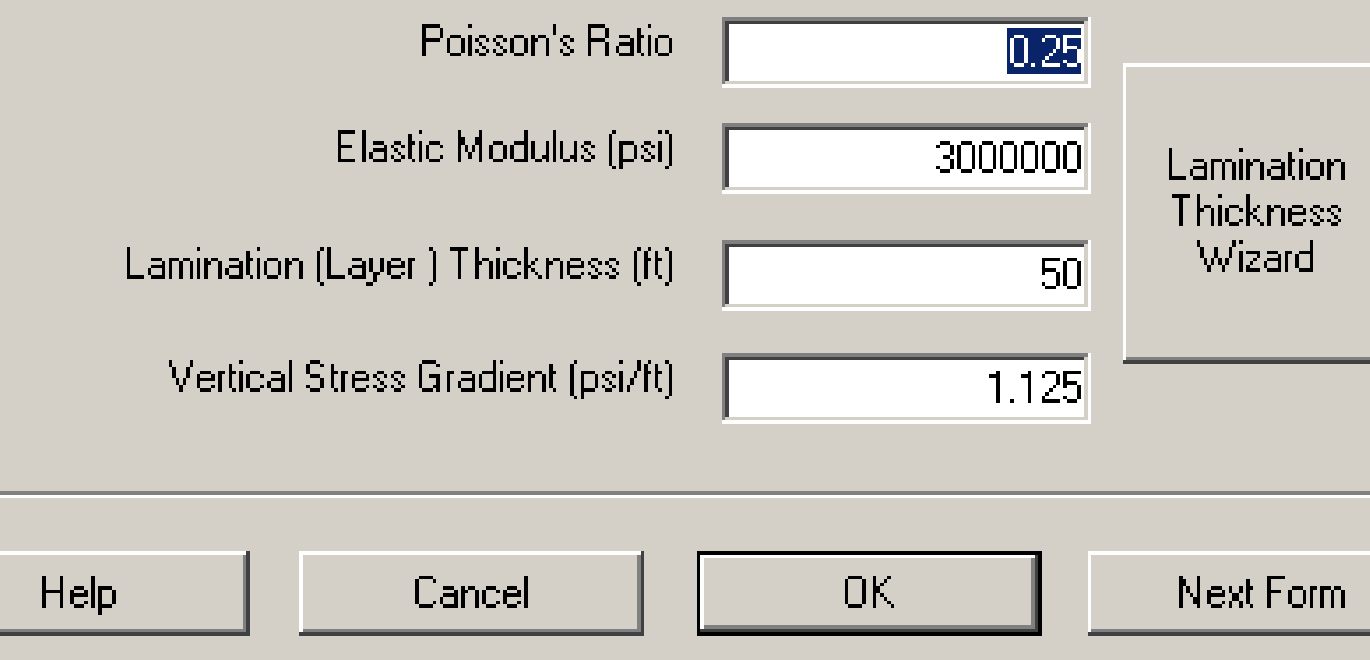

Next Form

Figure 7.1: Default Overburden / Rock Mass Parameters in the LaModel program.

Once this is complete, the seam materials must then be calibrated and created. First, the coal materials are created using the Elastic-Plastic for COAL Wizard using the form in Figure 7.2. 


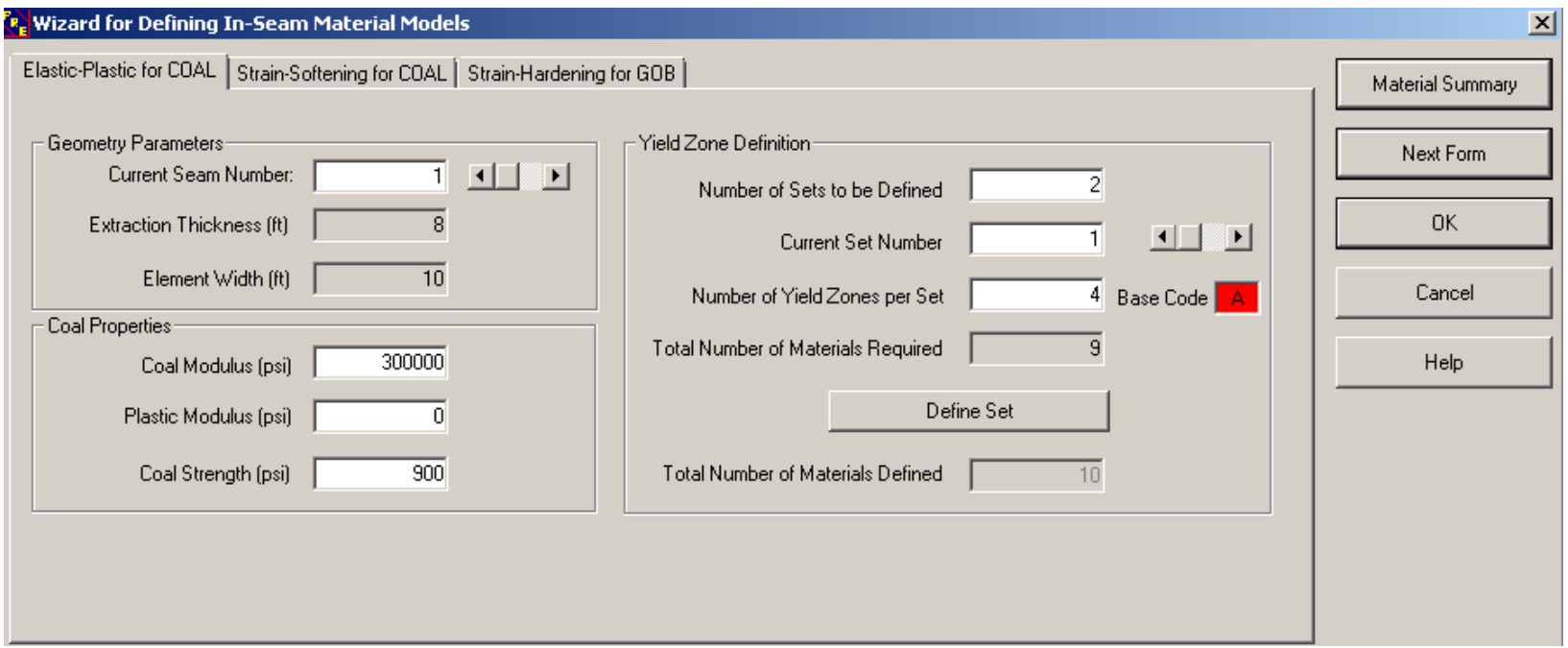

Figure 7.2: Elastic-Plastic for COAL Material Wizard

Default or previously entered values are already filled out in the form. Note the default Coal Strength of 900 psi, which was used to analyze the database and will be used in this example. If one uses a value other than 900 psi, which may or may not result in a better analysis, the model will no longer be consistent with the shallow cover database and the design guidelines from this research are no longer valid. The portion of the form that must be filled in is the Yield Zone Definition section. Because there are two seams with different parameters, two sets are defined. The first seam, the current set, requires four yield zones per set and 9 materials. Clicking define set then creates the coal materials for seam one. The same procedure is followed for the remaining seams.

Now that the coal materials have been created, the gob properties must be calibrated and created. This is done by using the Strain-Hardening for GOB Material Wizard (see Figure 7.3). 


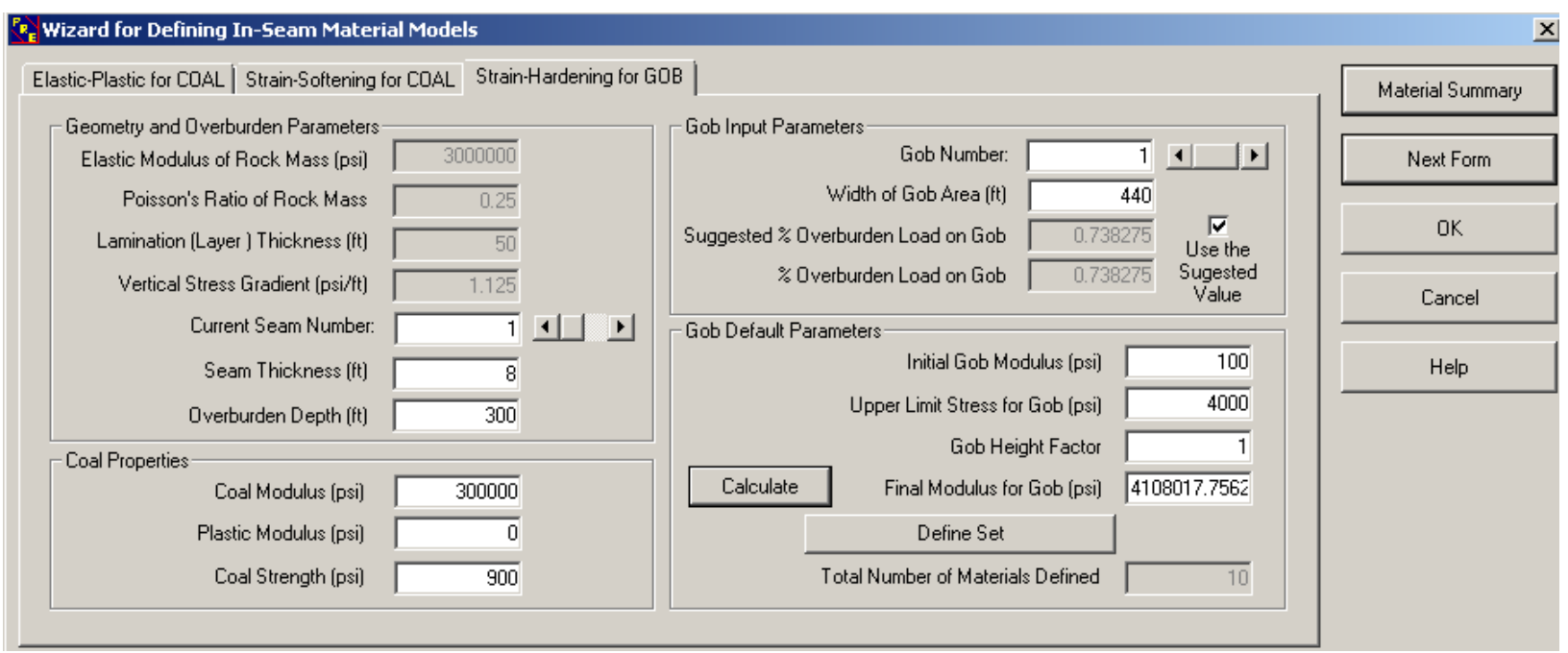

Figure 7.3: Strain-Hardening for GOB Material Wizard

The Gob Wizard is appears a bit more complicated than the Coal Wizard based on the number of input parameters. However, the Geometry and Overburden Parameters as well as the Coal Properties that have already been input on previous forms are automatically filled out in this form. The only parameter that changes in the Geometry and Overburden Parameters form is the Current Seam Number. In this case, the current seam is one and it would be changed to any of the other seams to create multiple gob materials.

The Gob Input Parameters allow the user to select the Gob Number, in this case one; because only one gob material is being created for seam one. In order to calibrate the gob material, both the Width of Gob Area and the \% Overburden Load on Gob parameters must be input by the user. In this case the user selects "Use the Suggested Value," then clicks the Calculate button in the Gob Default Parameters subsection resulting in the calibrated final gob modulus.

Once the seam materials have been defined, then the seam grid can be created. For this example, the seam grid matches the input data for the average case in Table 5.1. Additionally, a box has been drawn around the area that encompasses the AMZ. Specifically, the AMZ at a depth of $300 \mathrm{ft}$ has a breadth of $86 \mathrm{ft}$, which is then rounded to $90 \mathrm{ft}$. 


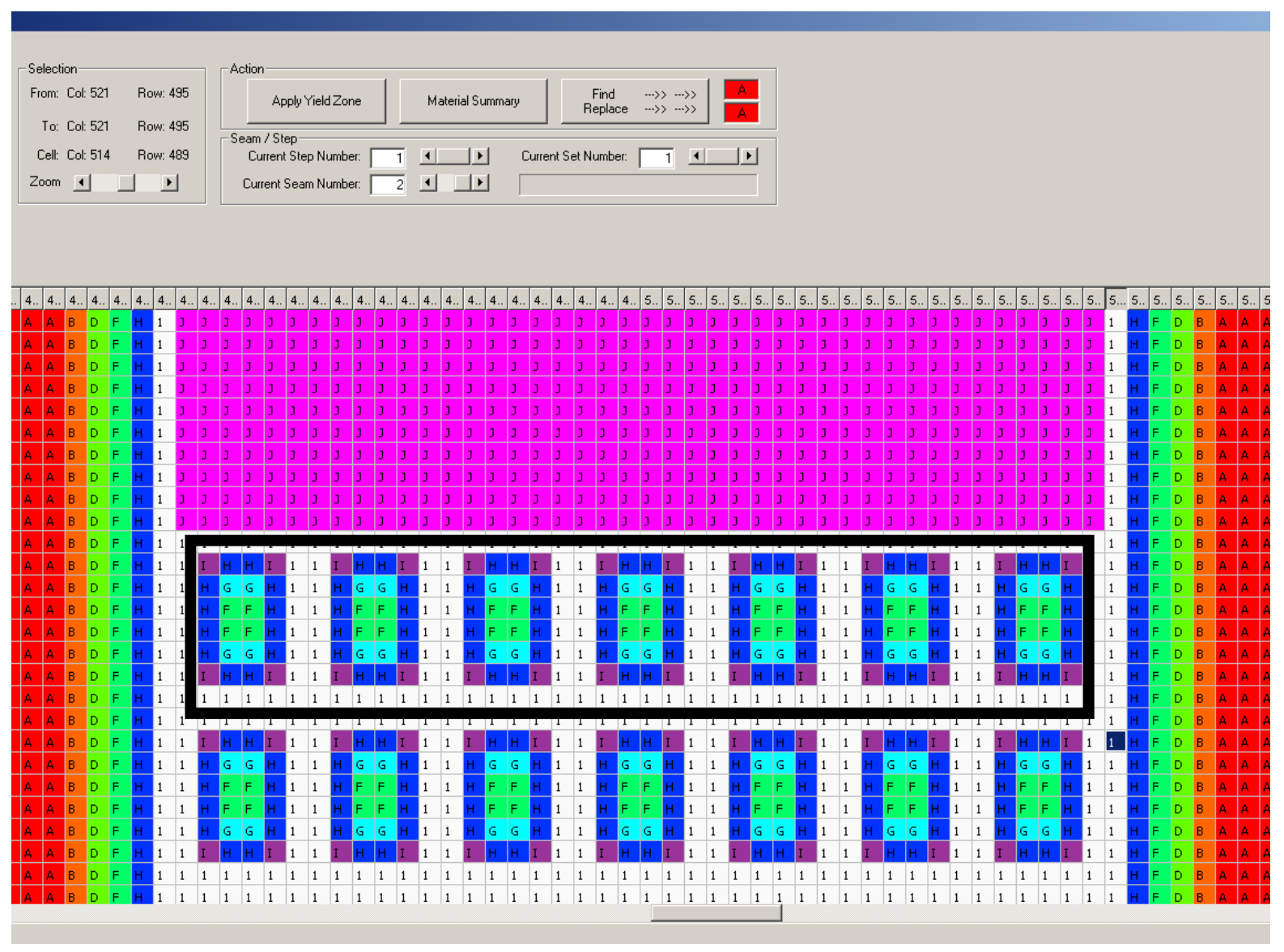

Figure 7.4 The seam grid for the average case.

Once the model has finished running, the analysis of the output is preformed. First, in order to determine global stability, calculate the pillar stability factor using a weighted average of the pillars, or portions thereof within the AMZ (see Table 7.1).

Table 7.1: LaModel stability factor calculation.

\begin{tabular}{|c|c|c|c|}
\hline Pillar & \# Elements & SF & \# Element X SF \\
\hline $\mathbf{1}$ & 24 & 3.0497 & 73.1928 \\
\hline $\mathbf{2}$ & 24 & 2.6524 & 63.6576 \\
\hline $\mathbf{3}$ & 24 & 2.5771 & 61.8504 \\
\hline $\mathbf{4}$ & 24 & 2.5671 & 61.6104 \\
\hline $\mathbf{5}$ & 24 & 2.5771 & 61.8504 \\
\hline $\mathbf{6}$ & 24 & 2.6524 & 63.6576 \\
\hline $\mathbf{7}$ & 24 & 3.0497 & 73.1928 \\
\hline Total & 168 & $\mathbf{2 . 7 3}$ & 459.012 \\
\hline Average & \multicolumn{3}{|l}{} \\
\hline
\end{tabular}


If part of a pillar is contained within the AMZ, then only the number of elements within the AMZ is counted for the calculation of the LaModel stability factor. With a stability factor of

2.73, the global stability criterion has been met and the local stability must then be assessed. To assess the local stability, observe the maximum multiple seam stress and the average CMRR for the area and determine if the particular case falls within the green, yellow, or red zones. 


\section{Chapter 8}

\section{Conclusions}

Several significant results can be drawn from the logistic regression analysis of the shallow cover database. Before discussing these in detail, it should be noted that to be statistically correct, these conclusions are only valid within the bounds of this database. The end user should always be cautious when extrapolating beyond these bounds.

Initially, a calibration procedure very similar to the existing deep cover calibration (Heasley et al., 2010) was developed for the shallow cover database and use the same wizards implemented into the LamPre 3.0 program. This allows the user to easily produce a standardized, calibrated model.

Then, the calibrated model results are compared with the analysis of the shallow cover database to allow an empirical determination the probability of success. To determine a suitable pillar size with an acceptably low probability of failure, use the following design guidelines.

- If the depth is less than $350 \mathrm{ft}$, use an $\mathrm{AMZ}$ stability factor greater than or equal to 2.0

- If the depth is greater than $450 \mathrm{ft}$, use an AMZ stability factor greater than or equal to 1.4 ,

- If the depth is between 350 and $450 \mathrm{ft}$, use an AMZ stability factor between 2.0 and 1.4 as determined by equation 6.6.

The massive pillar collapses show up in the database as pillar failures at very low depths $(<350 \mathrm{ft})$ and with very thin pillars $(\mathrm{w} / \mathrm{h}<3)$. With these narrow pillar widths, any spalling of the 
pillar or any geologic anomaly in the pillar can greatly reduce its strength; therefore, it seems reasonable to require a stability factor of 2.0 to guarantee section stability. This is the same situation that was found in the analysis of massive pillar collapses by Mark et al. (1997), where they recommend an ARMPS stability of 2.0 to prevent the pillar collapses versus a "normal" recommended ARMPS stability factor of 1.5. In the analysis of the shallow cover database in this paper, it appears that a stability factor of 2.0 should be used up to a depth of about $350 \mathrm{ft}$ and then the recommended deep cover stability factor of 1.4 appears suitable for all greater depths of cover.

Design guidelines based on the entry failure subset of the database are a bit less intuitive because they are based on observation of the database rather than pure statistical analysis. Design guidelines are based on these three categories of possible outcomes based on the database.

\section{Green}

Major local instability is unlikely if the Multiple Seam Stress is less than or equal to 200 psi and the CMRR is greater than or equal to 50 then.

\section{$\underline{\text { Yellow }}$}

The possibility of major local instability is considered elevated if the multiple seam stress is between 200 and 400 psi and the CMRR is between 41 and 50.

\section{$\underline{\text { Red }}$}

Major local instability is likely where the multiple seam stress is greater than 400 psi and the CMRR is less than 45 and highly likely when the Multiple Seam Stress is greater than 800 psi and the CMRR is less than 45 . 
This calibration procedure and associated design guidelines are yet another major milestone in the development of LaModel, because this database is in essence an extension of the deep cover database providing recommendations for a much wider range of cover depths, and also, multiple-seam interactions. 


\section{Chapter 9}

\section{Suggestions for Future Research}

Just as it is with all research studies, there are always limitations to its use and room for improvement. First, there is obvious room for expansion of the database. Increasing the sample size will allow for more accurate design guidelines and will probably result in an increased range of the database allowing less room for extrapolation for parameters such as the CMRR. Looking at the combined database, one can see a clear gap in the failure case histories at depths between $500 \mathrm{ft}$ and $950 \mathrm{ft}$. Moving forward, the addition of actual CMRR values as well as bolt design and the use of supplemental support could prove beneficial.

Additionally, some of the suggestions from the deep cover database have yet to be addressed such as better approximations for the abutment loading and gob loading. Recent advances by Tulu and Heasley (2012) in the area of abutment loading could prove to increase accuracy in the calibration resulting in a better analysis of the database. This work only considered elasticplastic coal elements and ignored the possibility that strain-softening coal elements might better model the database. Planned improvements to the LaModel program with a wizard which will make using strain-softening coal properties much easier could be an improvement. This could result in getting better approximations of pillar failures and again improve database analysis. The lamination thickness controlling rock mass stiffness was also held to a constant $50 \mathrm{ft}$. This research only briefly considers different calibration techniques which might yield better results. Additionally, a softer overburden was desired in order to get better multiple seam stresses. Since this proved to be a moot point due to the small size of the database, the original calibration 
calculations could more than likely be used without much change in the results. This would allow the deep cover and shallow cover databases to be more readily combined. 


\section{References}

Bieniawski, Z.T. (1968). "The Effect of Specimen Size on Compressive Strength of Coal.” In: International Journal of Rock Mechanics and Mining Sciences. 5:325-335.

Bieniawski Z.T. (1981). "Improved Design of Coal Pillars for U.S. Mining Conditions.” In: Proceedings of the $1^{\text {st }}$ International Conference on Ground Control in Mining, pp. 13-22.

Bunting, D. (1911). "Chamber Pillars in Deep Anthracite Mines." In: Transactions of the American Institute of Mining, Metallurgical, and Petroleum Engineers, vol. 42. pp. 236245.

Chase, F.E., Zipf, R.K., Mark, C. (1994). "The Massive Collapse of Coal Pillars - Case Histories from the United States." In: Proceedings of the $13^{\text {th }}$ International Conference on Ground Control in Mining, pp. 1-12.

Gates, R.A., Gauna, M., Morley, T.A., O’Donnell, J.R., Smith, G.E., Watkins, T.R., Weaver, C.A., Zelanko, J.C. (2008) "Report of Investigation, Fatal Underground Coal Burst Accidents, August 6 and 16, 2007, Crandall Canyon Mine.” [http://www.msha.gov/ Fatals/2007/CrandallCanyon/FTL07CrandallCanyon.pdf].

Hardy, R., Heasley, K.A. (2006). "Enhancements of the LaModel Stress Analysis Program." Presented at Society of Mining Engineers Annual Meeting. St. Louis, MO: March 26-29. Pre-print 06-067, 7 pp.

Haycocks, C., Zhou, Y. (1990). “Multiple-Seam Mining - A State-of-the-Art Review.” In: Proceedings of the $9^{\text {th }}$ International Conference on Ground Control in Mining, pp. 1-11.

Heasley, K.A. (1998). "Numerical modeling of coal mines with a laminated displacementdiscontinuity code." PhD dissertation. Golden, CO: Colorado School of Mines, 187 pp. 
Heasley, K.A. (2011). “A retrospective on LaModel (or Dr. Heasley's wild ride).” In: Proceedings of the $30^{\text {th }}$ International Conference on Ground Control in Mining, pp. 2129.

Heasley, K.A. (2012). "Calibrating the LaModel Program for Site Specific Conditions.” In: Proceedings of the $31^{\text {st }}$ International Conference on Ground Control in Mining, pp. 1-8.

Heasley, K.A., Agioutantis, Z. (2001). "LAMODEL - a boundary element program for coal mine design." In: Proceedings of the $10^{\text {th }}$ International Conference on Computer Methods and Advances in Geomechanics. Taylor \& Francis, pp. 1678-1682.

Heasley, K.A., Agioutantis, Z., Wang, Q. (2003). “Automatic grid generation allows faster analysis of coal mines." In: Transactions of the Society of Mining, Metallurgy and Exploration, Inc., vol. 314. Englewood, CO: Society of Mining, Metallurgy and Exploration, pp. $75-80$.

Heasley, K.A., Sears, M.M., Tulu, I.B., Calderon-Arteaga, C.H., Jimison II, L.W. (2010). "Calibrating the LaModel program for deep cover pillar retreat coal mining." In:

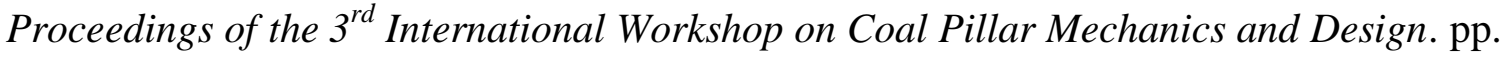
47-57. Presented in Morgantown, WV: July 26-29.

Hosmer, D.W., Lemeshow, S. (2000). Applied Logistic Regression. NY: Wiley, 375 pp.

Mark, C. (1990). “Pillar Design Methods for Longwall Mining.” Pittsburgh, PA: U.S. Deptartment of the Interior, Bureau of Mines, IC 9247.

Mark C. (1992). “Analysis of Longwall Pillar Stability (ALPS): an Update.” In: Proceedings of the Workshop on Coal Pillar Mechanics and Design. Pittsburgh, PA: U.S. Department of the Interior, Bureau of Mines, IC 9315, pp. 238-249. 
Mark, C. (1999). "Emperical Methods for Coal Pillar Design." In: Proceedings of the $2^{\text {nd }}$ International Workshop on Coal Pillar Mechanics and Design. Pittsburgh, PA: National Institute for Occupational Safety and Health, IC 9448, pp. 145-154.

Mark, C. (2009). "Deep cover pillar recovery in the U.S." In: Proceedings of the $28^{\text {th }}$ International Conference on Ground Control in Mining, pp. 1-9.

Mark, C. (2010). "Pillar design for deep cover retreat mining: ARMPS version 6 (2010)." In:

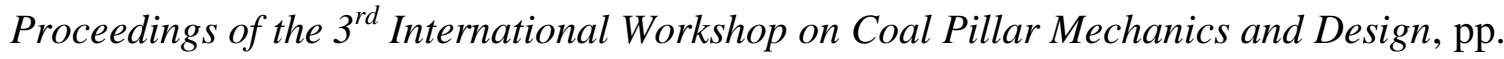
106-119. Presented in Morgantown, WV: July 26-29.

Mark, C., Barton, T.M. (1996). "The Uniaxial Compressive Strength of Coal: Should it be Used to Design Pillars?." In: Proceedings of the $15^{\text {th }}$ International Conference on Ground Control in Mining, pp. 61-78.

Mark, C., Chase, F.E. (1997). “Analysis of Retreat Mining Pillar Stability (ARMPS).” In: Mark, C., Tuchman, R.J., eds. Proceedings New Technology for Ground Control in Retreat Mining. Pittsburgh, PA: National Institute for Occupational Safety and Health, IC 9446, pp. 17-34.

Mark, C., Chase, F.E., Campoli, A.A. (1995). “Analysis of Retreat Mining Pillar Stability.” In: Proceedings of the $14^{\text {th }}$ International Conference on Ground Control in Mining, pp. 4959.

Mark, C., Chase, F.E., Pappas, D.M. (2007). "Multiple-seam mining in the United States: design based on case histories.” In: Mark, C., Tuchman, R.J., eds. Proceedings New Technology for Ground Control in Multiple-seam Mining. Pittsburgh, PA: National Institute for Occupational Safety and Health, IC 9495, pp. 15-27. 
Mark, C., Chase, F.E., Zipf, R.K. (1997). "Preventing massive pillar collapses in coal mines.” In: Mark, C., Tuchman, R.J., eds. Proceedings New Technology for Ground Control in Retreat Mining. Pittsburgh, PA: National Institute for Occupational Safety and Health, IC 9446, pp. 35-48.

Mark, C., Gauna, M., Cybulski, J., Karabin, G. (2011). “Applications of ARMPS (Version 6) to Practical Pillar Design Problems." In: Proceedings of the $30^{\text {th }}$ International Conference on Ground Control in Mining, pp. 1-9.

Molinda, G., Mark, C. (1993). “The Coal Mine Roof Rating (CMRR) - A Practical Rock Mass Classification for Coal Mines." In: Proceedings of the $12^{\text {th }}$ International Conference on Ground Control in Mining, pp. 92-104.

Obert, L., Duvall, W.I. (1967). Rock Mechanics and the Design of Structures in Rock. NY: Wiley, $650 \mathrm{pp}$.

Pappas, D.M. (2013). Email interview.

Pappas, D.M., Mark, C. (2012). "Roof and rib fall incident trends: a 10-year profile.” In: Transactions of the Society of Mining, Metallurgy and Exploration, Inc., vol. 330. Englewood, CO: Society of Mining, Metallurgy and Exploration, pp. 462-478.

Peduzzi, P., Concato, J., Kemper, E., Holford, T.R., Feinstein, A.R. (1996). “A Simulation Study of the Number of Events per Variable in Logistic Regression Analysis.” In: Journal of Clinical Epidemiology. 49:1373-9.

R Development Core Team (2011). "R: A language and environment for statistical computing." Vienna, Austria: R Foundation for Statistical Computing. ISBN 3-900051-07-0. [http://www.R-project.org/]. 
Salamon, M.D.G., Munro, A.H. (1967). "A study of the strength of coal pillars.” In: Journal of the South African Institute of Mining and Metallurgy. 68:55-67.

Sears, M.M., Heasley, K.A. (2009). “An application of energy release rate.” In: Proceedings of the $28^{\text {th }}$ International Conference on Ground Control in Mining, pp. 10-17.

Tulu, I.B., Heasley, K.A. (2012). "Investigating abutment load.” In: Proceedings of the $31^{\text {st }}$ International Conference on Ground Control in Mining, pp. 1-10. 


\section{Appendix A - The Shallow Cover Database}

Table A.1: The deep cover database.

\begin{tabular}{|c|c|c|c|c|c|c|c|c|c|}
\hline Mine & Case & $\begin{array}{l}\text { Mining } \\
\text { Height }\end{array}$ & $\begin{array}{l}\text { Overburden } \\
\text { Depth }\end{array}$ & $\begin{array}{l}\text { Crosscut } \\
\text { Spacing }\end{array}$ & $\begin{array}{c}\text { Number } \\
\text { of Entries }\end{array}$ & $\begin{array}{l}\text { Pillar } \\
\text { Plan }\end{array}$ & $\begin{array}{c}\text { Extent of } \\
\text { Active } \\
\text { Gob }\end{array}$ & $\begin{array}{c}\text { Extent of } \\
\text { First } \\
\text { Side Gob }\end{array}$ & $\begin{array}{c}\text { Extent of } \\
\text { 2nd Side } \\
\text { Gob }\end{array}$ \\
\hline $\mathrm{N}$ & $1 \mathrm{~B}$ & 5 & 610 & 100 & 6 & 70 & 365 & NA & NA \\
\hline $\mathrm{N}$ & $2 B$ & 5 & 640 & 100 & 6 & 70 & 785 & NA & NA \\
\hline $\mathrm{N}$ & $3 B$ & 5 & 615 & 100 & 6 & 70 & 1500 & NA & NA \\
\hline $\mathrm{N}$ & $9 \mathrm{~N}$ & 5 & 500 & 90 & 5 & 85 & NA & NA & NA \\
\hline $\mathrm{N}$ & $8 S$ & 5 & 460 & 75 & 7 & 55 & 445 & NA & NA \\
\hline$Q$ & 1 & 7 & 375 & 60 & 8 & 50 & NA & NA & NA \\
\hline 0 & 1 & 6.5 & 340 & 65 & 7 & 50 & NA & NA & NA \\
\hline$P$ & 3 & 4 & 650 & 100 & 5 & 70 & 1000 & 525 & NA \\
\hline$R$ & 1 & 10.5 & 320 & 100 & 7 & 50 & 220 & NA & NA \\
\hline$Q$ & 1 & 7 & 500 & 60 & 8 & 50 & NA & NA & NA \\
\hline$S$ & 1 & 13 & 430 & 80 & 7 & 55 & 360 & NA & NA \\
\hline$S$ & 5 & 13 & 340 & 80 & 7 & 55 & 400 & 500 & NA \\
\hline $\mathrm{T}$ & 1 & 9.5 & 275 & 60 & 17 & 30 & NA & NA & NA \\
\hline$U$ & 1 & 10 & 240 & 80 & 12 & 30 & NA & NA & NA \\
\hline$U$ & 2 & 10 & 245 & 60 & 12 & 30 & NA & NA & NA \\
\hline$U$ & 3 & 10 & 280 & 60 & 12 & 40 & NA & NA & NA \\
\hline $\mathrm{V}$ & 1 & 10 & 195 & 60 & 15 & 30 & NA & NA & NA \\
\hline$W$ & 1 & 11 & 225 & 50 & 12 & 50 & NA & NA & NA \\
\hline $\mathrm{N}$ & $4 S$ & 5 & 580 & 80 & 8 & 60 & 560 & NA & NA \\
\hline $\mathrm{N}$ & $5 S$ & 5 & 550 & 80 & 8 & 60 & 880 & NA & 360 \\
\hline $\mathrm{N}$ & $6 S$ & 5 & 410 & 80 & 6 & 65 & 800 & NA & NA \\
\hline $\mathrm{N}$ & $7 S$ & 5 & 480 & 80 & 4 & 65 & 500 & 885 & NA \\
\hline$R$ & 2 & 11 & 500 & 60 & 10 & 60 & NA & NA & NA \\
\hline $\mathrm{R}$ & 5 & 11 & 550 & 80 & 10 & 45 & NA & NA & NA \\
\hline$R$ & 6 & 11 & 600 & 85 & 10 & 60 & NA & NA & NA \\
\hline$Q$ & 2 & 7 & 350 & 60 & 8 & 50 & NA & NA & NA \\
\hline $\mathrm{O}$ & 2 & 6.5 & 350 & 70 & 5 & 55 & NA & NA & NA \\
\hline$P$ & 1 & 4 & 500 & 100 & 6 & 70 & 1000 & 525 & NA \\
\hline$P$ & 2 & 4 & 700 & 100 & 4 & 70 & 1000 & 525 & NA \\
\hline $\mathrm{L}$ & 1 & 5.4 & 580 & 95 & 5 & 60 & 600 & NA & NA \\
\hline$L$ & 2 & 5.2 & 500 & 100 & 6 & 55 & 500 & 320 & NA \\
\hline$L$ & 3 & 5 & 600 & 100 & 6 & 55 & 1000 & 335 & NA \\
\hline$L$ & 4 & 5.1 & 540 & 90 & 4 & 65 & 800 & NA & NA \\
\hline$S$ & 2 & 13 & 360 & 80 & 7 & 55 & 800 & NA & NA \\
\hline$S$ & 3 & 11 & 440 & 110 & 9 & 55 & 600 & NA & NA \\
\hline$S$ & 4 & 11 & 420 & 110 & 7 & 55 & 600 & 400 & NA \\
\hline $\mathrm{V}$ & 2 & 10 & 195 & 60 & 8 & 60 & 1000 & NA & NA \\
\hline$w$ & 2 & 11 & 225 & 60 & 10 & 60 & 400 & NA & NA \\
\hline
\end{tabular}




\begin{tabular}{|c|c|c|c|c|c|c|c|c|c|}
\hline Mine & Case & $\begin{array}{c}\text { Barrier } \\
\text { Pillar } \\
\text { Width }\end{array}$ & $\begin{array}{c}\text { Barrier } \\
\text { Pillar } \\
\text { Width2 }\end{array}$ & $\begin{array}{l}\text { Slab Cut } \\
\text { Depth }\end{array}$ & $\begin{array}{c}\text { Slab Cut } \\
\text { Depth2 }\end{array}$ & $\begin{array}{c}\text { Success } \\
\text { or } \\
\text { Failure }\end{array}$ & $\begin{array}{c}\text { Multiple } \\
\text { Seam }\end{array}$ & $\begin{array}{l}\text { LaModel } \\
\text { Stress SF }\end{array}$ & $\begin{array}{c}\text { Multiple } \\
\text { Seam } \\
\text { Stress }\end{array}$ \\
\hline $\mathrm{N}$ & $1 \mathrm{~B}$ & 1000 & 1000 & 30 & 30 & $F$ & $\mathrm{Y}$ & 2.69 & 951 \\
\hline $\mathrm{N}$ & $2 B$ & 1000 & 1000 & 30 & 30 & $F$ & $\bar{Y}$ & 2.77 & 1081 \\
\hline $\mathrm{N}$ & $3 B$ & 1000 & 1000 & 30 & 30 & $\mathrm{~F}$ & $\bar{Y}$ & 2.61 & 584 \\
\hline $\mathrm{N}$ & $9 \mathrm{~N}$ & NA & NA & NA & $\mathrm{NA}$ & $\mathrm{F}$ & $\mathrm{Y}$ & 4.41 & 325 \\
\hline $\mathrm{N}$ & $8 S$ & 1000 & 1000 & NA & $\mathrm{NA}$ & $\mathrm{F}$ & $\mathrm{Y}$ & 2.19 & 1011 \\
\hline$Q$ & 1 & NA & NA & NA & $\mathrm{NA}$ & $\mathrm{F}$ & $Y$ & 3.26 & 38 \\
\hline $\mathrm{O}$ & 1 & NA & $\mathrm{NA}$ & NA & $\mathrm{NA}$ & $\mathrm{F}$ & $\mathrm{Y}$ & 2.94 & 150 \\
\hline $\bar{P}$ & 3 & 60 & 1000 & 30 & 70 & $F$ & $\bar{Y}$ & 1.97 & 201 \\
\hline $\mathrm{R}$ & 1 & 1000 & NA & 170 & $\mathrm{NA}$ & $\mathrm{F}$ & $Y$ & 1.99 & 12 \\
\hline$Q$ & 1 & NA & NA & NA & $\mathrm{NA}$ & $\mathrm{F}$ & $\mathrm{Y}$ & 2.05 & 33 \\
\hline$S$ & 1 & NA & NA & NA & NA & $F$ & $\mathrm{~N}$ & 1.30 & 0 \\
\hline$S$ & 5 & $\mathrm{NA}$ & NA & NA & $\mathrm{NA}$ & $\mathrm{F}$ & $\mathrm{N}$ & 1.47 & 0 \\
\hline$T$ & 1 & NA & NA & NA & NA & $\mathrm{F}$ & $\mathrm{N}$ & 0.79 & 0 \\
\hline$U$ & 1 & NA & NA & NA & $\mathrm{NA}$ & $\mathrm{F}$ & $\mathrm{N}$ & 1.32 & 0 \\
\hline$U$ & 2 & NA & NA & NA & $\mathrm{NA}$ & $\mathrm{F}$ & $\mathrm{N}$ & 1.18 & 0 \\
\hline$U$ & 3 & NA & NA & NA & NA & $F$ & $\mathrm{~N}$ & 1.58 & 0 \\
\hline $\mathrm{V}$ & 1 & NA & NA & NA & NA & $\mathrm{F}$ & $\mathrm{N}$ & 1.42 & 0 \\
\hline$W$ & 1 & NA & NA & NA & $\mathrm{NA}$ & $\mathrm{F}$ & $\mathrm{N}$ & 2.25 & 0 \\
\hline $\mathrm{N}$ & $4 \mathrm{~S}$ & 1000 & 1000 & 35 & NA & $S$ & $Y$ & 1.97 & 374 \\
\hline $\mathrm{N}$ & $5 S$ & 1000 & 250 & 35 & NA & $S$ & $\mathrm{Y}$ & 1.97 & 751 \\
\hline $\mathrm{N}$ & $6 S$ & 1000 & 1000 & 65 & 125 & $S$ & $\mathrm{Y}$ & 2.55 & 216 \\
\hline $\mathrm{N}$ & $7 S$ & 275 & 1000 & NA & NA & $S$ & $\bar{Y}$ & 2.99 & 165 \\
\hline $\mathrm{R}$ & 2 & $\mathrm{NA}$ & NA & NA & $\mathrm{NA}$ & $S$ & $Y$ & 1.59 & 10 \\
\hline $\mathrm{R}$ & 5 & NA & NA & NA & NA & $S$ & $\mathrm{~N}$ & 1.59 & 0 \\
\hline $\mathrm{R}$ & 6 & NA & NA & NA & NA & $S$ & $\mathrm{~N}$ & 1.67 & 0 \\
\hline$Q$ & 2 & $\mathrm{NA}$ & NA & NA & $\mathrm{NA}$ & $S$ & $\mathrm{Y}$ & 2.06 & 38 \\
\hline 0 & 2 & NA & NA & NA & NA & $\mathrm{S}$ & $\mathrm{Y}$ & 4.15 & 60 \\
\hline $\mathrm{P}$ & 1 & 50 & 1000 & 30 & 30 & $S$ & $Y$ & 4.21 & 68 \\
\hline $\mathrm{P}$ & 2 & 60 & 1000 & 30 & 30 & $S$ & $\mathrm{Y}$ & 3.64 & 100 \\
\hline$L$ & 1 & 1000 & 1000 & 30 & 30 & $S$ & $Y$ & 3.47 & 125 \\
\hline$L$ & 2 & 120 & 1000 & 30 & 30 & $S$ & $Y$ & 2.73 & 100 \\
\hline$L$ & 3 & 125 & 1000 & 30 & 30 & $S$ & $\mathrm{Y}$ & 2.62 & 130 \\
\hline$L$ & 4 & 1000 & 1000 & 30 & 30 & $S$ & $Y$ & 4.27 & 210 \\
\hline$S$ & 2 & NA & NA & NA & NA & $S$ & $\mathrm{Y}$ & 1.57 & 0 \\
\hline$S$ & 3 & NA & NA & NA & NA & $S$ & $\mathrm{Y}$ & 1.38 & 0 \\
\hline $\mathrm{S}$ & 4 & 50 & NA & 20 & $\mathrm{NA}$ & $S$ & $Y$ & 1.38 & 0 \\
\hline $\mathrm{V}$ & 2 & NA & NA & NA & NA & $S$ & $\mathrm{~N}$ & 3.41 & 0 \\
\hline $\mathrm{W}$ & 2 & NA & NA & NA & NA & $S$ & $\mathrm{~N}$ & 3.49 & 0 \\
\hline
\end{tabular}

Note: The entry failures are highlighted blue, the pillar failures red, and the successes yellow. 


\section{Appendix B - Detailed Logistic Regression Analysis with R}

The following logistic regression example using the $\mathrm{R}$ program ( $\mathrm{R}$ Development Core Team, 2011) shows the single variable analysis of the pillar failure subset of the database in greater detail. First, the R program is statistical analysis software tool that requires a code based input and allows the user to install or write add-on packages.

To begin, one initially must read the pillar failure data, in this case a .csv file.

$>$ scpf<-read.csv("SCPF.csv", header=T)

Once the data is red into $\mathrm{R}$ a generalized linear model, meaning a logistic regression model, is created based on that particular data set, the pillar failure data.

$>$ scpf.out<-glm(SorF $\sim$ LaModelSF, family="binomial", data=scpf)

This code creates an object, scpf.out, with the model parameters as success or failure as the dependent variable and the LaModel stability factor as the independent variable. Now that the model has been created, the summary statistics must be displayed.

$>$ summary(scpf.out)

Call: $\operatorname{glm}($ formula $=$ SorF $\sim$ LaModelSF, family = "binomial", data = scpf $)$

Deviance Residuals:

Min 1Q Median 3Q Max

$\begin{array}{lllll}-1.8069 & -0.8684 & 0.1748 & 0.8485 & 1.4119\end{array}$

Coefficients:

$\begin{array}{lcccc} & \text { Estimate } & \text { Std. Error } & \mathrm{z} \text { value } & \operatorname{Pr}(>|\mathrm{z}|) \\ \text { (Intercept) } & -3.631 & 1.783 & -2.037 & 0.0417 * \\ \text { LaModelSF } & 2.243 & 1.006 & 2.229 & 0.0258 *\end{array}$

Signif. codes: 0 ‘***’ 0.001 '**' 0.01 '*’ 0.05 ‘' 0.1 ' ' 1

(Dispersion parameter for binomial family taken to be 1)

Null deviance: 38.191 on 29 degrees of freedom Residual deviance: 26.766 on 28 degrees of freedom AIC: 30.766 
Number of Fisher Scoring iterations: 6

The two important features of the summary statistics are 1) the model that has been called which should be checked for accuracy, as well as the logistic regression table which we see matches that of Table 6.1. The estimates represent the model coefficients (Equation 6.1); the standard error represents the standard deviation of the sampling distribution of the z-statistic, which is the number of standard deviations the datum is above the mean. Based on the small p-values, or the probability of obtaining a value at least as extreme as the estimate, of 0.0417 for the intercept and 0.0258 for the LaModel stability factor, we see that both of these values are statistically significant to the .05 , or $95 \%$ significance level.

For the purposes of this research, two add-on packages were installed. The epicalc (Epidemiological Calculator) package, in addition to its application to epidemiology, allows the user to easily perform ROC analysis with the following code.

$>\operatorname{lroc}($ scpf.out)

\$model.description

[1] "SorF LaModelSF"

\$auc

[1] 0.84

\$predicted.table predicted.prob Non-diseased Diseased

$\begin{array}{lll}0.1347 & 1 & 0\end{array}$ //truncated

$\begin{array}{lll}0.9973 & 0 & 1\end{array}$

\$diagnostic.table 1-Specificity Sensitivity

$1.0 \quad 1.00$

$\begin{array}{lll}>\quad 0.9 & 1.00\end{array}$

$\begin{array}{lll}> & 0.8 & 1.00\end{array}$

$>\quad 0.7 \quad 1.00$

$\begin{array}{lll}> & 0.6 & 1.00\end{array}$

$>\quad 0.6 \quad 0.90$

$\begin{array}{lll}> & 0.5 & 0.90\end{array}$ 


$\begin{array}{lll}> & 0.4 & 0.90 \\ > & 0.4 & 0.85 \\ > & 0.3 & 0.85 \\ > & 0.3 & 0.75 \\ > & 0.3 & 0.70 \\ > & 0.3 & 0.60 \\ > & 0.2 & 0.60 \\ > & 0.1 & 0.60 \\ > & 0.1 & 0.55 \\ > & 0.0 & 0.55 \\ > & 0.0 & 0.50 \\ > & 0.0 & 0.45 \\ > & 0.0 & 0.40 \\ > & 0.0 & 0.35 \\ > & 0.0 & 0.30 \\ > & 0.0 & 0.25 \\ > & 0.0 & 0.20 \\ > & 0.0 & 0.15 \\ > & 0.0 & 0.10 \\ > & 0.0 & 0.05 \\ > & 0.0 & 0.00\end{array}$

From this output, we see that the area under the ROC curve for this model is 0.84 and the sensitivity and specificity values are listed. The user can then take this data from the R output, put it in excel and plot the curve seen in Figure 6.1.

Now that the model equation and are under the ROC curve have been determined, the optimum cut point is determined by plotting the cut points from 0.1 to 1.0 for the model. This is accomplished by using the QuantPhys (Quantitative Psychology) package. While this package provides numerous tools for Psychologists, the only one portion of the package this research uses in the ClassLog () function. The classification table for the default 0.5 cut point is shown below (see Table 6.2).

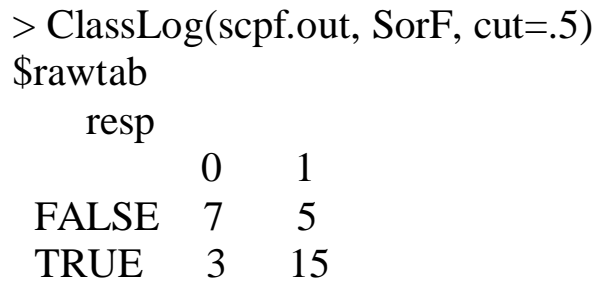




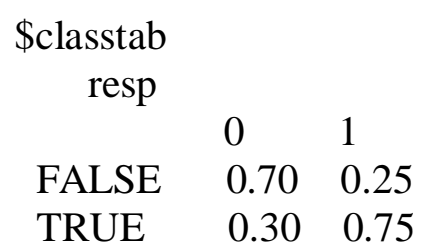

\$overall

[1] 0.7333333

\section{\$mcFadden}

[1] 0.2991573

This function shows that 7 false (failure) values are being reported as failures (70\%) and that 15 true (successful) values are being reported as successful (75\%). In other words, these cases are correctly classified. Additionally, the overall value of $73 \%$ is also displayed. To calculate the sensitivity, simply divide the number of correctly classified successes (15) by the total number of successes (20). Similarly, to calculate the specificity, divide the number of correctly classified failures (7) by the total number of failures (10). Again, these values are calculated and tabulated for a range of cut point and then plotted in Figure 6.2.

Now that the optimum cut point is plotted, one can determine the cut point where $90 \%$ of the failure cases are being correctly classified based on trial and error. This resulted in a cut point of 0.725 .

$>$ ClassLog(scpf.out, SorF, cut=.725)

\$rawtab

resp

$\begin{array}{llc} & 0 & 1 \\ \text { FALSE } & 9 & 8 \\ \text { TRUE } & 1 & 12\end{array}$

\$classtab

resp

$\begin{array}{lll} & 0 & 1 \\ \text { FALSE } & 0.9 & 0.4 \\ \text { TRUE } & 0.1 & 0.6\end{array}$


\$overall

[1] 0.7

\$mcFadden

[1] 0.2991573

One can now see with the cut point set at 0.725 that $90 \%$ of the failures are being correctly classified along with $60 \%$ of the successes and $70 \%$ of the overall cases. Because the cut point has been changed from the default 0.5 , the corresponding model intercept must now be adjusted. First, remember the original model equation 6.1.

$$
g(x)=2.243 S F-3.631
$$

Then, transform the selected cut point into log odds:

$$
\ln \left(\frac{0.725}{1-0.725}\right)=0.969
$$

Then, add the negative this value to the original intercept of -3.631 , the result of which is -4.600 making the new design equation (6.3):

$$
g(x)=2.243 S F-4.6
$$

Resulting in the required critical stability factor:

$$
\mathrm{SF}=2.05
$$


$\underline{\text { i t a }}$

\section{Morgan M. Sears}

Department of Mining Engineering

West Virginia University

Morgantown, WV 26501

P.O. Box 6070

Phone: (304) 685-0297

Morgantown, WV 26506

Fax: (304) 293-5708

msears@mix.wvu.edu

\section{EDUCATION}

\section{West Virginia University, Morgantown, West Virginia}

Ph.D. Candidate in Mining Engineering, Aug 2013 (Proposed)

Thesis Title (Tentative): Calibrating the LaModel Program: A Database Expansion and Statistical Analysis

Advisor: Keith Heasley, Ph.D.

\section{West Virginia University, Morgantown, West Virginia}

M.S. in Mining Engineering, Dec 2009

Thesis Title: Implementing Energy Release Rate Calculations Into the LaModel Program

Cumulative GPA: 3.75/4.0

Advisor: Keith Heasley, Ph.D.

West Virginia University, Morgantown, West Virginia

B.S. in Mining Engineering, May 2007

Cumulative GPA: 3.82/4.0

\section{RESEARCH EXPERIENCE}

Research Assistant, Laboratory of Dr. Keith Heasley, Ph.D., Aug 2008-Present

West Virginia University, Department of Mining Engineering

Morgantown, West Virginia

\section{Calibrating the LaModel Program for Shallow Cover Multiple-Seam Mines}

Currently expanding the LaModel deep cover case history database to include coal mines under shallower cover (less than 1000') for a nearly all-inclusive database. Beyond this, a statistical analysis will conclude the research.

\section{Implementing the Energy Release Rate Calculations into LaModel}

Showed that the Energy Release Rate calculations (used in the MULSIM program) could be utilized in the LaModel program. This research was conducted using a method involving implementation, verification, and demonstration. During model verification, we found that fundamental differences in the two programs behaviors cause similar, yet not identical results. A case study was then analyzed to highlight the program from a practical point of view. This resulted in conclusions similar to what was previously published. 


\section{Calibrating the LaModel Program for Deep Cover Pillar Recovery}

We utilized an existing calibration process, adapted it into "wizards" in the LaModel program, and then applied this calibration technique to a database of case histories. The data indicated that depth was not a factor in the Stability Factor (SF) statistically required for a successful pillar design. This research was groundbreaking in that it provided the first recommendations for usage of the laminated model since its inception in 1998.

\section{TEACHING EXPERIENCE}

Department of Mining Engineering, West Virginia University

- Rock Mechanics teaching assistant, 2011.

- Taught three classes and 2 lab sessions of Rock Mechanics/Ground Control, 2010.

- Proctored exams in Mine Power Systems, 2009-2010.

- Graded assignments for Underground Mining Systems, 2008.

College of Engineering and Mineral Resources, West Virginia University

- $\quad$ Tutored freshmen students in Algebra, Pre-Calculus, Trigonometry, Calculus I, Calculus II, and Physics, 2005-2006.

\section{HONORS AND AWARDS}

- $\quad$ Recipient - Syd S. Pend Ground Control Scholarship, 2012

- Phi Kappa Phi Honor Society, $1^{\text {st }}$ WVU MinE inductee, 2011-Present

- Member American Rock Mechanics Association, 2009

- $\quad$ Outstanding SME Student Chapter Award, as President, 2008

- $\quad$ Outstanding SME Student Chapter GEM Award, as GEM Coordinator, 2007

- $\quad$ Old Timers Award Recipient, 2007

- Department of Mining Engineering Faculty Outstanding Student Award, 2006 and 2010

- $\quad$ PCMIA Donald S. Kingery Student Award Recipient, 2006

- Member SME, 2004-Present

\section{INDUSTRY EXPERIENCE AND CERTIFICATIONS}

- Three months surface mining and engineering experience, 2005

- Three months underground mining experience, 2006

- Six months surface mining, engineering, and permitting experience, 2007-2008

- West Virginia EIT

- West Virginia Experienced Surface Miner

- West Virginia (80 Hour) Underground Apprentice Miner

\section{Publications}

Sears, M.M., Heasley, K.A. (2013). "Calibrating the LaModel Program for Shallow Cover Multiple-Seam Mines." In: Proceedings of the 32nd International Conference on Ground Control in Mining, pp. 10-17.

Heasley, K.A., Sears, M.M., Tulu, I.B., Calderon-Arteaga, C.H., Jimison II, L.W. (2010). "Calibrating the LaModel program for deep cover pillar retreat coal mining." In: Proceedings of the $3^{\text {rd }}$ International Workshop on Coal Pillar Mechanics and Design. pp. 47-57. Presented in Morgantown, WV: July 26-29.

Sears, M.M., Heasley, K.A. (2009). “An application of energy release rate.” In: Proceedings of the $28^{\text {th }}$ International Conference on Ground Control in Mining, pp. 10-17. 